UNIVERSIDADE DE SÃO PAULO

INSTITUTO DE GEOCIÊNCIAIS
UNIVERSITÉ DU SUD -

TOULON - VAR - PROTEE

\title{
CARACTERIZAÇÃO DA MATÉRIA ORGÂNICA DE SOLO IRRIGADO COM EFLUENTE DE ESTAÇÃO DE TRATAMENTO DE ESGOTO
}

Éric Louis Roger Noirtin

Orientadores: Profa. Dra. Célia Regina Montes

Prof. Dr. Yves Lucas

TESE DE DOUTORAMENTO

Programa de Pós-Graduação em Geoquímica e Geotectônica

São Paulo

2010 


\title{
CARACTERIZAÇÃO DA MATÉRIA ORGÂNICA DE SOLO IRRIGADO COM EFLUENTE DE ESTAÇÃO DE TRATAMENTO DE ESGOTO
}

\author{
Éric Louis Roger Noirtin \\ Orientadores: Profa. Dra. Célia Regina Montes \\ Prof. Dr. Yves Lucas \\ TESE DE DOUTORAMENTO \\ Programa de Pós-Graduação em Geoquímica e Geotectônica \\ São Paulo \\ 2010
}


FICHA CATALOGRÁFICA 
Aos meus pais, pelo amor incondicional, por serem minhas raízes e meus exemplos,

Aos meus amigos, sempre do meu lado, nas minhas maiores conquistas, assim como nas minhas horas mais sombrias,

À minha esposa, amor da minha vida, Aos meus bichos, fiéis companheiros,

Eu dedico. 


\section{Agradecimentos}

Este Trabalho só foi possível devido ao apoio que recebi de diversas pessoas e instituições. Em especial gostaria de agradecer:

À Profa. Dra. Célia Regina Montes e ao Prof. Dr. Yves Lucas pela orientação e a ajuda.

Ao Prof. Dr. Stephane Mounier pelo o apoio.

Ao Dr. Cedric Garnier pela disponibilidade.

À Profa. Dra. Milori pela ajuda e o acolhimento.

Ao Dr Sergio Luis de Jesus pelos preciosos conselhos e a amizade.

À Suely Teodoro pela paciência.

À Clotilde M.B. Cunha, Paulo e Anna Paula pela gentileza.

Ao Instituto de Geociências da Universidade de São Paulo (IGc-USP), ao Programa de Pós-graduação em Geoquímica e Geotectônica e à CAPES pela oportunidade e pela bolsa concedida.

Ao pessoal do PROTEE pelo supporte ao longo dos anos.

À Fundação de Amparo a Pesquisa do Estado de São Paulo (FAPESP) e à Companhia de Saneamento Básico do Estado de São Paulo pelo apoio financeiro e logístico.

E a todos que de alguma forma contribuíram para a realização deste trabalho e que, devido à péssima memória do autor, deixaram de ser citados. 


\section{SUMÁRIO}

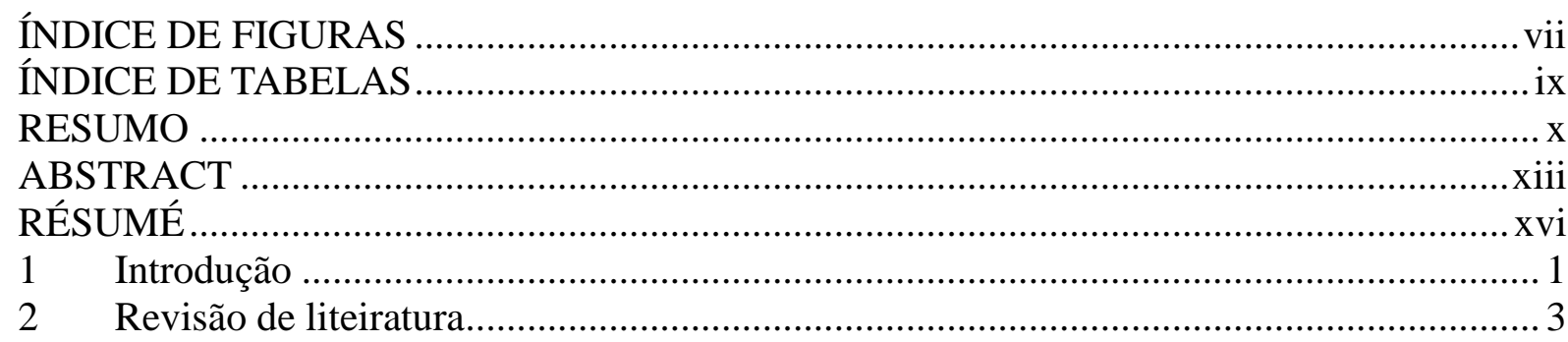

2.1 Efluentes de estação de tratamento de esgoto .............................................................. 3

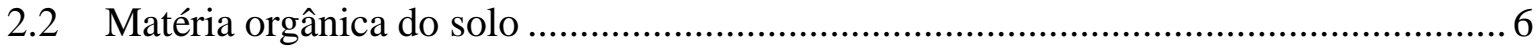

2.3 Resumo das características do solo, solução do solo e efluente a partir de trabalhos anteriores realizados na área de estudo............................................................................ 13

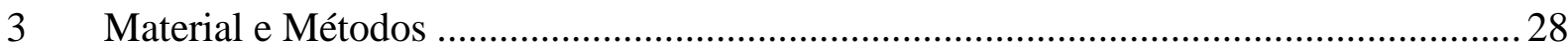

3.1 Área experimental e manutenção das condições experimentais ....................................28

3.2 Caracteríticas da água e do esgoto tratado e precipitação pluviométrica .......................30

3.3 Coleta, preparação e métodos de análises para as diferentes amostras estudadas ......33

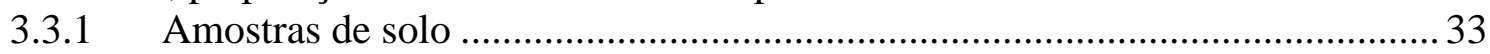

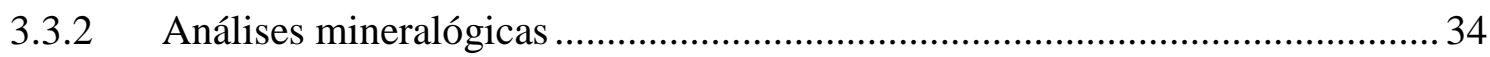

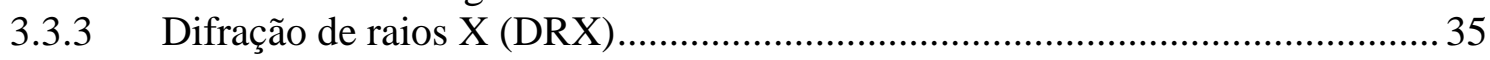

3.3.4 Análise térmica diferencial e gravimétrica (ATD-TG) .......................................36

3.3.5 Espectroscopia por reflectância difusa (ERD).................................................... 36

3.3.6 Separação densimétrica, determinação do carbono total e grau de humificação37

3.3.7 Fluorescência induzida por laser ..................................................................... 40

3.3.8 Fluorescência dos extratos de ácidos húmicos e fúlvicos extraídos das amostras

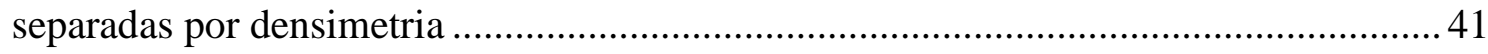

3.3.9 Solução do solo, efluente de estação de tratamento de esgoto e água potável. 44

$3.4 \quad$ Análise estatística dos dados ..................................................................................4 46

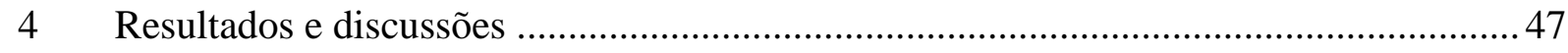

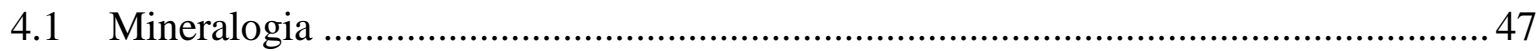

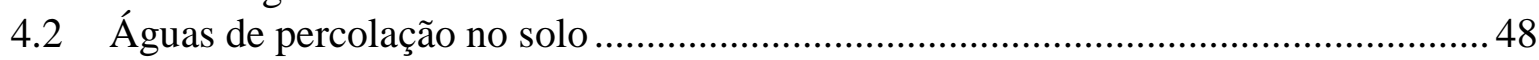

$4.3 \quad$ Teores de carbono no solo .................................................................................... 51

4.3.1 Carbono no solo total............................................................................... 51

4.3.2 Carbono nas diferentes frações densimétricas.....................................................5

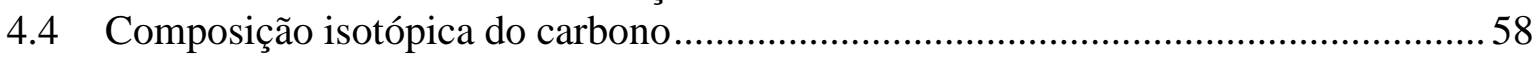

4.4.1 Composição isotópica do carbono no solo total ...............................................58

4.4.2 Composição isotópica na fração densimétrica superior a dois ............................. 60

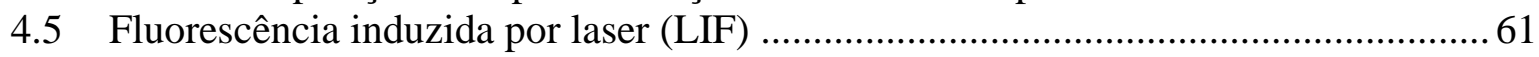

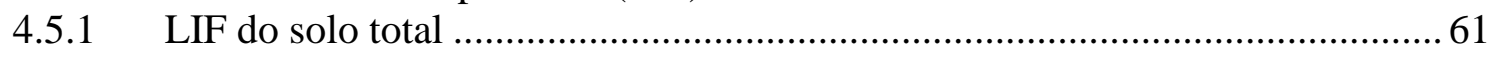

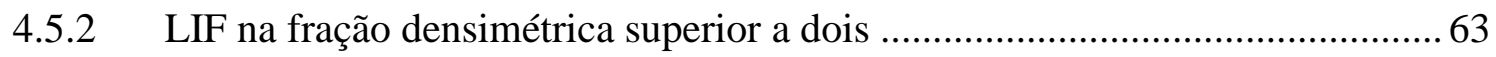

4.5.3 Evolução do IH durante o período experimental ................................................. 65

4.5.4 Relações entre o IH e a composição isotópica do carbono ……………………...73

$4.6 \quad$ Fluorescência tridimensional (3D) .......................................................................... 74

4.6.1 Fluorescência 3D dos extratos de solo total .................................................. 74

4.6.2 Fluorescência 3D das frações densimétricas .................................................. 78

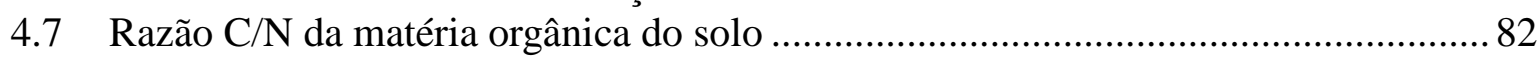

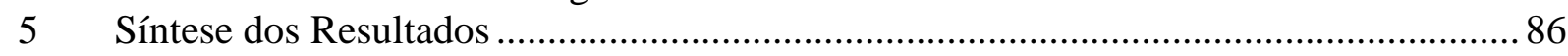




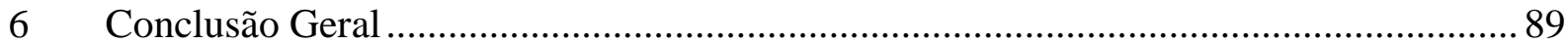

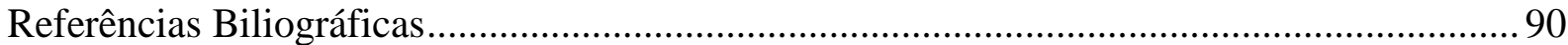

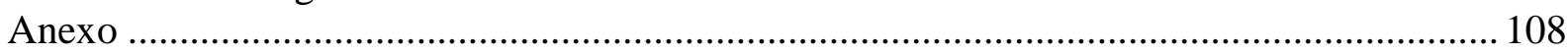




\section{ÍNDICE DE FIGURAS}

Figura 2.1 - Pluviometria e temperatura mensal média em Lins ....................................... 15

Figura 3.1 - Imagem de satélite mostrando a estação de tratamento de esgotos. .................29

Figura 3.2 - Precipitação semanal na área experimental. .................................................. 33

Figura 3.3 - Diagrama dos procedimentos para a separação densimétrica da matéria orgânica utilizado no presente estudo.

Figura 3.4 - Diagrama dos procedimentos de extração dos ácidos húmicos e fúlvicos analisados por fluorescência. 3D.

Figura 3.5 - Exemplo de matriz de excitação-emissão (EEM) do extrato da MOS de solo irrigado com efluente de estação de tratamento de esgoto.

Figura 3.6 - Componentes 1, 2 e 3 obtidas pelo método PARAFAC e descritivas da fluorescência 3-D dos extratos da MOS

Figura 4.1 - Peso das variáveis em relação aos dois primeiros eixos da análise de componentes principais das espécies dissolvidas nas soluções do solo. COD: carbono orgânico dissolvido.

Figura 4.2 - Relação entre o carbono orgânico do solo (COS), e o carbono orgânico dissolvido (COD) da solução do solo

Figura 4.3 - Evolução dos teores de carbono no solo (porcentagem em massa) para as profundidades nos diferentes tratamentos entre Janeiro 2003 e Junho 2009.

Figura 4.4 - Teores relativos de carbono (\%) nas diferentes frações densimétricas da MOS.

Figura 4.5 - Teores de carbono (\%) nas diferentes frações frações densimétricas da MOS, retirando-se a fração 1,6 liv.

Figura 4.6 - Composição isotópica $\left(\delta^{13} \mathrm{C}\right)$ da matéria orgânica do solo total.

Figura 4.7 - Composição isotópica $\left(\delta^{13} \mathrm{C}\right)$ da matéria orgânica do total e da fração $\mathrm{d}>2$ dos solos dos tratamentos SI e E66 (amostragem de Junho de 2007).

Figura 4.8 - Índice de humificação da MOS total (Junho 2007).

Figura 4.9 - Índice de humificação da MOS total e da fração d>2 para o tratamento SI (Junho 2007).

Figura 4.10 - Índice de humificação da fração d>2 da MOS dos solos dos tratamentos SI e E66 (Junho 2007). 
Figura 4.11 - Evolução temporal do índice de humificação para o solo do tratamento SI (solo total). 66

Figura 4.12 - Evolução temporal do índice de humificação para o solo do tratamento E66 (solo total).

Figura 4.13 - Evolução temporal do índice de humificação para o solo W100 (solo total)...68

Figura 4.14 - Comparação dos índices de humificação (IH) entre os tratamentos Si e E66 (Junho de 2007, solo total)

Figura 4.15 - Comparação dos índices de humificação (IH) entre os tratamentos Si, E66 e W100 (Maio de 2009; solo total).

Figura 4.16 - Comparação dos índices de humificação (IH) entre os tratamentos Si, E66 e

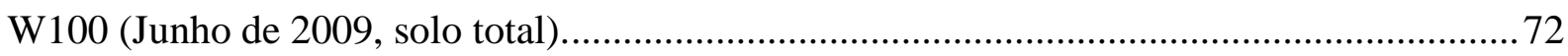

Figura 4.17 - Comparação entre o índeice de humificação (IH) determinado por fluorescência induzida por laser (LIF) e a composição isotópica $\left(\delta^{13} \mathrm{C}\right)$. d: densidade 73 Figura 4.18 - Índice ci /COT dos componentes 1, 2 e 3 dos extratos de solo total (Junho de 2007)....... 75

Figura 4.19 - Contribuições à fluorescência ci /COT das componentes 1, 2 e 3 dos extratos de MOS (Junho de 2007). 76

Figura 4.20 - Razão Ia/Ic (intensidade relativa aos compostos de tipo fúlvico/intensidade relativa aos compostos de tipo húmico) dos extratos de solo total (Junho de 2007). 77 Figura 4.21 - Comparação da razão Ia/Ic (intensidade relativa aos compostos de tipo fúlvico/intensidade relativa aos compostos de tipo húmico) dos extratos de solo total (Junho de 2007) e do IH (índice de humificação) do solo total.

Figura 4.22 - Índice ci /COT da componente 1 dos extratos de solo das frações densimétricas separadas (Junho de 2007).

Figura 4.23 - Índice ci /COT da componente 2 dos extratos de solo das frações densimétricas separadas (Junho de 2007). 80

Figura 4.24 - Índice ci /COT da componente 3 dos extratos de solo das frações densimétricas separadas (Junho de 2007).

Figura 4.25 - Razão C/N para as amostras de solo total (SI e E66) e para as amostras da fração densimétrica superior a 2 (SI d>2 e E66 d>2) (amostragem de junho 2007).

Figura 4.26 - Comparação entre a razão $\mathrm{C} / \mathrm{N}$ e o índice de humificação (IH) determinado por

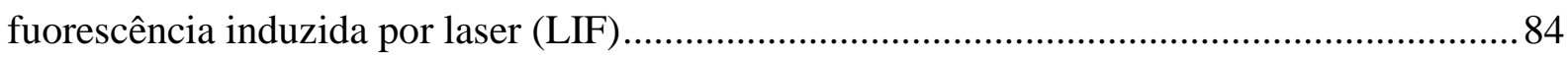

Figura 4.27 - Comparação entre a razão $\mathrm{C} / \mathrm{N}$ e a composição isotópica $\left(\delta^{13} \mathrm{C}\right)$...... 85 


\section{ÍNDICE DE TABELAS}

Tabela 3.1 - Características da água e do esgoto tratado utilizados na irrigação do capimBermuda Tifton 85 e valores médios de esgotos tratados apresentados na literatura. 31

Tabela 4.1 - Composição mineralógica das amostras brutas e frações granulométricas separadas representativas para os solos dos tratmentos E66 e SI.

Tabela 4.2 - Análise térmica diferencial e gravimétrica (ATD-TG) e espectroscopia por reflectância difusa (ERD) das amostras brutas dos solos dos tratamentos E66 e SI. ............... 48

Tabela 4.3 - Matriz de corelação entre as espécies dissolvidas na solução do solo.............. 49

Tabela 4.4 - Peso dos eixos fatoriais na explicação da variância..........................................50

Tabela 4.5 - Fracionamento densimétrico da matéria orgânica do solo (MOS) (g)..............55

Tabela 4.6 - Índice de humificação (IH) para as amostras de solo total (junho 2007). ........62

Tabela 4.7 - Comparação entre os valores do índice de humificação (IH) para as amostras de solo total e da fração densimétrica superior a 2 para o tratamento SI (junho de 2007)...... 63

Tabela 4.8 - Comparação entre os valores do índice de humificação (IH) para as amostras de solo da fração de densidade superior a 2 para os tratametos SI e E66. 64

Tabela 4.9 - Evolução do índice de humificação (IH) para as amostras de solo total no

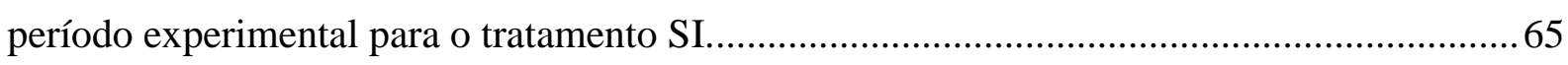

Tabela 4.10 - Evolução do índice de humificação (IH) para as amostras de solo total no

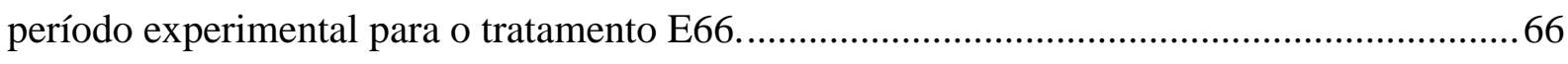

Tabela 4.11 - Evolução do índice de humificação (IH) para as amostras de solo total no

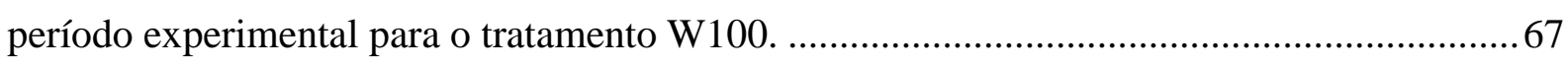

Tabela 4.12 - Índices de humificação (IH) para as amostras de solos coletadas em junho 2007

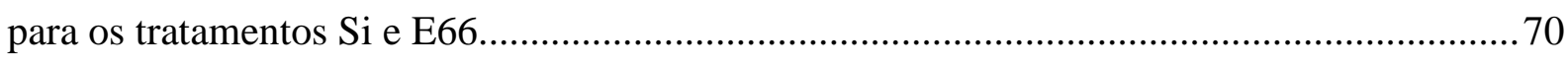

Tabela 4.13 - Índices de humificação (IH) para as amostras de solos coletadas em maio 2009

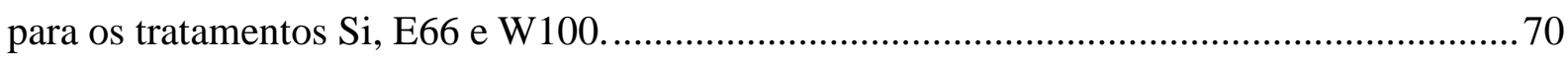

Tabela 4.14 - Índices de humificação (IH) para as amostras de solos coletadas em de junho

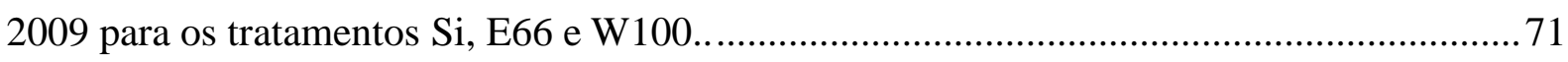




\section{RESUMO}

Diante dos recentes estudos sobre as mudanças climáticas, a preocupação sobre a repartição e a disponibilidades dos recursos hídricos é cada vez maior, estimulando pesquisas sobre métodos de reuso de água. Dentre estes métodos, o uso de efluente de estação de tratamento de esgoto (EETE) para irrigação de culturas agrícolas apresenta várias vantagens, como por exemplo, suprir a necessidade hídrica das plantas e fornecer nutrientes essenciais ao seu desenvolvimento, evitar o despejo dos efluentes nos corpos d'água e ainda poderia ser considerado como um tratamento complementar dos esgotos tratados. Entretanto, os impactos nos solos tropicais que o uso de efluentes para irrigação agrícola podem causar precisam ser melhores conhecidos. Desta forma, pesquisas vêm sendo realizadas desde 2002 no campo experimental de reuso de água em Lins (SP) cujos objetivos visam a sustentabilidade do uso de efluente de tratamento de esgoto para irrigação de culturas agrícolas. Entre as culturas ali estudadas selecionou-se para o desenvolvimento deste trabalho de doutorado, a área cultivada com capim-Bermuda Tifton 85 e o foco da pesquisa foi avaliar os efeitos da irrigação com efluente sobre a matéria orgânica do solo (MOS). O delineamento experimental foi de blocos completos casualisados com três tratamentos e quatro repetições e o período do experimento em campo foi de junho de 2007 a junho de 2009. Os tratamentos avaliados foram SI: sem irrigação e sem fertilização, tratamento de referência, E66 - irrigação com EETE e adubação de $343 \mathrm{~kg} \mathrm{ha}^{-1}$ ano $^{-1}$ de nitrato de amônio, $416 \mathrm{~kg} \mathrm{ha}^{-1}$ ano $^{-1}$ de $\mathrm{K}_{2} \mathrm{O}$ e $140 \mathrm{~kg} \mathrm{ha}^{-1}$ ano $^{-1} \mathrm{P}_{2} \mathrm{O}_{5}$ e W100: irrigação com água potável e adição de $520 \mathrm{~kg} \mathrm{ha}^{-1} \mathrm{ano}^{-1}$ de nitrogênio via nitrato de amônio, $416 \mathrm{~kg} \mathrm{ha}^{-1}$ ano $^{-1}$ de $\mathrm{K}_{2} \mathrm{O}$ e $140 \mathrm{~kg} \mathrm{ha}^{-1}$ ano $^{-1} \mathrm{P}_{2} \mathrm{O}_{5}$. A mineralogia do solo determinada por difração de raios-X, análise térmica diferencial e por espectroscopia de refletância difusa, apresentou-se simples, caracterizada, principalmente, pela presença 
dominante de quartzo e por caulinita, gibbsita, goethita e hematita. A água do solo foi coletada por meio de lisimetros de sucção e observou-se uma forte correlação $(0,93)$ entre os valores de $\mathrm{NO}_{2}{ }^{-}$e de $\mathrm{NO}_{3}{ }^{-}$e coeficientes de correlação mais baixos, mas ainda consideráveis entre a profundidade e o $\mathrm{K}^{+}, \mathrm{Na}^{+}$e $\mathrm{NO}_{3}{ }^{-}, \mathrm{Cl}^{-}$e $\mathrm{F}^{-}, \mathrm{Cl}^{-}$e $\mathrm{SO}_{4}{ }^{2-}$. Apesar dos altos teores de carbono orgânico dissolvido e de amônio no efluente, a correlação entre estes compostos foi negativa $(0,40)$, reforçando estudos anteriores que mostraram que o alto teor de $\mathrm{NH}_{4}{ }^{+}$estimula uma alta atividade microbiana, resultando numa rápida oxidação do amônio em nitrato e subsequente absorção desta espécie pelas plantas. No solo, os teores de carbono foram baixos (inferiores a 1\%) para os solos irrigados (E66 e W100) e para o solo de referência (SI), com esses valores decrescendo com a profundidade. $\mathrm{O}$ estoque de carbono foi menor nos solos irrigados que no solo sem irrigação. As amostras de solo dos tratamentos SI e E66 foram submetidas à separação densimétrica, obtendo-se as frações: densidade <1,6 livre, composta por restos de planta poucos decompostas; densidade superior a 2, representada pela fase mineral; e as frações de densidade $<1,6$ occ, $1,6<\mathrm{d}<1,8 ; 1,8<\mathrm{d}<2,0$, compostas de fragmentos de planta cobertos pela fase mineral. Observou-se que em ambos os solos mais de $60 \%$ de carbono encontrava-se associado à fase mineral, sendo principalmente formado por matéria orgânica muito humificada e matéria orgânica associada aos microrganismos. Os resultados obtidos das análises da razão isotópica do $\mathrm{C}\left(\delta^{13} \mathrm{C}\right)$ nos solos totais não evidenciaram influência do efluente, porém mostraram que a irrigação promoveu uma desestruturação dos agregados. Esta observação foi confirmada pela comparação dos índices de humificação das frações de densidades superior a 2 calculados a partir dos teores de carbono e das intensidades de fluorescência induzidas por laser. Os espectros de fluorescência da matéria orgânica extraída por uma solução $\mathrm{NaOH} 1 \mathrm{~mol} \mathrm{~L}^{-1}$ e tratados com o método matemático PARAFAC, permitiram identificar três componentes: a primeira associada as proteínas, a segunda aos ácidos húmicos e a terceira aos ácidos fúlvicos. Apesar da interpretação dos resultados ter sido 
dificultada pela provável não homogeneidade da extração da matéria orgânica, eles indicaram uma transferência da matéria orgânica mais lábil das camadas superficiais para as camada mais profunda do perfil de solo. A análise conjunta dos resultados obtidos permitiu concluir que: (i) a diminuição do estoque de carbono dos solos irrigados e o aumento do grau de humificação da matéria orgânica do solo associada à fração mineral são, principalmente, conseqüência da desestabilização dos agregados devido aos altos teores de sódio do efluente e água potável. O controle do processo de sodificação é fundamental para manter as características da matéria orgânica do solo, bem como para manter sua condutividade hidráulica; (ii) não foram observadas diferenças entre o comportamento da matéria orgânica do solo irrigado com efluente de estação de tratamento de esgoto e a do solo irrigado com água potável. Evidenciando que as alterações na MOS são provenientes, sobretudo, do processo de irrigação com águas sódicas e não especificamente com efluente de estação de tratamento de esgoto; (iii) as técnicas de fluorescência utilizadas para a carcacterização da matéria orgânica aparentemente se mostraram sensíveis para monitorar as variações da MOS, no entanto, ainda é necessário se conhecer melhor a relação entre os sinais observados nos espectros e as propriedades agronômicas

Palavras-chave: matéria orgânica, solo, fluorescência, efluente, tratamento de esgoto, água do solo, capim-Bermuda 


\section{ABSTRACT}

In face of recent studies on climate changes, the concern about sharing availability of water resources is increasing, stimulating research about methods of water reuse. Among these methods, the use of treated sewage effluent (TSE) for irrigation of agricultural crops presents several advantages, such as supplying water for plants, providing essential nutrients for its development, avoiding effluent spillage in the water stream and it might be also considered a supplementary treatment to treated sewage effluent. In the mean time, the impact the effluents might cause on tropical soils, requires further study. In this way, some research on the reuse of water-experimental-field is being carried out in Lins(SP) since 2002. The main objective of this research is to reuse the effluent water to irrigate crops in a sustainable way. Among the studied crops, the planted area with Tifton 85 Bermudagrass was selected in order to develop this Study. The experimental layout was of randomized complete blocks and composed of three treatments, four repetitions and the period of the experiment in the field was carried out from June 2007 to June 2009. The treatments applied were SI: without irrigation and without fertilization, the reference treatment, E66 - irrigated with TSE and fertilized with $343 \mathrm{~kg} \mathrm{ha}^{-1}$ year ${ }^{-1}$ ammonium nitrate, $416 \mathrm{~kg} \mathrm{ha}^{-1}$ year $^{-1}$ of $\mathrm{K}_{2} \mathrm{O}$ and $140 \mathrm{~kg} \mathrm{ha}^{-1}$ year $^{-1}$ of $\mathrm{P}_{2} \mathrm{O}_{5}$, and $\mathrm{W} 100$ - irrigated with drinking water and fertilized with $520 \mathrm{~kg} \mathrm{ha}^{-1}$ year $^{-1}$ ammonium nitrate, 416 $\mathrm{kg} \mathrm{ha}^{-1}$ year $^{-1}$ of $\mathrm{K}_{2} \mathrm{O}$ and $140 \mathrm{~kg} \mathrm{ha}^{-1}$ year $^{-1}$ of $\mathrm{P}_{2} \mathrm{O}_{5}$. The soil mineralogy that was determined by X-ray diffraction, Thermogravimetric analysis and Diffuse reflectance spectroscopy, was simple, mainly characterized by Kaolinite, gibbsite, goethite and hematite. The soil water was collected by suction lysimeter and showed a strong correlation $(0,93)$ between $\mathrm{NO}_{2}{ }^{-}$and $\mathrm{NO}_{3}{ }^{-}$ values and lower correlation, but still noticeable, between depth and $\mathrm{K}^{+}, \mathrm{Na}^{+}$e $\mathrm{NO}_{3}{ }^{-}, \mathrm{Cl}^{-}$e $\mathrm{F}^{-}$, $\mathrm{Cl}^{-}$e $\mathrm{SO}_{4}{ }^{2-}$. Regardless the high concentration of dissolved organic carbon and ammonium of 
the effluent, the correlation between those component was negative $(0,40)$ strengthening previous studies which showed that high concentration of $\mathrm{NH}_{4}^{+}$promote a high microbiological activity, resulting in quick oxidation of the ammonium in nitrate and subsequent absorption of this specie by plants. In the soil, concentrations of carbon were low (lower than 1\%) for the irrigated soils (E66 and W100) and for the reference (SI) soil, and those values decreased according to the depth. The soils samples of SI and E66 were separated in density fractions. The fractions obtained were: dentisy $<1,6$ free, composed of plant fragments poorly decomposed; density $>2$ is composed by the mineral phase; The fraction of densities $<1,6$ occ, $1,6<\mathrm{d}<1,8 ; 1,8<\mathrm{d}<2,0$ was composed by plant fragments incrusted by minerals. In both soils more than $60 \%$ of the carbon was associated with the mineral phase, mainly composed by highly humified organic matter and microbial product. The results obtained from $\delta^{13} \mathrm{C}$ isotopic ratio analysis of total soils failed to prove the influence of the effluent, but showed irrigation promoted aggregate destabilisation. This observation was confirmed by the comparison of the humification indices of density $>2$ fractions, which were calculated from the carbon concentrations and Lazer induced fluorescence intensities. The fluorescence spectres of organic matter extracted by $\mathrm{NaOH} 1$ mol $\mathrm{L}^{-1}$ and treated parallel factor analysis (PARAFAC) algorithm, permits the identification of 3 components: the first associated to protein, the second to humic acid and the third to fulvic acid. Regardless the difficult interpretation of the results due to the probable nonhomogeneity of the extraction, they indicate a transfer of solute organic matter from superficial to deeper layers of the soil. The analysis of the results obtained allows us to conclude: (i) the decrease of the soil carbon on irrigated soils and the increase of the humification of the mineral associated organic matter are caused mainly by the destabilization of aggregates due to high concentration of $\mathrm{Na}^{+}$in the effluent and drinking water. The control of the sodification process is fundamental to maintain soil organic matter characteristic, as 
well as the soil hydraulic conductivity. Differences in the behavior of the soil organic matter from effluent irrigated soil and drinking water irrigated soil were not observed. This shows that the changes are due to irrigation with sodic water and not specifically to waste water treatment plant effluent irrigation. The control of the sodification process is fundamental to maintain the soil organic matter characteristic, as well as the soil hydraulic conductivity. (ii) Differences in the behaviour of the soil organic matter between effluent irrigated soil and drinking water irrigated soil were not observed. This shows that the changes are due to the irrigation with sodic water and not specifically to the irrigation with waste water treatment plant effluent. (iii) the fluorescence utilized to characterized the organic matter apparently showed sensitiveness to monitor MOS variations. However, further study is essential in order to understand the relationship among the observed scope and agronomic properties

Keywords: organic matter, soil, fluorescence, effluent, sewage treatment, soil water, Bermudagrass 


\section{RÉSUMÉ}

Devant les récentes études sur les changements climatique, la préoccupation au sujet de la répartition et de la disponibilité des ressources hydriques est chaque jour plus grande, stimulant la recherche sur les méthodes de réutilisation de l'eau. Entre ces méthodes, l'utilisation d'effluent de station de traitement des eaux usées (EST) pour l'irrigation des cultures agricoles présente plusieurs avantage comme, par exemple, subvenir au besoin en eau des plantes, fournir les nutriments essentiels à leurs développement, empêcher que ces effluents soient jeté dans les plans d'eau, ou encore pour servir de traitement complémentaire de l'effluent. Cependant, l'impact sur les sols tropicaux de l'utilisation des effluents dans l'irrigation agricole à besoin d'être mieux connu. Ainsi, depuis 2002, des recherches ont été réalisé dans la zone expérimentale de réutilisation des eaux usées de Lins (SP) avec pour objectif de déterminer la viabilité de l'utilisation d'effluent de station de traitement des eaux usées pour l'irrigation agricole. Entre les cultures étudiées, le capim-Bermuda Tifton 85 a été sélectionné pour cette étude de doctorat, et l'objet de la recherche a été d'évaluer les effets de l'irrigation avec l'effluent sur la matière organique du sol. Le dispositif expérimental était en blocs aléatoires avec 3 traitements, 4 répétitions et une période expérimentale de juin 2007 à Juin 2009. Les traitements évalués furent SI: non irrigué et non fetilizé, E66, irrigué avec l'EST, et fertilizé avec $343 \mathrm{~kg}$ ha- 1 an-1 de nitrate d'ammonium, $416 \mathrm{~kg} \mathrm{ha}^{-1} \mathrm{an}^{-1}$ de $\mathrm{K}_{2} \mathrm{O}$ et $140 \mathrm{~kg} \mathrm{ha}^{-1} \mathrm{an}^{-1} \mathrm{P}_{2} \mathrm{O}_{5}$ et W100, irrigué avec de l'eau potable et fertilizé avec $520 \mathrm{~kg} \mathrm{ha}^{-1} \mathrm{an}^{-1}$ de nitrate d'ammonium, $416 \mathrm{~kg} \mathrm{ha}^{-1} \mathrm{an}^{-1}$ de $\mathrm{K}_{2} \mathrm{O}$ et $140 \mathrm{~kg} \mathrm{ha}^{-1} \mathrm{an}^{-1} \mathrm{P}_{2} \mathrm{O}_{5}$. La minéralogie déterminé par diffraction de rayon-X, analyse thermodifférentiel, et par spectroscopie par réflectance diffuse, c'est montrée simple, principalement caractérisée par la présence de quartz, kaolinite, gibbsite, goethite et hematite. Les eaux de sol ont été collectées avec des 
lysimétres à succion et il a été observé une forte corrélation $(0,93)$ entre les valeurs de $\mathrm{NO}_{2}{ }^{-}$et de $\mathrm{NO}_{3}{ }^{-}$, et des coefficients de corrélations plus bas mais, néanmoins significatif, entre la profondeur et $\mathrm{K}^{+}, \mathrm{Na}^{+}$e $\mathrm{NO}^{-}, \mathrm{Cl}^{-}$e $\mathrm{F}^{-}, \mathrm{Cl}^{-}$e $\mathrm{SO}_{4}{ }^{2-}$. Malgré les hautes concentrations en carbone organique dissout et en ammonium, la corrélation entre ces deux composés a été négative $(0,40)$, renforçant les études antérieurs qui montrent qu'une forte teneur en $\mathrm{NH} 4^{+}$ favorise une forte activité microbienne, résultant en une rapide oxydation de l'ammonium en nitrate qui est alors absorbé par les plantes. Dans le sol, les teneurs en carbone ce sont montrées basses (inferieur a 1\%) pour les sols irrigués (E66 et W100) et pour le sol de référence (SI), ces valeurs diminuant avec la profondeur. Le stock de carbone des sols irrigués a été inférieur au sol de référence. Les échantillons de sol des traitements SI et E66 ont été soumis a une séparation par densité, définissant les fractions: densité <1,6 libre, composée de restes de plantes peu décomposés; densité >2, représentant la phase minérale; et les fractions de densité $<1,6$ occ, $1,6<\mathrm{d}<1,8,1,8<\mathrm{d}<2,0$, composées de fragments de plantes couverts par la phase minérale. Il a été observé que dans les 2 sols, plus de $60 \%$ du carbone était associé à la phase minérale, étant principalement composé de matière organique très humifiée et de matière organique associée à l'activité des micro-organismes. Les résultats obtenu avec l'analyse du rapport isotopique du C ( $\delta 13 \mathrm{C})$, dans les sols entiers n'ont pas montré d'influence de l'effluent, mais ont montré que l'irrigation a favorisé la déstructuration des agrégats. Ces observations ont été confirmées par la comparaison des indices d'humification des fractions de densité supérieur à 2, calculés à partir des teneurs en carbone et des intensités de fluorescence induite par laser. Les spectres de fluorescence de la matière organique extraite par une solution de $\mathrm{NaOH} 1 \mathrm{~mol} \mathrm{~L}^{-1}$, et traités avec la méthode mathématique PARAFAC, ont permis d'identifier trois composés: le premier associé aux protéines, le deuxième associé aux acides humiques, et le troisiéme associé aux acides fulviques. Malgré que l'interprétation des résultats ait été difficultée par la probable inhomogénéité de l'extraction de la matière 
organique, ils ont indiqué un transfert de la matière organique labile des couches supérieures aux couches inférieures du sol. L'analyse conjointe des résultats obtenus a permis de conclure que: (i) la diminution du stock de carbone des sols irrigués et l'augmentation du degrés d'humification de la matière organique du sol associée à la fraction minéral sont principalement des conséquences de la déstabilisation des agrégats due aux fortes teneurs en sodium de l'effluent et de l'eau potable. Le contrôle des processus de sodification est fondamental pour maintenir les caractéristiques de la matière organique du sol et la conductivité hydriques; (ii) il n'a pas été observé de différences entre le comportement de la matière organique du sol irrigué avec effluent de station de traitement des eaux usées et celle du sol irrigué avec l'eau potable. Ceci met en évidence que les altérations de la matière organique du sol sont dues au processus d'irrigation avec des eaux sodiques et non spécifiquement à l'utilisation de l'effluent de station de traitement des eaux usées; (iii) les techniques de fluorescence utilisées pour chartériser la matière organique du sol ce sont montrées suffisamment sensible, mais il est cependant nécessaire d'approfondir la relation entre les signaux observés et les propriétés agronomiques.

Mots clefs: matière organique, sol, effluent, traitement des eaux usées, eau du sol, capimBermuda 


\section{Introdução}

As mudanças climáticas bem como o desenvolvimento crescente da população mundial levam cada vez mais a preocupações sobre a disponibilidade, a repartição e o uso dos recursos hídricos. Recentemente, um grupo de cientistas em um fórum internacional sobre as mudanças climáticas, publicou os resultados de um estudo criterioso sobre o tema (INTERGOVERNMENTAL PANEL ON CLIMATE CHANGE, 2007). O relatório demonstrou que para o próximo século a temperatura média mundial vai se elevar em até $6^{\circ} \mathrm{C}$ provocando o aumento na intensidade e na duração das secas. Mais especificamente, as regiões sub-tropicais do Brasil enfrentarão uma diminuição nas quantidades de precipitações que poderão chegar a $20 \%$.

Além dos problemas econômicos, ecológicos e de saúde, a escassez dos recursos naturais e a diminuição do acesso à água, também provocarão insegurança e conflitos violentos em várias partes do mundo (GLEICK et al., 1994; HOMMER-DIXON, 1994; HENSEL et al., 2006; INTERGOVERNMENTAL PANEL ON CLIMATE CHANGE, 2007). Essas constatações levam os cientistas a intensificar as pesquisas sobre novas fontes de água potável e métodos de reuso de água.

A título de exemplo pode ser citado a dessalinização da água do mar como fonte de água potável (MISRA, 2007; REDDY \& GHAFFOU, 2007) e como métodos de reuso de água, o uso de águas de chuvas e de águas cinzas, para utilização em descargas de vasos sanitários (FRIEDLER \& HADARI, 2006; GHISI et al., 2006; GODDARD, 2006; GHISI et al., 2007a; GHISI et al., 2007b; KIM et al., 2007; VILARREAL \& DIXON, 2007), o uso de efluente de lavagem de recintos de animais (ALI et al., 2006; ALI et al., 2007), de culturas de peixes (CASTRO et al., 2006) e os efluentes de estações de tratamento de esgoto para irrigação de culturas agrícolas (AL LAHHAM et al., 2003; SINGH \& BHATI, 2005; 
JANOSOVA et al., 2006; PETALA et al., 2006; SHARMA \& ASHWATH, 2006).

No tocante a este último método de reuso de água, a irrigação com efluentes de estação de tratatamento de esgoto é economicamente interessente, pois além de economizar os recursos hídricos de qualidade para irrigar culturas agrícolas, fornece parte dos nutrientes essenciais para as plantas. Além disso, o sistema solo-planta atua como "filtro vivo" o que permite também minimizar o uso de sistemas de tratmento de esgotos terciários que, em geral, são de alto custo. Entretanto, apesar dos aspectos favoráveis, os teores elevados de sódio e a adição de matéria orgânica e nitrogênio, podem alterar, por vezes, negativamente a estrutura e a fertilidade do solo. (FEIGIN et al., 1978; BOND, 1998).

Dentro do intuito geral de avaliação da sustentabilidade da irrigação de cultutras agrícolas com efluentes de estação de tratamento de esgotos (EETE), foi objetivo do presente trabalho caracterizar a matéria orgânica dos solos irrigados (EETE e água potável) e comparála àquela do sistema sem irrigação. 


\section{Revisão de liteiratura}

\subsection{Efluentes de estação de tratamento de esgoto}

Com o crescimento constante da população mundial, o uso de efluentes de estação de tratamento de esgoto doméstico (EETE) para irrigação tornou-se uma via particularmente interessante, tanto economicamente, quanto ecologicamente (LUBELLO et al., 2004). O tratamento de esgoto através de processos biológicos, cada vez mais utilizado em cidades brasileiras, gera dois subprodutos: o lodo de esgoto e o efluente.

O lodo de esgoto (LDE) é um resíduo semi-sólido com altos teores de matéria orgânica, nitrogênio e fósforo (FUENTES et al., 2007; SINGH \& AGRAWAL, 2007) que, quando aplicado ao solo, melhora suas características físicas e químicas (SILVEIRA et al., 2003; VEERESH et al., 2003a). Essas características, somadas às grandes quantidades produzidas anualmente, fazem dele um produto muito interessante para a adubação de solos agrícolas (FUENTES et al., 2007). Entretanto, esse produto contém, em geral, altos teores de metais pesados (sobretudo esgotos com importante contribuição industrial), que podem se acumular no solo, sendo tóxicos para as plantas ali cultivadas. Se as plantas por um lado não morrem, por outro elas podem constituir grave ameaça à cadeia trófica. (VEERESH et al., 2003b; FORSBERG et al., 2006; WALTER et al., 2006; SINGH \& AGRAWAL, 2007).

O efluente é também rico em nitrogênio e fósforo, e eventualmente, em matéria orgânica e, geralmente, apresenta baixa concentração em metais pesados (CAMERON et al., 1997; BOND,1998; KARVELAS et al., 2003). Apesar dessa vantagem, a maior parte dos EETE é atualmente lançada nos corpos hídricos (rios, lagos, mares) ocasionando problemas de saúde, de eutrofização das águas e aumento da população de algas, devido à presença de patógenos e de macronutrientes, respectivamente (BOND, 1998; VALIELA et al., 2000a; VALIELA et al., 2000b; CLOERN, 2001; ARANDACIREROL et al., 2006; TOZES, 2006). 
Entretanto, paradoxalmente, a agricultura utiliza $70 \%$ da água consumida mundialmente (essa porcentagem pode ultrapassar 90\% em alguns países) (WORLD HEALTH ORGANIZATION, 2006) e a maior parte dos adubos produzidos.

Nesse contexto, o uso do EETE apresenta várias vantagens. Economicamente, a produção de EETE é, geralmente, constante e fiável e permite reduzir os custos de fertilizantes podendo levar à economia, em alguns casos, de 80\%, na adubação nitrogenada via fertilizante mineral (FEIGIN et al., 1991; AL LAHHAM et al., 2003; FONSECA, 2005; FONSECA, 2007; QADIR et al., 2007). Além disso, o sistema solo-planta atua como filtro removendo os nutrientes, poluentes e organismos patogênicos que só um tratamento de esgoto terciário, de alto custo, conseguiria remover eficientemente (BOUWER; CHANEY, 1974; TOZES, 2006).

Ecologicamente, a utilização de EETE na irrigação reduz a sua disposição em ecossistemas sensíveis, diminui os riscos de poluição, reduz o consumo de água para irrigação e contribui para a recarga de aqüíferos (U.S. ENVIRONMENTAL PROTECTION AGENCY, 2004). Entretanto, a aplicação dos EETE no solo não deve ser feita indiscriminadamente e, se o processo não for cuidadosamente manejado e monitorado, as características químicas e físicas do solo podem ser alteradas (BOUWER; CHANEY, 1974; FEIGIN et al., 1991). Os EETE contêm, geralmente, altas concentrações de sais que podem se acumular na zona radicular pela evapotranspiração e também prejudicar o crescimento das plantas em solos mal drenados (BOND, 1998).

O sódio presente em altas concentrações é um dos maiores problemas da irrigação com EETE. O aumento de sódio no solo provoca a expansão e a dispersão das argilas devido à substituição de cátions bivalentes pelo íon $\mathrm{Na}^{+}$, monovalente e de grande esfera de hidratação (SUMNER, 1993; HALLIWELL et al., 2001). Esses fenômenos provocam a obstrução gradual dos poros e a redução da condutividade hídrica (SUMNER, 1993; 
EMONGOR; RAMOLEMANA, 2004; GONÇALVES, 2005; BAGARELLO et al., 2006; GLOAGUEN, 2006; GHIBERTO et al., 2007), ocasionando diminuição da condutividade hidráulica, impermeabilização do solo, escoamento superficial e erosão do solo, e decréscimo na aeração do solo (LADO et al., 2004; REICHARDT \& TIMM, 2004; FETTER, 1993; MC BRIDE, 1997).

Os elementos químicos podem ser lixiviados pela introdução do ácido carbônico $\left(\mathrm{H}_{2} \mathrm{CO}_{3}, \mathrm{HCO}_{3}^{-}\right)$e da matéria orgânica pouca humificada (fragmentos celulares, exudatos metabólicos, entre outros) carregados pelo EETE (BOUWER; CHANEY, 1974). Atuando sobre o $\mathrm{pH}$, o primeiro modifica o equilíbrio das reações de oxido-redução, liberando os elementos precipitados ou adsorvidos na superfície dos minerais e da matéria orgânica (ROBERT, 1996; HELMKE, 2000; BRADY; WEIL, 2002). No segundo caso, a matéria orgânica pouca humificada, por ser uma fonte de energia facilmente acessível, é rapidamente degradada pelos microrganismos do solo, levando a um aumento de população. Este aumento da atividade microbiana estimula a degradação da matéria orgânica endogênica (BOUWER; CHANEY, 1974). A degradação dos dois tipos de matéria orgânica libera dioxido de carbono assim como compostos carbônicos de baixo peso molecular que, por quelação, formam complexos solúveis com os metais, levando a sua lixiviação (STEVENSON, 1994; ROSE et al, 1998; DARBAN et al, 2000; MARTINEZ et al, 2001; BRADY; WEIL, 2002).

Outro problema na utilização de EETE na irrigação é o manejo dos nitratos que podem contaminar as águas subterrâneas (QUIN \& FORSYTHE, 1978; LINDEN et al., 1981; FEIGIN et al., 1991; EMONGOR; RAMOLEMANA, 2004; CHOI et al., 2007). Além dos problemas de eutrofização resultantes da descarga nas águas superficiais (BOND, 1998; VALIELA et al., 2000a; VALIELA et al., 2000b; CLOERN, 2001; ARANDACIREROL et al., 2006; DAVIDSON et al., 2006). O nitrato $\left(\mathrm{NO}_{3}{ }^{-}\right)$é altamente prejudicial à saúde humana, particularmente para mulheres grávidas e crianças (WORLD HEALTH ORGANIZATION, 
2006). Por esse motivo, a Organização Mundial da Saúde recomenda não ultrapassar 50 mg $\mathrm{L}^{-1}$ de $\mathrm{NO}_{3}^{-}$nas águas destinadas ao consumo humano e o monitoramento cuidadoso das águas subterrâneas (WORLD HEALTH ORGANIZATION, 2006).

Os vírus, bactérias, protozoários e helmintos são as formas mais comuns de patógenos presentes nos EETE (TOZES, 2006). Esses microrganismos podem apresentar riscos a saúde humana, pelo contato direto com o efluente (DERRY et al., 2006; QADIR et al., 2007), aos usuários de águas contaminadas pelos patógenos devido ao escoamento superficial dos campos irrigados com EETE (TOZES, 2006; SERVAIS et al., 2007) ou aos consumidores de frutas e legumes que receberam o efluente (AL-LAHHAM et al., 2003; EMONGOR; RAMOLEMANA, 2004).

Portanto, se a utilização do EETE na agricultura apresenta inúmeras vantagens, o seu uso necessita ser monitorado para não induzir mudanças físicas, químicas e biológias adversas ao sistema solo-planta-água.

\subsection{Matéria orgânica do solo}

O solo, com 2000 petagramas de carbono, é o segundo maior reservatório deste elemento na Terra (HOUGHTON, 2003). A maior parte deste carbono está presente na forma de matéria orgânica.

O termo matéria orgânica do solo (MOS) se refere ao conjunto de compostos orgânicos presentes no solo. Ele engloba a liteira, a biomassa microbiana, as raízes, as enzimas, os compostos orgânicos dissolvidos e o húmus.

A MOS é fonte de nutrientes para a biota, além de ser importante para o ambiente no combate ao aquecimento global e, desta forma, possui importância econômica no mercado do carbono (BALDOCK; NELSON, 2000). Ela favorece a retenção da água, modifica a 
capacidade de troca catiônica do solo e contribui para retenção/eliminação dos poluentes.

O processo de formação da matéria orgânica do solo (MOS) começa com a síntese de matéria orgânica a partir do $\mathrm{CO}_{2}$ atmosférico durante o processo de fotossíntese que ocorre nos vegetais. Neste processo, o dióxido de carbono é transformado em um açúcar simples, a glucose $\left(\mathrm{C}_{6} \mathrm{H}_{12} \mathrm{O}_{6}\right)$, que é usada como fonte de energia pela planta ou convertida em peptídeo e estruturas mais complexas tais como proteína, amido, lignina, etc. (CAMPBELL, 1995; BALDOCK; NELSON, 2000)

O carbono assim fixado ao longo do crescimento da planta é depois depositado (folhas) ou incorporado (raízes, exsudato das raízes) no solo durante o crescimento e a morte do vegetal. Esse material torna-se, então, uma fonte de nutrientes para os organismos do solo que vão decompô-lo, transformá-lo e assimilá-lo. Entretanto, é preciso ressaltar que o papel destes organismos, que apresentam funções diferentes, não é somente limitado à mineralização da matéria orgânica, mas envolve também a redução do tamanho das partículas da liteira, o transporte, a redistribuição da MOS e a translocação dos microrganismos. Toda a cadeia produz formas mais complexas à base de carbono, tais como quitinas, proteínas, polissacarídeos, etc (BALDOCK; NELSON, 2000).

As bactérias e os fungos são os grupos mais importantes na decomposição da MOS, pois produzem compostos extracelulares que auxiliam na formação dos agregados do solo e grupos especializados que promovem a ciclagem do nitrogênio. Os fungos, particularmente eficazes na degradação de compostos resistentes como a lignina, participam também da agregação e do enriquecimento em MOS por meio de suas hifas e dos exudatos a que dão origem (OADES, 1989; OADES; WATERS, 1991). Minhocas, além de criar macroporos que aumentam a infiltração da água e a aeração, adicionam secreções e bactérias, e modificam a repartição da matéria orgânica no solo. Protozoários, artrópodes e nematóides aceleram a decomposição ao consumir resíduos vegetais, fungos e bactérias (BALDOCK; NELSON, 
2000).

Para melhor entender o processo de formação da MOS, vários autores usaram a técnica de ressonância magnética nuclear e observaram a diminuição dos grupos $\mathrm{O}$-alkil e o enriquecimento de grupos carboxil, metoxil, fenolyc e alcil com o aumento do grau de humificação da matéria orgânica. Assim, chegaram à conclusão que os componentes mais facilmente degradáveis (açúcares, aminoácidos, proteínas) são primeiramente decompostos pelos organismos levando a um aumento da concentração dos componentes mais resistentes, tais como a lignina ou a celulose (GOLCHIN et al., 1994a; ZECH et al., 1997). Entretanto, outros estudos revelaram que a matéria orgânica não se acumula indefinidamente no solo, mas que chega a um equilíbrio que é dependente tanto de fatores inerentes à matéria orgânica como à fatores externos.

Além da quantidade de material que entra no ciclo, a flora e a fauna determinam também a qualidade da MOS. As plantas, ainda que constituídas dos mesmos componentes, os contêm em proporções muito variáveis dependendo da espécie considerada e, obviamente, essas variações na qualidade do material de entrada refletem nas taxas de humificação e de mineralização (KONONOVA, 1966). Por exemplo, lignina e celulose são altamente recalcitrantes a mineralização, enquanto proteína e carboidratos são fontes de nutrientes prontamente disponível para o ambiente. Stevenson (1994) ressalta que a falta de um dos nutrientes essenciais (nitrogênio $(\mathrm{N})$, fósforo $(\mathrm{P})$, enxofre $(\mathrm{S})$ ) limitará a quantidade de húmus estável que será sintetizado. Zech et al. (1997) baseando-se na razão C/N chegaram à mesma conclusão.

O clima é outro fator que influi na matéria orgânica do solo, pois condiciona em grande parte a umidade, a temperatura e as radiações solares. Esses três parâmetros, além de contribuírem para a seleção das espécies presentes numa zona geográfica, condicionam a atividade dos organismos. Portanto, na ausência de limitações de nutrientes, a produção 
vegetal é determinada pelo clima (STEVENSON, 1994; CAMPBELL, 1995). Estudando a degradabilidade do carbono orgânico em solos nos quais foram adicionadas quantidades conhecidas de matéria orgânica a fim de se obter texturas diferentes, Thomsen et al. (1999) demonstraram que a atividade microbiana de decomposição é altamente correlacionada ao volume de água do solo. Sollins et al. (1996) em uma revisão sobre os mecanismos de controle da estabilização/desestabilização da matéria orgânica do solo ressaltam também a importância da umidade e da temperatura nas atividades microbianas e enzimáticas. Guggenberger et al. (2001) discutindo sobre o efeito do gradiente climatológico na Sibéria concluiram que o frio, através de sua influência na vegetação, impacta também a qualidade da matéria orgânica.

A estabilização da MOS pelas interações com a fração mineral do solo é um fato bem conhecido. A adsorção da matéria orgânica aos argilominerais é efetuada por troca catiônica, por ligação hidrofóbica no caso de minerais já cobertos por matéria orgânica, ou pela formação de pontes por cátion polivalente $\left(\mathrm{Ca}^{2+}, \mathrm{Mg}^{2+}, \ldots\right)$ (SOLLINS et al.,1996; ZECH et al., 1997). Nos solos tropicais, onde os óxidos de ferro e de alumínio são abundantes, as interações ocorrem principalmente por atração eletrostática, por ponte de hidrogênio e por reação de troca de ligante (OADES, 1989; WAGAI \& MAYER, 2007).

A estrutura do solo também controla os processos biológicos pela incorporação do material orgânico aos agregados (GOLCHIN et al., 1994a; GOLCHIN et al., 1995; TISDALL; OADES, 1982) ou pela sua retenção nos poros menores que $1 \mu \mathrm{m}$ (ELLIOT; COLEMAN, 1988). Em ambos os casos, a matéria orgânica é fisicamente inacessível aos organismos decompositores.

Por expor a matéria orgânica do solo aos processos de decomposição, as práticas agrícolas e as alterações no manejo do solo devem ser cuidadosamente efetuadas para não provocar a redução de seu conteúdo (JASTROW, 1996; SIX et al., 1999). 
Historicamente a MOS foi dividida em duas categorias: as substâncias não húmicas (20 a 30\% do COS, carbono orgânico do solo) e as substâncias húmicas (SH). As substâncias não húmicas, são resíduos de plantas, assim como compostos orgânicos bem definidos, tais como os aminoácidos, a lignina, os açúcares, os carboidratos e os ácidos nucléicos. As substâncias húmicas são subprodutos da decomposição das primeiras, e compostos sintetizados pelos microrganismos. São altamente resistentes aos ataques dos microrganismos, possuem alto peso molecular, cor escura, estrutura não definida e são heterogêneas (STEVENSON, 1994; BRADY; WEIL, 2002).

Na prática, os componentes das SH foram classificados em função de sua solubilidade na solução usada para extração. Foram definidos três tipos de compostos: i) os ácidos fúlvicos, solúveis em solução ácida e em solução básica; ii) os ácidos húmicos, solúveis em solução básica e insolúveis em solução ácida; e iii) as huminas, insolúveis em solução básica. (STEVENSON, 1994)

O primeiro conceito sobre as $\mathrm{SH}$ considerou-as como polímeros macromoleculares formados pela condensação de diversos compostos tais como aminoácidos, lignina, celulose, açúcares (KONONOVA, 1966; SCHULTEN, 1995) e levou a modelos complexos de macromoleculas, e as seguintes definições: (i) as substâncias húmicas são materiais polieletrólitos, de cores escuras, parcialmente aromáticas, ácidas, hidrófilas, molecularmente flexíveis, (SCHNITZER, 1986); (ii) as substâncias húmicas são uma categoria geral de substâncias orgânicas ocorrendo naturalmente que podem ser, geralmente, caracterizadas como sendo de cor amarela até negra, de peso molecular elevado e refratária (AIKEN, 1985). Entretanto, com o desenvolvimento de técnicas analíticas e novos resultados, outro conceito foi estabelecido para as substâncias húmicas (PICOLO et al., 1996; PICOLO, 2001), sendo estas descritas como uma associação supramolecular de moléculas heterogêneas relativamente 
pequenas, unidas por ligações fracas como é o caso das interações de Van Der Waals, $\pi$ - $\pi$, CH- $\pi$. (PICOLO et al., 2002; PICOLO et al., 2003)

A importância da matéria orgânica como fonte de nutrientes é conhecida desde a antiguidade, tanto é que os romanos já julgavam a qualidade da terra pela sua cor (KONONOVA, 1966; WAKSMAN, 1938). Atualmente sabe-se que a matéria orgânica do solo é o maior reservatório de $\mathrm{N}, \mathrm{Pe} \mathrm{S}$.

Stevenson (1994) observou que o valor médio da razão C/N/S para solo sob florestas e pastagens é de 200:10:1, enquanto a proporção de C/N/P/S para solos agrícolas é 140:10:1,3:1,3. Os nutrientes podem estar presentes como parte das estruturas das moléculas orgânicas $(\mathrm{N}, \mathrm{P}, \mathrm{S})$, na forma de cátions trocáveis $(\mathrm{Ca}, \mathrm{Mg}, \mathrm{K}, .$.$) , ou ainda, complexados na$ matéria orgânica $(\mathrm{Cu}, \mathrm{Fe}, \mathrm{Zn}, \ldots)$, sendo lentamente liberados através dos processos biológicos e físico-químicos da mineralização. Mais de $90 \%$ do nitrogênio presente no solo está na forma orgânica (CHAPMAN et al., 2001), sendo que 40 a 50\% são parte de compostos químicos bem definidos e facilmente degradáveis tais como os aminoácidos (STEVENSON, 1994). O fósforo está presente principalmente na forma de inositol fosfato (2 a 50\%), fosfolipídeo (1 a $5 \%$ ) e ácido nucleico (0,2 a 2,5\%). (BALDOCK; NELSON, 2000)

O húmus geralmente contribui com 25 a $90 \%$ no poder de adsorção de cátions na superfície dos minerais dos solos e retém de forma facilmente trocável os nutrientes potássio, magnésio, cálcio, etc. (BRADY; WEIL, 2002). Esse efeito é particularmente importante em solos altamente intemperizados, ricos em caolinita e óxidos e óxi-hidróxidos de ferro e alumínio com baixa capacidade de troca catiônica (ZECH et al., 1997).

A matéria orgânica, através da variedade dos grupos ácidos e básicos, é responsável por uma grande parte da capacidade de tamponamento do $\mathrm{pH}$ nos solos. A presença de grupos funcionais possibilita também reações de complexação com cátions (BALDOCK; NELSON, 2000). 
Azevedo et al. (2001) estudando a camada de 0-20 cm de solos Aluvial, Glei pouco Húmico, Glei Húmico e Orgânico artificialmente drenado, demonstraram por meio dos parâmetros das isotermas de Freundlich e Langmuir que a matéria orgânica está correlacionada a quantidade de boro retido no solo. Além dos metais, a matéria orgânica está também envolvida na retenção de moléculas tóxicas como os pesticidas e herbicidas. Fuscalo et al. (1999) estudando a persistência dos herbicidas Atrazine, Metribuzin e Sinazine na camada 0-15 cm de dois solos do sudeste da Província de Buenos Aires, Argentina, demonstraram que a adsorção dos herbicidas aumenta com maiores teores de matéria orgânica, diminuindo assim suas persistências. Resultados semelhantes foram publicados sobre os herbicidas Imazaquin em Latossolo Vermelho distrófico sob plantio direto e convencional (OLIVEIRA et al., 2004), Ácido 2,4-Dichlorophenoxyacetic em Latossolo Roxo (PRADO et al., 2001), ou ainda Acetochloro em Argissolo Vermelho distrófico (FERRI et al., 2005), esse último se ligando preferencialmente às huminas.

A formação e a estabilidade de agregados dos solos são favorecidas, principalmente, pelas substâncias produzidas durante a decomposição da MOS. No conceito da hierarquia dos agregados de Tisdall e Oades (1982), os diferentes agentes de ligação atuam em diferentes estágios de agregação. Esses agentes foram classificados como transitórios (polissacarídeo derivado das plantas e dos microrganismos), temporários (raízes, hifa de fungo) e persistentes (matéria orgânica num estado avançado de humificação, complexos de cátions polivalentes). Os agregados de tamanho inferiores a $20 \mu \mathrm{m}$ e as partículas primárias são ligados entre si por agentes persistentes em agregados de tamanhos inferiores a $250 \mu \mathrm{m}$. Estes últimos são ligados por agentes transitórios e temporários em agregados de tamanhos superiores. Oades e Waters (1991) modificaram esta classificação, sendo a proposta por estes autores a utilizada atualmente. Nesta nova classificação, os agregados de tamanho superior a $250 \mu \mathrm{m}$ foram denominados macroagregados e sua integridade é mantida pelas raízes das plantas. Quando as 
raízes morrem e se decompõem, os macroagregados perdem a estabilidade passando a agregados menores com tamanhos compreendidos entre 250 e $20 \mu \mathrm{m}$ denominados microagregados. A fração dos agregados compreendida entre 250 e $20 \mu \mathrm{m}$ foi inicialmente dividida em duas (WATERS \& OADES, 1991): agregados compreendidos entre 250 e $90 \mu \mathrm{m}$ e entre 90 e $20 \mu \mathrm{m}$. A fração entre 250 e $20 \mu \mathrm{m}$ é muito mais estável que os macroagregados. Os resíduos de plantas servem de núcleos para microagregados que os protegem de uma degradação rápida. Os cimentos dos microagregados são, principalmente, produtos da decomposição dos núcleos orgânicos. Nos agregados inferiores a $20 \mu \mathrm{m}$, até os produtos mais recalcitrantes, como a lignina, são decompostos restando, em sua maior parte, argila, óxidos de ferro e alumínio. Neste caso, a matéria orgânica contida nestes agregados inferiores a $20 \mu \mathrm{m}$ é composta principalmente por produtos dos microrganismos.

Golchin et al. (1994b) e Golchin et al. (1995), separando os agregados por diferença de densidade e analisando a matéria orgânica a partir de técnicas de ressonância magnética nuclear, mostraram que a matéria orgânica contida nos agregados mais estáveis são de um lado mucilagens e metabólitos produzidos pelos microrganismos durante a decomposição de resíduos de plantas e núcleos orgânicos, esses produtos tendo um papel de cimento entre partículas, de outro lado compostos humificados caracterízados por alta precentagem de cilcos aromáticos. Os estudos citados por Von Lützow et al. (2007) relacionam a matéria orgânica mais evoluida, portanto com maior grau de humificação, aos agregados de tamanho menor e de densidade maior.

\subsection{Resumo das características do solo, solução do solo e efluente a partir de trabalhos anteriores realizados na área de estudo.}

A área experimental localizada no município de Lins ( $49^{\circ} 50^{\prime} \mathrm{W}$ e $\left.22^{\circ} 21^{\prime} \mathrm{S}\right)$, Estado de

São Paulo, utilizada para o desenvolvimento deste trabalho vem sendo estudada desde o ano 
2000, sendo que várias pesquisas com objetivos distintos foram ali conduzidas. Será apresentada uma revisão sobre os principais resultados obtidos nestas pequisas visando contextualizar o presente trabalho, no que diz respeito a área cultivada com capim-Bermuda Tifton 85 que será objeto deste doutorado.

Os trabalhos realizados na área cultivada com capim-Bermuda Tifton 85 tiveram como objetivos verificar a possibilidade do uso do efluente como fonte alternativa de água e nitrogênio, avaliar as alterações em propriedades do solo e efeitos na microbiota em razão da irrigação com EETE (FONSECA, 2005; FONSECA et al., 2007; NOGUERIA et al., 2005; NOGUEIRA, 2008; SANTOS, 2008).

A região de estudo faz parte do Planalto Ocidental Paulista que ocupa cerca de $50 \%$ do Estado de São Paulo sendo o relevo, de modo geral, suave a levemente ondulado, exceto nas proximidades das cuestas basálticas. A área experimental esta inserida na Formação Adamantina (Cretáceo Superior), pertencente ao Grupo Bauru na bacia sedimentar do Paraná, localmente caracterizada por um banco de arenito de granulação fina a muito fina, moderadamente selecionado, com espessura superior a três metros (IBRAHIM, 2002).

O clima da região é classificado como Cwa, caracterizado como mesotérmico de inverno seco segundo a classificação de Koppen. A temperatura anual média varia entre $18^{\circ} \mathrm{C}$ e $22^{\circ} \mathrm{C}$ e a precipitação anual entre 1100 e $1300 \mathrm{~mm}$, sendo que a precipitação é menor que 30 mm durante o mês mais seco (IBRAHIM, 2002). (Figura 2.1). 


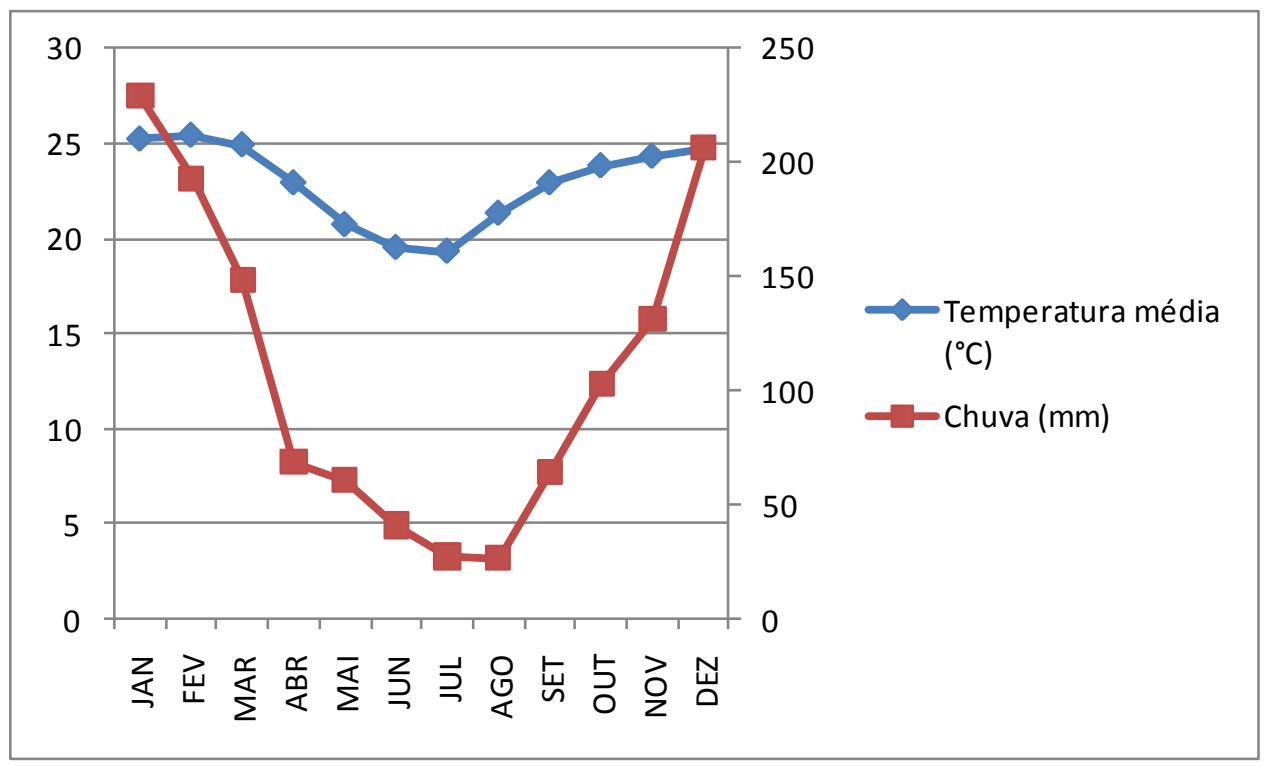

Figura 2.1 - Pluviometria e temperatura mensal média em Lins (10 últimos anos, fonte: http://www.cpa.unicamp.br/outras-informacoes/clima_muni_308.html).

De acordo com o mapa pedológico do Estado de São Paulo, o solo desta região é classificado como Argissolo Vermelho-Amarelo distrófico, com textura argilosa e Argissolo Vermelho distrófico e eutrófico, com textura arenosa/média, em relevo suavemente ondulado (OLIVEIRA, 1999). Os constituintes minerais da fração argila são de baixa atividade e o horizonte B textural situa-se imediatamente abaixo do horizonte A ou E, sendo fortemente arenoso. Na região de Lins os solos têm mudança textural abrupta, conferindo maior susceptibilidade à erosão (OLIVEIRA, 1999).

Os solos do campo experimental constituem um sistema Latossolo (a montente) Argissolo (a jusante), com caracteristicas morfológicas relativamente homogêneas. Apresentam ao longo da vertente intensa porosidade, caracterizada pelo empilhamento dos grãos do esqueleto quartzoso, predominante, e pelo arranjo entre os microagregados granulares (IBRAHIM, 2002; IBRAHIM \& MELFI, 2008).

O solo onde está sendo desenvolvido o presente estudo foi classificado como Argissolo Vermelho distrófico Latossólico. Sete horizontes foram identificados até a profundidade de $210 \mathrm{~cm}$. A textura é areia-franca nos horizontes A e AB e franco-argilo- 
arenosa nos demais. Os horizontes Bt1 a Bt3 (até $200 \mathrm{~cm}$ ) têm estrutura em blocos subangulares de grau moderado a fraco passando no Bw para grau fraco, que se desfazem em agregados granulares. A macroporosidade é alta em todo o perfil. Raízes foram observadas até $160 \mathrm{~cm}$ de profundidade, e, também, uma atividade biológica intensa até a profundidade de 56 cm (IBRAHIM, 2002; IBRAHIM \& MELFI, 2008). A mineralogia predominantemente é constituída por quartzo, caulinita, hematita, magnetita e/ou maghemita e illita e tem como minerais acessórios ilmenita, zircão, turmalina e epídoto (IBRAHIM, 2002; IBRAHIM \& MELFI, 2008).

Os estudos realizados por Fonseca (2005) e Fonseca et al. (2007) entre os anos de 2003 e 2005, visaram avaliar o potencial de utilização do efluente secundário de esgoto tratado (ESET) de origem doméstica como uma fonte alternativa de água e de nitrogênio ao capim-Bermuda Tifton 85, monitorando o sistema solo-planta-água. Para tal foram empregados cinco tratamentos experimentais que consistiram na variação da dose de fertilizante nitrogenado mineral (FNM) e irrigação com efluente (E0, E33, E66 e E100 irrigação com ESET e adição de 0, 171,6; 343,2 e $520 \mathrm{~kg} \mathrm{ha}^{-1} \mathrm{ano}^{-1}$ de FNM) e água potável (W100 (controle) - irrigação com água potável e adição de $520 \mathrm{~kg} \mathrm{ha}^{-1}$ ano $^{-1} \mathrm{FNM}$ ).

Por ocasião da instalação do experimento, o solo apresentava características intrínsecas a solos altamente intemperizados: baixa fertilidade natural, baixa saturação por bases nas camadas 20-100 cm, baixas concentrações de carbono total e nitrogênio total, cargas elétricas predominantemente negativas, baixas concentrações de micronutrientes e elementos tóxicos A capacidade de armazenamento de água do solo era pequena, o que implicava na necessidade de maior freqüência de irrigação.

Os constituintes químicos analisados nas amostras do ESET apresentaram maior variação quando comparados aos da água de abastecimento utilizada na irrigação. Os constituintes do ESET variaram ao longo do ano, sobretudo na estação chuvosa (verão) 
verificando-se diminuição em suas concentrações devido aos efeitos de diluição. A irrigação com ESET apresenta menor risco de sodificação do solo quando comparado à água potável de Lins pelo fato de apresentar menor razão de adsorção de sódio (RAS) e uma maior condutividade elétrica.

Pelo fato do capim-Bermuda Tifton 85 responder linearmente até $600 \mathrm{~kg} \mathrm{ha}^{-1} \mathrm{ano}^{-1} \mathrm{de}$ FNM e a irrigação com ESET ter proporcionado não somente aporte médio de N-mineral, mas também de outros nutrientes, o uso de doses mais elevadas de FNM associadas à irrigação com ESET ocasionaram maiores rendimentos de matéria seca (MS). Assim, observou-se que a substituição da água potável pelo ESET, na irrigação do capim, pode levar à economia de 32,2 a 81,0\% na dose de FNM necessária. Comprando com outros estudos, estes rendimentos foram altos principalmente devido ao fator irrigação. As freqüientes irrigações ocasionaram uma baixa tensão da água no solo, levado ao aumento da eficiência de uso do N. Entretanto, o menor rendimento obtido na ausência de FNM demonstrou que o efluente não supre toda a necessidade de $\mathrm{N}$ do capim.

Os tratamentos empregados ocasionaram pequenas alterações do $\mathrm{pH}$ (menor que uma unidade) do solo e da solução no solo somente na camada 0-10 cm. Devido ao pH da água potável empregada na irrigação do tratamento de controle W100 ser maior que o pH do ESET, a solução do solo da camada 0-10 cm apresentou o maior $\mathrm{pH}$. Porém, graças ao efeito do ESET como amenizador da acidez do solo, os pH não diferiram estatisticamente. Durante o estudo, o solo e a solução do solo ainda sofreram alterações sazonais de pH na maior parte das camadas devido a: (i) liberação de próton pelos microrganismos que atuam no ciclo do $\mathrm{N}$ e na degradação da MOS; (ii) lixiviação de íons acidificação do solo por as chuvas; (iii) ao aporte de $\mathrm{HCO}_{3}{ }^{-}$por o ESET; (iv) ao baixo poder tampão do solo estudado.

Os tratamentos ocasionaram alterações da acidez potencial do solo $(\mathrm{H}+\mathrm{Al})$ somente nas camadas 0-10, 20-40 e 40-60 cm, e nas concentrações de Al trocável somente nas 
camadas 0-10 e 20-40 cm. Os tratamentos que receberam maiores doses de FNM apresentaram menores valores de pH e maiores concentrações de $\mathrm{H}+\mathrm{Al}$ e $\mathrm{Al}$ trocável.

Devido a o baixo rendimento de MS decorrido da ausência de FNM que ocasionou menor crescimento, desenvolvimento vegetal e exportação dos elementos, as maiores concentrações de $\mathrm{Ca}, \mathrm{Mg}$ e $\mathrm{K}$ trocável foram observadas no tratamento $\mathrm{E} 0$. As maiores concentrações de $\mathrm{Ca}, \mathrm{Mg}$, e $\mathrm{K}$ solúvel no extrato de saturação foram observadas no tratamento E0. Os efeitos dos tratamentos nas concentrações destes elementos na solução do solo não foram similares aos ocorridos no complexo de troca, pois foram observados baixos coeficientes de correlação ou inexistência de correlação entre os parâmetros trocável e percentual trocável com o Ca solúvel.

Sodicidade do solo

Os tratamentos empregados ocasionaram alterações nas concentrações de Na trocável no solo e no percentual de sódio trocável (PST) nas camadas superficiais (até $20 \mathrm{~cm}$ ) assim como na camada de 80 a $100 \mathrm{~cm}$. Em algumas camadas as chuvas do verão e início de outono promoveram diminuição na concentração de Na trocável e no PST. O acúmulo semestral foi inferior a 50kg ha ${ }^{-1}$, mesmo com aporte médio anual via irrigação variando de 569,5 a 2127,4 $\mathrm{kg} \mathrm{ha}^{-1}$. Embora a maior parte do Na-efluente que atingiu o solo foi perdida do sistema via lixiviação, as concentrações de $\mathrm{Na}$ solúvel das camadas superficiais estão grandemente relacionadas à capacidade de extração deste elemento pelas plantas.

Apesar da associação das características do capim-Bermuda Tifton 85 e das práticas agronômicas (fertilização e irrigação) adequadas ter mantido o sistema solo-planta eficiente para receber irrigação com ESET, os autores concluem que o curto prazo do experimento impede afirmar que o sistema solo-planta suportará, em longo prazo, o elevado aporte de $\mathrm{Na}$ 
via irrigação.

Foi também observado que o aumento das concentrações de $\mathrm{Na}$ no solo alterarou sua fertilidade. $\mathrm{O} \mathrm{Ca}$ e o $\mathrm{Mg}$ foram progressivamente substituídos pelo $\mathrm{Na}$, ocasionando uma diminuição destes elementos, simultaneamente ao aumento do Na trocável e solúvel, do PST e da RAS da solução do solo.

Fósforo, enxofre, carbono e nitrogênio

Os tratamentos empregados ocasionaram alterações nas concentrações de P, S, disponível nas camadas superficiais do solo. O sistema solo-pastagem atuou como "filtro vivo" em relação ao P-efluente, pois maiores doses de irrigação com ESET não proporcionaram aumento do $\mathrm{P}$ no solo, mas ocasionaram incremento no acúmulo deste elemento nas planta. A quantidade de irrigação foi o fator que controlou a quantidade de $\mathrm{S}$ no capim.

Durante o experimento, as doses de FNM, o aporte de N-efluente, ou o tipo de água empregada na irrigação não foram suficientes para ocasionar alterações nas concentrações de carbono total $(\mathrm{CT})$ e nitrogênio total $(\mathrm{NT})$ no solo. Apesar da adição de FNM associada à irrigação ter promovido maior rendimento de MS, o aporte de resíduos orgânicos não foi suficiente para promover incremento nas concentrações da MOS. A relação C/N diminui com o tempo de experimentação, mas não foi diferente para os tratamentos.

$\mathrm{Na}$ solução do solo, as concentrações de $\mathrm{N}_{-} \mathrm{NO}_{3}{ }^{-}+\mathrm{N}_{-} \mathrm{NO}_{2}{ }^{-}, \mathrm{N}-\mathrm{NH}_{4}{ }^{+}, \mathrm{e} \mathrm{N}-$ mineral $(\mathrm{N}-$ $\mathrm{NO}_{3}{ }^{-}+\mathrm{N}-\mathrm{NO}_{2}{ }^{-}+\mathrm{N}^{-} \mathrm{NH}_{4}{ }^{+}$) foram alteradas pelos tratamentos, principalmente na camada 0-10 cm. As maiores concentrações de $\mathrm{N}_{-} \mathrm{NO}_{3}{ }^{-}$foram observadas nos tratamentos que receberam doses mais elevadas de $\mathrm{N}$, sobretudo, associadas à irrigação com ESET, e as menores concentrações de $\mathrm{N}_{-} \mathrm{NH}_{4}{ }^{+}$foram observadas nos tratamentos que receberam maiores doses de 
irrigação e/ou de FNM.

Micronutrientes e elementos tóxicos

Os tratamentos influenciaram as concentrações de B disponível no solo somente na camada 0-10 cm. Como para o $\mathrm{B}$, o fato da água e o ESET terem apresentado baixas concentrações, a irrigação não ocasionou aporte significante de $\mathrm{Cu}$ e $\mathrm{Zn}$, não alterando suas biodisponibilidades. As concentrações de Fe, Mn, e Cr disponível foram influenciadas pelos tratamentos apenas nas camadas superficiais, até $20 \mathrm{~cm}$. As concentrações disponíveis de Cd, $\mathrm{Ni}$ e $\mathrm{Pb}$ se encontravam abaixo do limite de detecção do método empregado.

Como conclusão geral tem-se que o ESET pode substituir eficientemente a água convencional de irrigação em sistema de produção de feno de capim-Bermuda Tifton 85. Essa substituição pode proporcionar benefícios econômicos e aumento da qualidade do capim. Ainda, o ESET pode atuar como amenizador da acidez do solo. A magnitude de resposta do capim ao ESET, bem como da economia de nitrogênio via fertilizante mineral (FNM) é dependente da precipitação pluvial e da lâmina de irrigação empregada. Assim, a substituição da água potável pelo ESET, na irrigação do capim, pode levar à economia de 32,2 a 81,0\% na dose de NFM necessária à obtenção de altos rendimentos, sem ocasionar alterações negativas no conteúdo de nutrientes nas plantas e na fertilidade do solo (FONSECA, 2005 e FONSECA et al. 2007).

O trabalho de Nogueira (2008), avaliou a dinâmica do carbono e do nitrogênio e o impacto dos manejos (irrigação associada à doses de fertilizante nitrogenado) sobre a qualidade do solo por meio de estudos de indicadores microbiológicos. Os tratamentos 
empregados para o estudo foram os mesmos já descrito nos trabalhos de Fonseca (2005) e Fonseca et al. (2007), acrescentando-se um tratamento que não recebeu irrigação nem fertilização (SI). Considerando os objetivos de seu trabalho, foram considerados dois anos hidrológicos (2004 a 2007) com as amostragens realizadas nos períodos de seca (de abril até setembro) e chuva (de outubro até março). Assim como apresentado anteriormente, serão descritos os resultados mais importantes obtidos por Nogueria (2008).

Os sólidos suspensos totais contidos no efluente representaram uma entrada de 1,7 t $\mathrm{ha}^{-1}$ de carga orgânica no primeiro ano hidrológico, $0,7 \mathrm{t} \mathrm{ha}^{-1}$ no segundo ano e no terceiro ano, sendo que $35 \%$ deste aporte correspondeu ao carbono particulado total. Entretanto, de acordo com a fisiologia das gramíneas, as entradas de $\mathrm{C}$ mais importantes no sistema solo foram as provenientes da deposição de resíduos vegetais pelo capim-Bermuda Tifton 85 (6 a 9 $\mathrm{Mg}$ de $\mathrm{C} \mathrm{ha}^{-1} \mathrm{ano}^{-1}$ ). Os resultados sugerem também uma permanência desta liteira sobre o solo relativamente pequena com valores médios de emissão de $\mathrm{C}-\mathrm{CO}_{2}$ oriundos da decomposição de 8,7 a 11,5 $\mathrm{Mg}$ de $\mathrm{C} \mathrm{ha}^{-1}$ ano $^{-1}$. Das entradas totais de C no sistema, 20 a $45 \%$ foram do $\mathrm{C}$ acumulado na liteira, 48 a $64 \% \mathrm{C}$ mineralizado (resíduos de plantas decompostos), e 2,1 a 5,3\% do C orgânico via esgoto tratado.

A análise das variações dos conteúdos de carbono na fração estável da MOS mostraram que os tratamentos irrigados com água e com efluente apresentaram um decréscimo dos estoques de $\mathrm{C}$ em relação ao tratamento SI. Contudo, o decréscimo nos tratamentos irrigados com esgoto tratado foi inferior aos tratamentos irrigados com água, provavelmente devido à estabilização do $\mathrm{C}$ nos complexos organominerais, como função da maior liberação de exsudatos orgânicos pelas raízes e decomposição de raízes mortas. Com relação à composição isotópica, os tratamentos irrigados com valores sempre menores que o tratamento SI sugerem uma possível desestruturação dos microagregados tornando o carbono remanescente oriundo da vegetação C3 pré-existente ao capim disponível para o microbiota. 
Comparando a prática convencional (W100) com as parcelas irrigadas com efluente ou sem irrigação, não foi observado aumento das emissões de $\mathrm{CO}_{2}$. As emissões de $\mathrm{CH}_{4}$, de forma geral, foram negligíveis para os solos de todos os tratamentos.

Refletindo sobre o balanço global de C, a imobilização de C (parte aérea e sistema radicular), o acúmulo de C (raízes mortas, exsudatos e liteira) e exportação de C (biomassa) pelo capim-Bermuda Tifton 85 , como resultado dos estímulos da irrigação e fertilização ao aumento de sua produção primária líquida (PPL), ao longo dos anos de monitoramento, sugerem que os tratamentos irrigados com esgoto tratado têm compensado a saída de $\mathrm{C}\left(\mathrm{CO}_{2}\right)$ do sistema.

Como mencionado o aporte dos SST representou a entrada de $1,7 \mathrm{t} \mathrm{ha}^{-1}$ de carga orgânica no primeiro ano hidrológico, $0,7 \mathrm{t} \mathrm{ha}^{-1}$ no segundo e terceiro anos. Do SST proveniente do esgoto tratado, 6\% corresponderam a nitrogênio particulado total (NPT). As entradas de $\mathrm{N}$ através do esgoto tratado constituíram-se de $70 \%$ de $\mathrm{N}^{-\mathrm{NH}_{4}}{ }^{+}, 27 \%$ de NPT e $3 \%$ de $\mathrm{N}^{-\mathrm{NO}_{3}}{ }^{-}$

Considerando as variações quantativas do $\mathrm{N}$ na fração estável da matéria orgânica do solo, os estoques de $\mathrm{N}$ nos tratamentos irrigados com efluente não mostraram diferenças em relação aos estoques das parcelas não irrigadas. O tratamento W100 apresentou uma diminuição do seu estoque de $\mathrm{N}$, provavelmente devido à desestruturação de complexos organominerais, em função dos processos de sodificação, disponibilizando o N para o microbiota e as plantas.

Os resultados mostraram variações na qualidade no $\mathrm{N}$ para os tratamentos que receberam esgoto tratado, sendo os valores de $\delta^{15} \mathrm{~N}$ para a camada 0 a $5 \mathrm{~cm}$ maiores que para os outros tratamentos. A autora sugere que isto se deve ao aumento da diversidade microbiana pela introdução no sistema de microrganismos não nativos e pelo favorecimento das comunidades existentes pelos compostos orgânicos e inorgânicos facilmente disponibilizados 
pelo esgoto tratado.

Os conteúdos de $\mathrm{N}-\mathrm{NH}_{4}{ }^{+}$e N-NO${ }_{3}{ }^{-}$no solo mostram claramente o efeito da fertilização (acréscimo) e da absorção das plantas e imobilização pela microbiota (decréscimo), e também o efeito dos tratamentos, pois os tratamentos irrigados com esgoto tratado que receberam maiores doses de $\mathrm{N}$ mineral apresentaram os maiores conteúdos. As taxas líquidas de mineralização e nitrificação negativas ou nulas nas épocas Seca-04, Chuvas-05 e Seca-05 indicaram predominância de processos de imobilização do $\mathrm{N}$ pela microbiota em virtude de uma alta relação C:N da MOS. Nas épocas de Chuvas-06 e Seca-06, as taxas tornaram-se positivas indicando a diminuição da relação $\mathrm{C}: \mathrm{N}$ da $\mathrm{MOS}$, término do efeito priming e ciclagem interna de $\mathrm{N}$ na camada avaliada.

As emissões de $\mathrm{NO}_{2}$ pelo solo no experimento realizado por Nogueira (2008) foram condicionadas pelas entradas de $\mathrm{N}$ no sistema via fertilizante mineral e esgoto tratado, sendo as maiores emissões observadas após a aplicação de $\mathrm{N}$ mineral nos tratamentos irrigados com esgoto tratado.

No primeiro ano hidrológico as maiores lâminas de irrigação para os tratamentos irrigados ocasionaram elevadas exportações de $\mathrm{N}$ pela biomassa vegetal. A partir do segundo ano a exportação de $\mathrm{N}$ diminuiu juntamente com as lâminas de irrigação aplicadas. As exportações máximas foram obtidas com os tratamentos E100 e E66, este último apresentando rendimento próximo ao ideal nas épocas de chuvas. Neste estudo a irrigação com esgoto tratado permitiu uma redução de $\mathrm{N}$ mineral como fertilizante de 54\%. Valor intermediário àquele obtido por Fonseca (2005) e Fonseca et al. (2007).

No caso do estudo de Nogueira (2008), a baixa relação C:N das entradas de insumos nos tratamentos irrigados, quando aliadas à disponibilidade hídrica, indicam favorecimento das atividades de mineralização pelos microrganismos. 
As variações do $\mathrm{pH}$ foram temporárias, sendo os menores valores observadas três e quinze dias após o manejo. Essas variações provavelmente foram em razão da oxidação do amônio decorrente da utilização de fertilizantes nitrogenados e da baixa capacidade de tamponamento do solo da área experimental. Entretanto, as entradas de bicarbonato via irrigação favoreceram a alcalinização do meio compensando a acidificação. No tratamento SI, a decomposição dos resíduos orgânicos do capim acumulado na superfície do solo promoveu uma elevação do pH de 5,7 a 6,5 ao longo do experimento.

Os tratamentos tiveram efeito no carbono orgânico total (COT) somente na época de Seca-06 e não tiveram efeito significativo no NT do solo. As concentrações do C da biomassa microbiana $\left(\mathrm{C}_{\mathrm{mic}}\right)$ mostraram-se dependentes da umidade do solo, aumentando e diminuindo conforme este parâmetro. Entretanto, o aumento médio de Cmic ao longo do tempo sugere um incremento da comunidade microbiana. $\mathrm{O} N$ na biomassa microbiana $\left(\mathrm{N}_{\text {mic }}\right)$ variou conforme a disponibilidade de $\mathrm{N}$ no sistema, diminuindo durante as épocas de maiores entradas de $\mathrm{N}$. Durante primeiro ano hidrológico, a relação $\mathrm{C}_{\text {mic }}: \mathrm{N}_{\text {mic }}$ permaneceu estável, caracterizando uma população microbiana composta principalmente por bactérias. Os menores conteúdos de água no solo no segundo ano e provável alterações na composição da liteira, alteraram, aparentemente, a diversidade microbiana no solo.

$\mathrm{O}$ indicador microbiológico $\mathrm{C}_{\text {mic }}$ :COT refletiu o comportamento do $\mathrm{Cmic}$, variando com as condições de umidade do solo. A variação de 2,3 a 3,8\% deste indicador mostrou a boa resilienca do sistema. O quociente metabólico $(\mathrm{qCO} 2)$ refletiu a resposta positiva do sistema ao manejo no primeiro ano, e o estresse do microbiota ocasionado pela diminuição do volume de água no segundo ano.

Os tratamentos aplicados no trabalho de Nogueira (2008) permitiram concluir que considerando apenas o elemento carbono, o tratamento E33 (171,6 $\mathrm{kg} \mathrm{ha}^{-1} \mathrm{ano}^{-1}$ de FNM) seria o manejo mais sustentável utilizando-se esgoto tratado na irrigação. A quantidade de C 
exportada por E33, como biomassa, não diferiu das maiores produções e a alteração em seu estoque de $\mathrm{C}$ foi inferior aos demais tratamentos irrigados. Contudo, de acordo com as demais variáveis avaliadas, o manejo com maior sustentabilidade produtiva e ambiental é a prática aplicada no tratamento E100 (520 $\mathrm{kg} \mathrm{ha}^{-1}$ ano $^{-1}$ de FNM), sistema agrícola onde as saídas de $\mathrm{N}$ não superaram as suas entradas. Nos demais tratamentos a produção foi mantida pela utilização do $\mathrm{N}$ do sistema solo, situação que provavelmente não se sustentará a longo prazo. Através do monitoramento dos indicadores $\mathrm{C}_{\text {mic }}$ :COT e qCO2, a irrigação com esgoto tratado não representa, em áreas com três anos de manejo, uma prática que implique em alterações na qualidade do solo.

Com o objetivo de avaliar e caracterizar através de métodos químicos e espectroscópicos as alterações da matéria orgânica (MO) e seus principais constituintes húmicos em solos submetidos e não submetidos à aplicação de esgotos tratados (ET), Santos (2008) desenvolveu um estudo na área experimental cultivada com capim-Bermuda Tifton 85, utilizando os mesmos tratamentos descritos por Fonseca (2005) e Nogueira (2008).

De maneira geral, após aproximadamente quatro anos de irrigação com ET, não foram observadas alterações na MO, em razão dos tratmentos aplicados. No caso da análise elementar $(\mathrm{C}, \mathrm{H}, \mathrm{N}, \mathrm{S})$ a técnica não se mostrou sensível o suficiente para detectar as mudanças. As razões $\mathrm{C} / \mathrm{N}$ para todos os tratamentos também estão dentro dos intervalos referidos na literatura. A razão $\mathrm{H} / \mathrm{C}$ indicou maior percentual de grupos alifáticos para os ácidos húmicos $(\mathrm{AH})$, sendo também comprovado através dos espectros de ressonância magnética nuclear $\left({ }^{13} \mathrm{C}\right.$ RMN VACP/MAS). A razão $\mathrm{O} / \mathrm{C}$ foi similar em todos os casos não mostrando, portanto, efeito dos diferentes tratamentos. Os espectros de infravermelho com transformada de Fourier (FTIR) obtidos são típicos para AH. Neles as principais bandas estão associadas à grupos carboxila, carbonila, amida, amina, hidroxila, fenóis e aromáticos. Assim 
como os espectros de FTIR, os espectros de ${ }^{13} \mathrm{C}$ RMN VACP/MAS foram semelhantes para todas as amostras de $\mathrm{AH}$ analisadas, possuindo maior percentual de grupos alifáticos do que aromáticos, e a aplicação das águas residuárias não alteraram, de forma significativa, a distribuição dos grupos funcionais no espectro. A espectroscopia de fluorescência, entretanto, demonstrou ser uma ferramenta sensível para a avaliação das alterações ocorridas nas amostras de $\mathrm{AH}$ extraídos dos solos sob os diferentes tipos de tratamentos. De maneira geral, a espectroscopia de fluorescência bidimensional mostrou que a irrigação com águas residuárias não afetou significativamente a estrutura do AH das camadas superficiais, mas causou um ligeiro aumento do grau de humificação em profundidade. Esta tendência foi observada através dos três índices de humificação calculados, sugerindo que a irrigação com águas residuárias favorece a formação de substância húmicas $(\mathrm{SH})$ solúveis que tendem a se acumular em profundidade. Os espectros tridimensionais mostraram que a fluorescência dos AH de um mesmo tratamento aumenta com a profundidade. Comparando-se os tratamentos W100 (irrigação com água de consumo e adição de $520 \mathrm{~kg} \mathrm{ha}^{-1}$ ano $^{-1} \mathrm{FNM}$ ) e E100 (irrigação com esgoto tratado e $520 \mathrm{~kg} \mathrm{ha}^{-1} \mathrm{ano}^{-1}$ de FNM), observou-se que a irrigação com águas residuárias promoveu um aumento na concentração de estruturas fluorescentes em geral, possivelmente acarretado por um aumento na atividade microbiana e consequiente degradação da matéria orgânica do solo. Mudanças estruturais também foram observadas pela espectroscopia 3D através da razão entre os máximos de excitação em 470 e 320 nm (R3D). Os AH dos solos irrigados com águas residuárias mostraram alterações estruturais muito mais significativas do que os solos irrigados com água de consumo quando comparados ao solo sem irrigação (SI - referência). Os resultados da espectroscopia de fluorescência induzida por laser (FIL) aplicada aos solos inteiros mostraram um incremento no grau de humificação da matéria orgânica com a profundidade do solo, similar ao observado na fluorescência dos AH em solução. A partir dos resultados obtidos por ressonância paramagnética eletrônica (RPE) 
foi observado um incremento na concentração de radicais livres semiquinona (RLS) em profundidade para todos os tratamentos e nas amostras de $\mathrm{AH}$ extraídas dos solos irrigados com águas residuárias, a concentração de RLS foi maior. Comparando-se os tratamentos E100 e W100, observou-se que a aplicação das águas residuárias aumentou a concentração de RLS e o grau de humificação dos AH do solo, corroborando com os resultados obtidos por meio dos espectros de fluorescência tridimensional.

Como conclusão geral Santos (2008) ressaltou que os resultados obtidos pelas diferentes técnicas espectroscópicas e químicas mostraram que a irrigação com águas residuárias pelo período de quatro anos não afetou de maneira significativa a MOS. Uma ligeira elevação do grau de humificação foi observada, principalmente para os AH. 


\section{Material e Métodos}

\section{1 Área experimental e manutenção das condições experimentais}

O presente estudo, como mencionado, foi realizado no campo experimental construído pela Universidade de São Paulo (Núcleo de Pesquisa em Geoquímica e Geofísica da Litosfera - NUPEGEL/USP) em parceira com a companhia de Saneamento Básico do Estado de São Paulo (SABESP), no município de Lins $\left(21^{\circ} 40^{\prime} 43^{\prime \prime}\right.$ S, 4944’23” W), Estado de São Paulo, para realizar pesquisas sobre a sustentabilidade da utilização de efluentes de esgoto tratado na irrigação de culturas agrícolas, verificando os impactos no sistema solo-planta-água (Figura $1)$.

O sistema de tratamento de esgoto é por lagoas de estabilização constituído por três conjuntos, dispostos em paralelo, de lagoas anaeróbias (tratamento primário) seguidas por lagoas facultativas fotossintéticas (tratamento secundário), com capacidade de $55.522 \mathrm{~m}^{3}$ e $23.227 \mathrm{~m}^{3}$, respectivamente, e com uma produção de efluente secundário de esgoto tratado de $140 \mathrm{~L} \mathrm{~s}^{-1}$ (Figura 1).

Para os estudos específicos que foram realizados no presente trabalho, selecionou-se, dentro do campo experimental, a área com experimento já implantado utilizando o capimBermuda Tifton 85 (FONSECA, 2005; NOGUEIRA, 2008, SANTOS, 2008). Esta área foi escolhida em razão da irrigação do capim estar sendo realizada desde 2003, de forma contínua, o que poderia permitir uma avaliação dos efeitos da aplicação dos efluentes em atributos do solo, cujas alterações não são imediatas. 


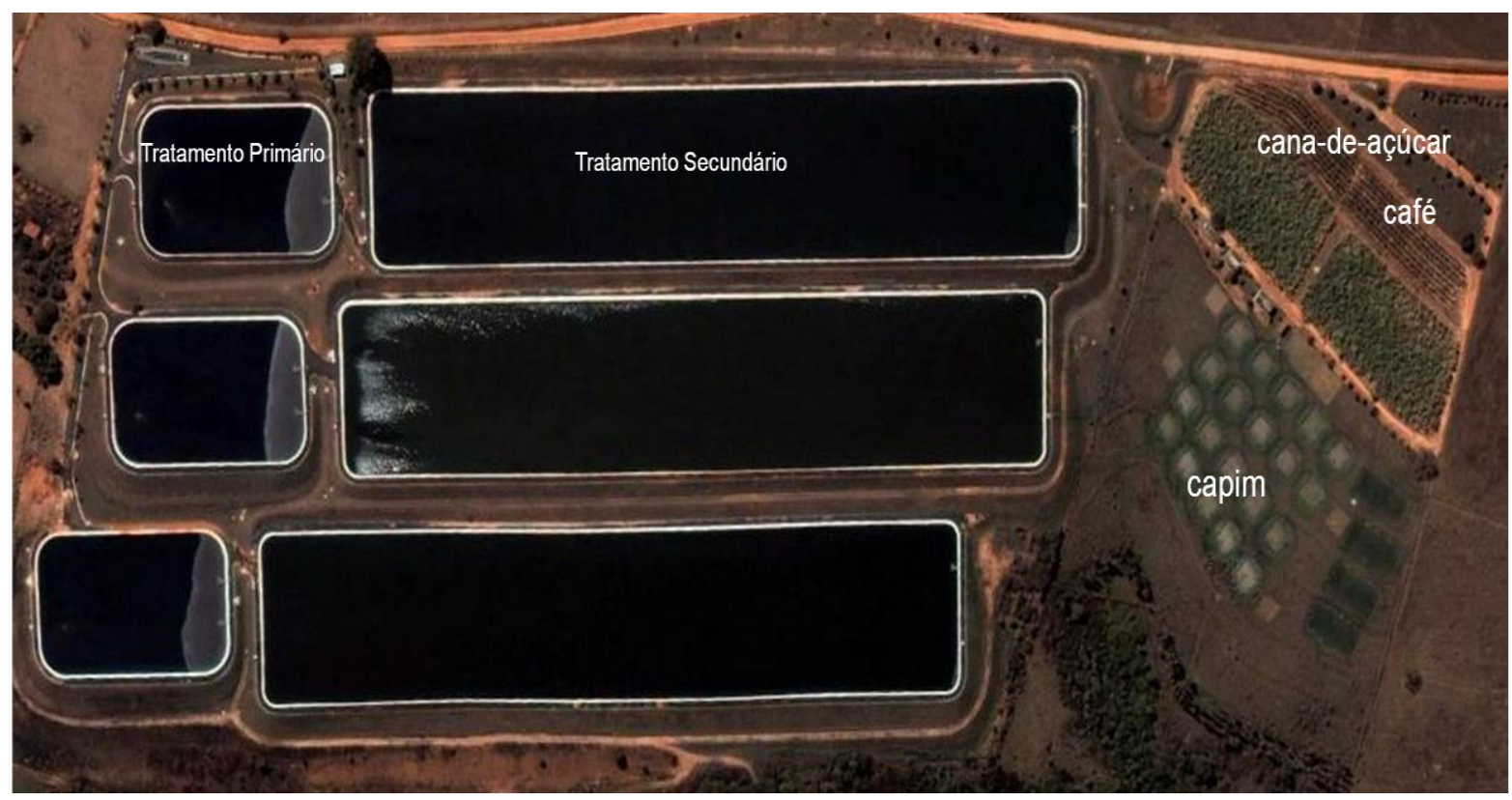

Figura 3.1 - Imagem de satélite mostrando a estação de tratamento de esgotos (lagoas anaeróbias - tratamento primário, seguidas de lagoas facultativas - tratamento secundário) e o campo experimental de capim-Bermuda Tifton 85, cana-deaçúcar e café.

O solo da área plantada com capim-Bermuda Tifton-85 foi classificado como Argissolo Vermelho Distrófico Latossólico (IBRAHIM, 2002; IBRAHIM \& MELFI, 2008), com as camadas de 0 a $40 \mathrm{~cm}$ classificadas como textura média-arenosa e de 40 a $100 \mathrm{~cm}$, textura média-argilosa (20\% de argila).

O delineamento experimental, estabelecido nos trabalhos de Fonseca (2005) e Nogueira (2008), foi o de blocos completos casualizados, com seis tratamentos e quatro repetições. Os tratamentos empregados foram: SI: sem irrigação e sem fertilização; W100: irrigação com água potável e adição de $520 \mathrm{~kg} \mathrm{ha}^{-1} \mathrm{ano}^{-1}$ de nitrogênio via nitrato de amônio; E0, E33, E66 e E100: irrigação com esgoto tratado e adição de 0, 172, 343 e $520 \mathrm{~kg} \mathrm{ha}^{-1}$ ano $^{-1}$ de nitrato de amônio, respectivamente. O corte e a remoção do capim foi realizado bimestralmente. As parcelas foram dimensionadas com $10 \mathrm{~m}$ de largura, $10 \mathrm{~m}$ de comprimento, com distância de 10 m entre si e entre blocos, perfazendo uma área total de 100 $\mathrm{m}^{2}$. A área útil por unidade experimental foi de $48 \mathrm{~m}^{2}$, após ter sido desprezado 1,0 $\mathrm{m}$ de cada 
lado (bordadura) e $16 \mathrm{~m}^{2}$ centrais da parcela (área cuja precipitação dos aspersores não era uniforme). O sistema de irrigação empregado foi o de aspersão convencional com aspersores instalados a $90 \mathrm{~cm}$ da superfície do solo no centro de cada parcela. O manejo da irrigação foi realizado na frequiência de dois dias pela leitura dos tensiômetros a partir da tensão crítica do solo para a cultura $(-34 \mathrm{kPa})$, na camada de 0 a $60 \mathrm{~cm}$.

Para atingir os objetivos da presente pesquisa foram selecionados para a coleta de dados de solo e solução do solo os tratamentos E66, W100 e SI. O tratamento E66 foi selecionado por apresentar, segundo Fonseca (2005) e Fonseca et al., (2007), maior interesse econômico (produtividade e economia de nitrogênio) e impacto no solo semelhante aos demais tratamentos irrigados com efluente testados no trabalho daqueles autores e, portanto, o manejo que poderia se empregado comercialmente, Os tratamentos W100 e SI foram considerados os controles para comparação com as parecelas irrgadas com esgoto tratado.

\subsection{Caracteríticas da água e do esgoto tratado e precipitação pluviométrica}

As principais características da água e do EETE empregados na irrigação do capimBermuda Tifton 85 podem ser observadas na Tabela 3.1 .

A água utilizada na irrigação é a mesma fornecida à população do município de Lins, sendo classificada como termal, mineral, predominantemente alcalina-sódica e alcalinabicarbonatada (Código de Águas Minerais; BRASIL, 1945) e tem como fonte os aqüíferos Guarani e Serra Geral.

Quando comparadas aos valores da literiatura (BOUWER; CHANEY, 1974; FEIGIN et al., 1978; ASANO; PETTYGROVE, 1987; FEIGIN et al., 1991; PESCOD, 1992), as concentrações médias para a maior parte dos constituintes do EETE de Lins são consideradas 
normais. As exceções são para as concentrações de CPT (ligeiramente superiores a média),

$\mathrm{Ca}, \mathrm{Mg}$ e $\mathrm{Mn}$ (valores inferiores as concentrações médias).

Tabela 3.1 - Características da água e do esgoto tratado utilizados na irrigação do capimBermuda Tifton 85 e valores médios de esgotos tratados apresentados na literatura.

\begin{tabular}{|c|c|c|c|c|c|}
\hline & Unidade & Água & $\begin{array}{l}\text { Esgoto } \\
\text { Tratado }\end{array}$ & $\begin{array}{c}\text { Concentração } \\
\text { normal }^{(1)}\end{array}$ & Referência \\
\hline \multicolumn{6}{|l|}{ Características } \\
\hline $\mathrm{SST}^{(2)}$ & $\mathrm{mg} \mathrm{L}^{-1}$ & - & $127,8 \pm 20,4$ & - & - \\
\hline $\mathrm{SDT}^{(3)}$ & $\mathrm{mg} \mathrm{L}^{-1}$ & $429 \pm 67$ & $691 \pm 70$ & 400 a 1200 & Feigin et al. (1991) \\
\hline $\mathrm{CPT}^{(4)}$ & $\mathrm{mg} \mathrm{L}^{-1}$ & - & $44,9 \pm 10,0$ & 10 a 30 & Bouwer e Chaney \\
\hline $\mathrm{CID}^{(5)}$ & $\mathrm{mg} \mathrm{L}^{-1}$ & $43,6 \pm 8,7$ & $84,7 \pm 17,0$ & - & - \\
\hline $\mathrm{COD}^{(6)}$ & $m g L^{-1}$ & $1,6 \pm 2,2$ & $22,0 \pm 17,7$ & 30 a 60 & $\begin{array}{c}\text { Bouwer e Chaney } \\
\text { (1974) }\end{array}$ \\
\hline$\delta^{13} \mathrm{C}^{(7)}$ & $(\%)$ & - & $-23,8 \pm 1,34$ & - & - \\
\hline $\mathrm{CE}^{(8)}$ & $\mathrm{dS} \mathrm{m}^{-1}$ & $0,43 \pm 0,1$ & $0,85 \pm 0,1$ & 1,0 a 8,1 & Pescod (1992) \\
\hline $\mathrm{pH}$ & & 9,5 & 7,5 & 7,8 a 8,1 & Feigin et al. (1991) \\
\hline $\begin{array}{c}\mathrm{RAS}^{(9)} \text { de } 6 \text { a } \\
12\end{array}$ & \multirow{2}{*}{$\left.(\mathrm{mmol} \mathrm{L})^{-1}\right)^{0,5}$} & \multirow{2}{*}{\multicolumn{2}{|c|}{$32,2 \pm 10,1$}} & \multirow{2}{*}{4,5 a 7,9} & \multirow{2}{*}{ Feigin et al. (1991) } \\
\hline $\begin{array}{c}\text { RAS de } 20 \text { a } \\
40\end{array}$ & & & & & \\
\hline $\mathrm{Na}^{+(10)}$ & $\mathrm{mg} \mathrm{L}^{-1}$ & $88,9 \pm 33,5$ & $131,7 \pm 6,6$ & 50 a 250 & Feigin et al. (1991) \\
\hline $\mathrm{Cl}^{-(10)}$ & $\mathrm{mg} \mathrm{L}^{-1}$ & $5,9 \pm 1,08$ & $63,4 \pm 7,9$ & 40 a 200 & Feigin et al. (1991) \\
\hline $\mathrm{B}^{(11)}$ & $\mathrm{mg} \mathrm{L}^{-1}$ & $0,15 \pm 0,04$ & $0,17 \pm 0,08$ & 0 a 1 & Feigin et al. (1991) \\
\hline $\mathrm{Ca}^{(11)}$ & $\mathrm{mg} \mathrm{L}^{-1}$ & $0,83 \pm 0,33$ & $8,06 \pm 1,07$ & 20 a 120 & Feigin et al. (1991) \\
\hline $\mathrm{Mg}^{(11)}$ & $\mathrm{mg} \mathrm{L}^{-1}$ & $0,17 \pm 0,04$ & $1,86 \pm 0,46$ & 10 a 50 & Feigin et al. (1991) \\
\hline $\mathrm{HCO}_{3}^{--(10)}$ & $\mathrm{mg} \mathrm{L} \mathrm{L}^{-1}$ & $\begin{array}{c}231,3 \pm \\
22,5\end{array}$ & $449,0 \pm 79,1$ & 200 a 700 & Feigin et al. (1991) \\
\hline $\mathrm{NPT}^{(10)}$ & $\mathrm{mg} \mathrm{L}^{-1}$ & - & $8,5 \pm 2,0$ & 10 a 50 & Feigin et al. (1991) \\
\hline $\mathrm{N}-\mathrm{NO}_{4}^{+(10)-}$ & $\mathrm{mg} \mathrm{L}^{-1}$ & - & $22,2 \pm 5,2$ & 1 a 40 & Feigin et al. (1991) \\
\hline $\mathrm{N}-\mathrm{NO}_{3}^{-(10)-}$ & $\mathrm{mg} \mathrm{L}^{-1}$ & $0,42 \pm 0,5$ & $0,80 \pm 0,6$ & 0 a 10 & Feigin et al. (1991) \\
\hline $\mathrm{Al}^{(12)}$ & $\mathrm{mg} \mathrm{L}^{-1}$ & $0,04 \pm 0,02$ & $0,03 \pm 0,02$ & - & - \\
\hline $\mathrm{Cd}^{(12)}$ & $m g L^{-1}$ & $\mathrm{nd}^{(13)}$ & nd & $<0,002^{(14)}$ & $\begin{array}{c}\text { Asano e Pettygrove } \\
(1987)\end{array}$ \\
\hline $\mathrm{Cr}^{(12)}$ & $\mathrm{mg} \mathrm{L}^{-1}$ & nd & nd & $<0,020^{(14)}$ & $\begin{array}{c}\text { Asano e Pettygrove } \\
\text { (1987) }\end{array}$ \\
\hline $\mathrm{Cu}^{(12)}$ & $\mathrm{mg} \mathrm{L}^{-1}$ & $\begin{array}{c}0,001 \pm 0,00 \\
1\end{array}$ & $\begin{array}{c}0,002 \pm \\
0,001\end{array}$ & $0,040^{(14)}$ & Feigin et al. (1991) \\
\hline $\mathrm{F}^{(12)}$ & $\mathrm{mg} \mathrm{L}^{-1}$ & $0,70 \pm 0,14$ & $0,48 \pm 0,32$ & $1,2^{(14)}$ & Pescod (1992) \\
\hline $\mathrm{Fe}^{(12)}$ & $\mathrm{mg} \mathrm{L}^{-1}$ & $\mathrm{Nd}$ & $0,08 \pm 0,06$ & $0,300^{(14)}$ & Pescod (1992) \\
\hline $\mathrm{Mn}^{(12)}$ & $m g \mathrm{~L}^{-1}$ & $\begin{array}{c}0,002 \pm 0,00 \\
2\end{array}$ & $\begin{array}{c}0,015 \pm \\
0,006\end{array}$ & 0,200 a 0,700 & Pescod (1992) \\
\hline $\mathrm{Ni}^{(12)}$ & $\mathrm{mg} \mathrm{L}^{-1}$ & $\mathrm{Nd}$ & nd & $0,007^{(14)}$ & Feigin et al. (1991) \\
\hline $\mathrm{Zn}^{(12)}$ & $\mathrm{mg} \mathrm{L}^{-1}$ & $\mathrm{Nd}$ & 0,02 & $0,040^{(14)}$ & Feigin et al. (1991) \\
\hline
\end{tabular}

(1) Faixa de concentração considerada normal para os constituintes do efluente secundário de esgoto tratado (ESET), de acordo com as referências apresentadas nesta tabela; (2)Sólidos suspensos totais; (3)Sólidos dissolvidos totais (GLOAGUEN, 2006); (4)Carbono particulado total (NOGUERIA, 2008); (5)Carbono inorgânico dissolvido (NOGUEIRA, 2008); (6)Carbono orgânico dissolvido (NOGUEIRA, 2008); (7)Composição isotópica do C contido nos SST (NOGUEIRA, 2008). (8)Condutividade elétrica; (9)Razão de adsorção de sódio nos intervalos que compreendem os valores de RAS determinados na água e no esgoto tratado (FONSECA, 2005); (10) Nogueira, 2008; (11 e 12) Fonseca, 2005, (13)Concentração abaixo do limite de 
detecção do método empregado. (14) Valores de referência.

Comparando as caracteríticas do efluente e da água potável com os valores orientadores da Food and Agriculture Organization of the United Nations (FAO) (AYERS; WESTCOT, 1985) para a qualidade das águas para utilização na irrigação agrícola, verifica-se que: (i) os valores dos sólidos suspensos totais classificam o efluente como grau de restrição "severo"; (ii) em relação a salinidade, a água apresenta grau de restrição "baixo" quanto aos seus valores de condutividade elétrica e sólidos dissolvidos totais e o efluente é classificado com grau de restrição "baixo a moderado"; (iii) quanto aos riscos de sodificação a água e o efluente apresentam graus de restrição "severo" e "baixo a moderado", respectivamente; (iv)

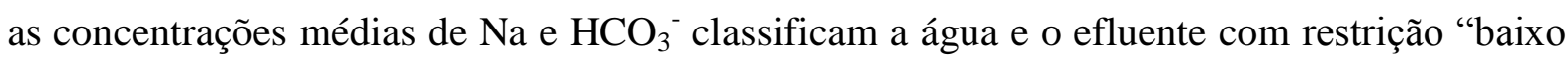
a moderado"; (v) as concentrações de $\mathrm{Cl}^{-}, \mathrm{B}$ e $\mathrm{N}^{-\mathrm{NO}_{3}}{ }^{-}$são adequadas ao uso agrícola para os dois tipos de águas de irrigação; (vi) o pH da água apresenta-se acima do intervalo normal considerado adequado para as águas de irrigação $(6,5-8,0)$ e o efluente está dentro do limite; (vii) os elementos $\mathrm{Al}, \mathrm{Cd}, \mathrm{Cr}, \mathrm{Cu}, \mathrm{F}, \mathrm{Fe}, \mathrm{Mn}, \mathrm{Ni}$, e $\mathrm{Zn}$ apresentam concentrações abaixo dos valores limitantes para a irrigação.

Considerando as concentrações de C no efluente e a lâmina de irrigação aplicada, Nogueira (2008) determinou que o aporte de C via efluente representou apenas $5,3 \%$ do carbono total acumulado no solo, sendo que as contribuições mais importantes foram provenientes da deposição de resíduos vegetais.

Na Figura 3.2 está representada a precipitação pluviométrica semanal na área experimental de janeiro de 2003 a maio de 2009, correspondendo, aproximadamente, ao período de irrigação total que o capim-Bermuda Tifton 85 recebeu desde a implantação do campo experimental de Lins. Desde o ínicio do experimento com o capim-Bermuda Tifton 85 
(janeiro de 2003) até o final do período experimental do presente trabalho (junho de 2009) os solos dos tratamentos E66 e W100, receberam, respectivamente, da ordem de 3560 e 3210 mm de lâmina de irrigação.

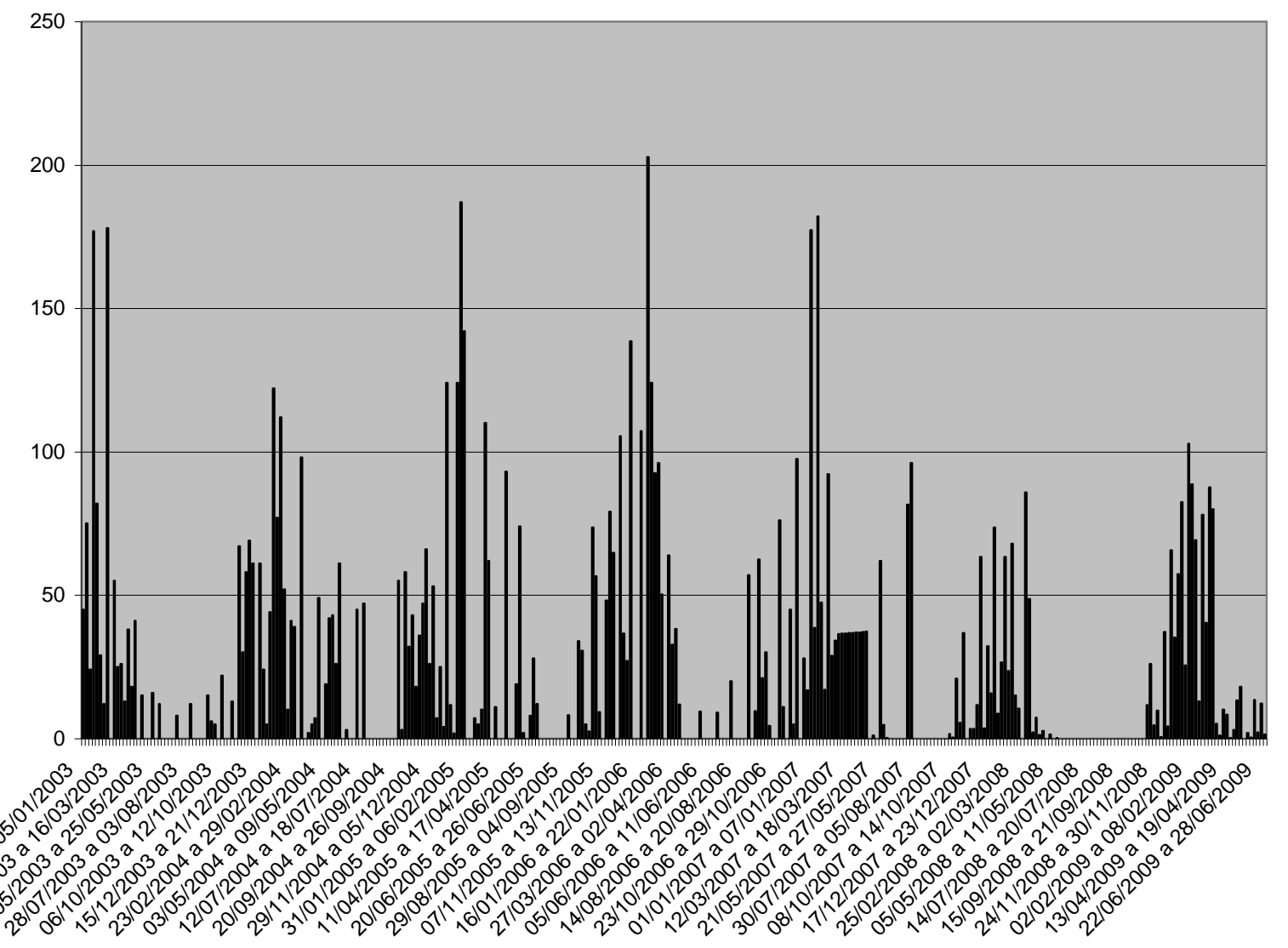

Figura 3.2 - Precipitação semanal na área experimental ( $\mathrm{mm}$ de lâmina d'água) (fonte CIIAGRO, 2010).

\subsection{Coleta, preparação e métodos de análises para as diferentes amostras estudadas}

\subsubsection{Amostras de solo}

As amostras de solo foram coletadas em junho 2007, maio e junho de 2009 mediante o emprego de trado tipo holandês nas camadas 0-5, 5-10, 10-20, 20-40, 40-60, 60-80, 80-100 cm de cada uma das quatro repetições dos tratamentos E66 e SI na a primeira coleta, e E66, SI e W100 nas demais amostragens. As amostras individuais coletadas em cada parcela 
correspondendo a uma determinada profundidade de um determinado tratamento, foram misturadas e homogeneizadas para formarem as amostras compostas representativas que foram submetidas às diferentes análises. O detalhamento das coletas até $20 \mathrm{~cm}$ foi, sobretudo, em razão dos estudos que foram realizados sobre carbono do solo.

As amostras de solo da primeira amostragem (junho 2007) foram submetidas às análises mineralógicas. Ainda para estas amostras foi realizada uma separação por diferença de densidade para a determinação, nas diferentes frações, do carbono total e do grau de humificação por fluorescência UV-visível. Foi também realizado a determinação do grau de humificado com a LIF nas amostras de solo inteiro (ou total) e nos solos da fração de densidade >2. Nas amostras de solo inteiro das três coletas (junho 2007, maio e junho de 2009) foi determinado o teor de carbono total e o grau de humificação usando-se o equipamento portátil de LIF.

\subsubsection{Análises mineralógicas}

As análises mineralógicas foram realizadas mediante emprego de métodos instrumentais de difração de raios $\mathrm{X}(\mathrm{DRX})$, de análise térmica diferencial e gravimétrica (ATD-TG) e de espectroscopia óptica por reflectância difusa (ERD). As análises foram realizadas nos Laboratórios de Mineralogia do Núcleo de Pesquisa em Geoquímica e Geofísica da Litosfera (Nupegel), USP.

As análises mineralógicas por DRX, ATD-TG e ERD foram realizadas em amostras brutas (terra fina seca ao ar - TFSA). As frações granulométricas areia, silte e argila foram analisadas por DRX.

A amostra de TFSA recebeu um tratamento prévio com peróxido de hidrogênio $\left(\mathrm{H}_{2} \mathrm{O}_{2}\right)$ para a remoção de matéria orgânica. Livre de matéria orgânica, a TFSA foi dividida em duas 
partes, sendo uma submetida ao tratamento com ditionito-citrato-bicarbonato de sódio (CBD) para remoção dos óxidos e oxidróxidos de ferro (MEHRA; JACKSON, 1958) e a outra não tratada. Essas amostras separadas foram passadas por peneira de malha $0,053 \mathrm{~mm}$ para a separação da fração areia, tendo como resultado amostras constituídas pelas frações silte e argila. Em seguida, adicionou-se às amostras $\mathrm{NaOH} 0,02 \mathrm{~mol} \mathrm{~L}^{-1}$, como agente dispersante, a fim de separar a fração inferior a 0,002 mm. A partir dessa separação feita por centrifugação a $700 \mathrm{rpm}$, controlada por tacômetro, obtiveram-se as frações argila e silte. As amostras das frações areia e silte, livres de matéria orgânica, as amostras brutas dos perfis (TFSA) foram moídas em almofariz de ágata e passadas por peneira com malha de 0,106 mm, para a realização das diferentes análises.

Para as análises por DRX procedimentos adicionais foram realizados, considerando que certos minerais quando submetidos a determinados tratamentos podem apresentar variação na distância interplanar 001, o que facilita o processo de identificação. Dessa forma, a fração argila livre de matéria orgânica e deferrificada foi separada em três partes: (i) argila (CDB), (ii) argila $(\mathrm{CDB})$ saturada com $\mathrm{K}^{+}(\mathrm{KCl})$ para posterior tratamento térmico $(110,350 \mathrm{e}$ $\left.550^{\circ} \mathrm{C}\right)$ e (iii) argila $(\mathrm{CDB})$ saturada com $\mathrm{Mg}^{2+}(\mathrm{MgCl})$ para posterior solvatação com etilenoglicol (JACKSON, 1969).

\subsubsection{Difração de raios X (DRX)}

Essas análises foram realizadas em difratômetro Philips PW 1877 operado em potencial de $40 \mathrm{kV}$, corrente de $40 \mathrm{~mA}$, fonte de $\mathrm{Cu}$ (radiação $\mathrm{K} \alpha, \lambda=1,54186 \AA$ ) ), com monocromador para eliminação da radiação $\mathrm{K} \beta$, com varredura de passo de $0,02^{\circ}(2 \theta)$ e tempo de acumulação de 1 segundo por passo.

Tanto as amostras brutas dos solos como as frações areia e silte pulverizadas foram 
depositadas em porta-amostra e analisadas em amplitude de varredura de $3^{\circ}$ a $90^{\circ}(2 \theta)$. As amostras das frações argila livre de matéria orgânica, argila livre de matéria orgânica e de óxidos de ferro e argila tratada com $\mathrm{Mg}^{2+}$ e $\mathrm{K}^{+}$foram depositadas sobre lâminas de vidro e analisadas em amplitude de varredura de $3^{\circ}$ a $65^{\circ}(2 \theta)$.

\subsubsection{Análise térmica diferencial e gravimétrica (ATD-TG)}

A identificação de caulinita e gibbsita, também realizadas por DRX, e a semiquantificação de caulinita e gibbsita foram realizadas por análise térmica diferencial e gravimétrica. As amostras brutas (TFSA) pulverizadas foram depositadas em porta-amostra de alumina e levadas ao analisador Shimadzu DTG-60H-Simultaneous DTA-TG, operado em ciclo de aquecimento e resfriamento a partir da temperatura ambiente até $1200^{\circ} \mathrm{C}$, com razão de aquecimento de $10{ }^{\circ} \mathrm{C} \min ^{-1}$ e uso de atmosfera de $\mathrm{N}_{2}$.

A gibbsita foi identificada pela ocorrência de picos endotérmicos de 240 a $256^{\circ} \mathrm{C}$, característicos de sua desidroxilação. A ocorrência de picos endotérmicos de 503 a $517{ }^{\circ} \mathrm{C}$ e exotérmicos de 980 a $992{ }^{\circ} \mathrm{C}$ está relacionada, respectivamente, à desidroxilação da caulinita e à formação da metacaulinita.

\subsubsection{Espectroscopia por reflectância difusa (ERD)}

A identificação de óxidos e oxidróxidos de ferro por reflectância difusa foi realizada em amostras brutas pulverizadas do solo nas diferentes camadas. Às amostras pulverizadas foi adicionado óleo de parafina para espectrofotometria PHOTREX® ${ }^{\circledR}$ com a finalidade de ressaltar as bandas de absorção. Essas amostras foram colocadas em porta-amostra com janela de quartzo, evitando-se compactar a fim de minimizar a orientação preferencial e a reflexão 
especular.

As medidas foram realizadas no espectrômetro Varian, um Cary 5 (UV-VIS-NIR) equipado com esfera integradora de 110 mm de diâmetro coberta com Halon (Labsphere, Inc., USA).

A reflectância $R$ das amostras foi medida em relação a um padrão de Halon. Os espectros foram obtidos no intervalo de 350 a $840 \mathrm{~nm}$, com incrementos de $0,1 \mathrm{~nm}$. A reflectância foi transformada na função de reemissão de Kubelka Munk $\left[\mathrm{f}(\mathrm{R})=(1-\mathrm{R})^{2} / 2\right.$ R], a qual é proporcional a concentração do absorvedor. Das curvas obtidas foi calculada a segunda derivada (MALENGREAU et al., 1996), que foi a seguir suavizada usando o ajuste cubic spline. Os óxidos e oxidróxidos de ferro foram identificados a partir da posição das bandas de absorção mais intensas (KOSMAS et al., 1984; SCHEINOST et al., 1999) determinadas nas curvas da segunda derivada após suavização. A identificação da goethita ocorreu por meio de bandas de absorção entre 475 e 481 nm (transição eletrônica ETP). A hematita foi identificada em bandas de absorção entre 526 e 553 nm (transição eletrônica ETP). A quantificação foi realizada a partir das medidas das amplitudes das bandas absorção da goethita e hematita, conforme procedimento descrito em Scheinost et al. (1999).

\subsubsection{Separação densimétrica, determinação do carbono total e grau de humificação}

As preparações e análises das amostras de solo foram realizadas nos laboratórios do NUPEGEL/USP, da Embrapa Instrumentação Agropecuária, São Carlos, SP e do PROTEE, Université du Sud Toulon - Var.

Devido às baixas concentrações em $\operatorname{COS}$ (carbono orgânico do solo) nos solos estudados (NOGUEIRA 2008), as amostras foram submetidas a um fracionamento por densidades, objetivando separar o material orgânico em função do grau de humificação 
(GOLCHIN et al., 1994a; GOLCHIN et al., 1994b).

As amostras de solo foram passadas em peneira de malha de $2 \mathrm{~mm}$ e, após este procedimento, o fracionamento foi realizado utilizando-se politungstato de sódio $\left(\mathrm{Na}_{6}\left(\mathrm{H}_{2} \mathrm{~W}_{12} \mathrm{O}_{40}\right) \cdot \mathrm{H}_{2} \mathrm{O}\right)$ dissolvido em água, em concentrações de $0,25,0,33,0,42 \mathrm{~mol} \mathrm{~L}^{-1}$, para se obter as densidades 1,6, 1,8 e 2,0, respectivamente (GOLCHIN et al., 1994b). Após a separação da matéria orgânica livre (fresca), pela solução de densidade 1,6, o solo foi submetido ao ultrassom para dispersão dos agregados e então realizada a separação nas demais densidades (Figura 3). Os resultados esperados para cada fração são:

- d<1,6 livre: matéria orgânica livre da fração mineral, ainda não decomposta ou pouca descomposta (restos vegetais).

- Após o emprego do ultra-som:

- 2,0<d: fração mineral livre. A matéria orgânica nesta fração é principalmente associada aos microrganismos.

- $1,8<\mathrm{d}<2,0$ : matéria orgânica pouco decomposta, fortemente ligada à fração mineral.

- 1,6<d<1,8: matéria orgânica mais decomposta que a fração precedente e menos associada à fase mineral.

- d<1,6 oclusa: matéria orgânica muito decomposta, livre da fração mineral. 
Amostras de terra fina seca ao ar

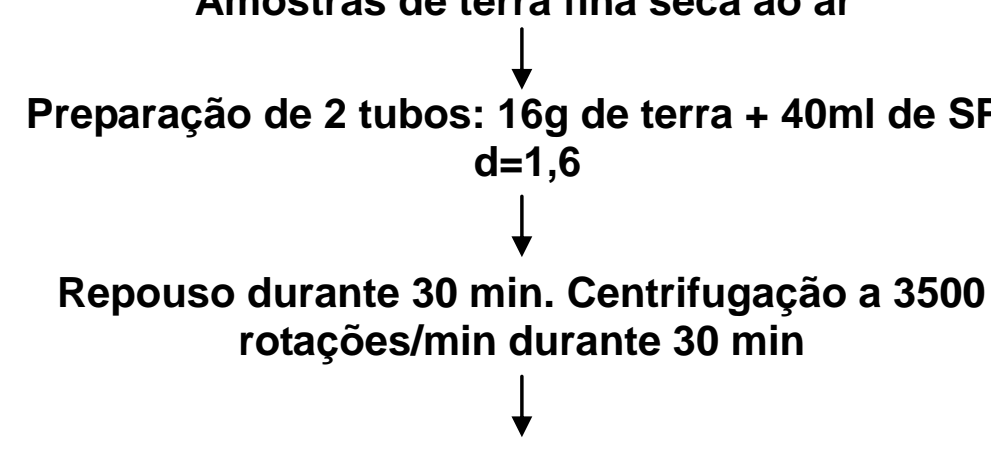

Filtração com filtro de fibra de vidro $(0,70$ micrometro) previamente queimado a $450^{\circ} \mathrm{C}$

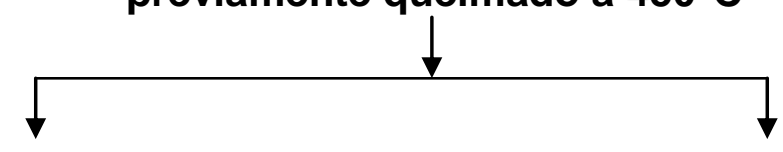

Amostra 1: fração 1,6L (seca em estufa)

Adição de $40 \mathrm{~mL}$ de SPT $\mathrm{d}=1,6$ a amostra.
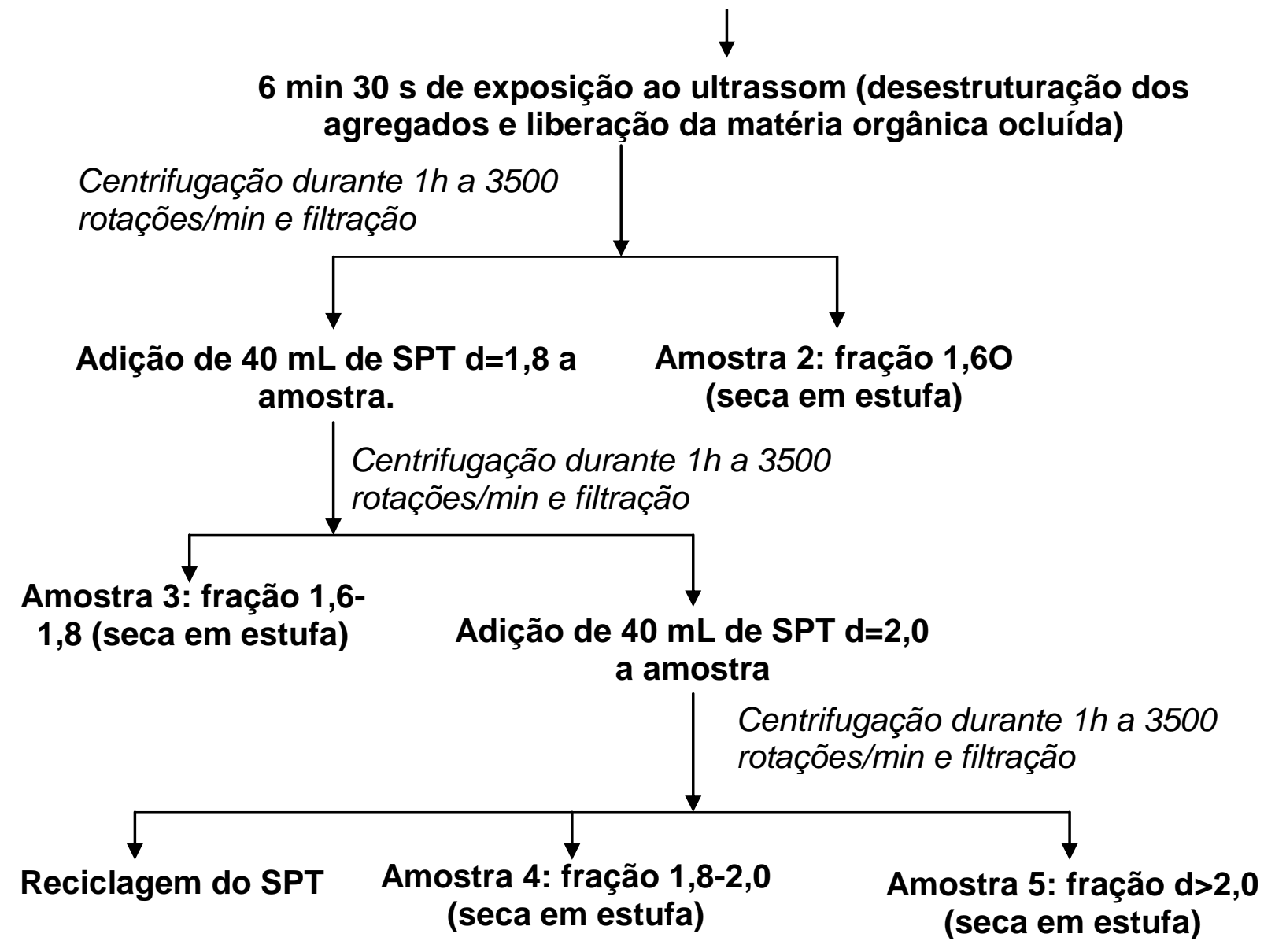

Figura 3.3 - Diagrama dos procedimentos para a separação densimétrica da matéria orgânica utilizado no presente estudo. SPT - solução de politungstato de sódio.

O carbono total foi determinado nas amostras brutas (solo total) e em cada fração 
separada por combustão a seco (NELSON; SOMMERS, 1996) em equipamento Shimadzu TOC-5000A acoplado ao módulo SSM-5000A do laboratório PROTEE.

\subsubsection{Fluorescência induzida por laser}

As amostras de TFSA do solo total de junho 2007, março de 2009 e junho de 2009 foram analisadas com o dispositivo portátil. Aproximadamente $5 \mathrm{~g}$ de TFSA foram compactadas (pressão de 10 bars) para formar as pastilhas que foram submetidas às análises. As amostras foram excitadas com uma radiação de comprimento de onda de $405 \mathrm{~nm}$.

As amostras de TFSA da coleta de junho de 2007 e aquelas correspondentes a fração de densidade superior a 2 foram analisadas usando o laser de laboratório (MILORI, 2006). Aproximadamente $5 \mathrm{~g}$ de amostra foram introduzidas numa cápsula com janela de quartzo. As amostras foram excitadas com $300 \mathrm{~mW}$ de luz monocromática com comprimento de onda de $458 \mathrm{~nm}$ produzido por um laser de argônio.

Independentemente do equipamento de medida utilizado, a normalização entre a intensidade de emissão e a concentração de fluoróforos presente na MOS foi realizada por meio do cálculo do índice de humificação. O índice de humificação é definido como razão entre o valor da área (ACF) sob o espectro de emissão de fluorescência e o valor do carbono orgânico total (COT) presente na amostra (MILORI et al 2004, 2006):

$$
I H=\frac{A C F}{C O T}
$$

Em razão das diferenças técnicas entre os dois equipamentos, os índices de humificação só puderam ser comparados entre as amostras medidas no mesmo aparelho. 
Verificou, porém, que as variações relativas dos $\mathrm{IH}$ foram indênticas independente do equipamento utilizado.

3.3.8 Fluorescência dos extratos de ácidos húmicos e fúlvicos extraídos das amostras separadas por densimetria

Os ácidos húmicos e fúlvicos foram extraídos das amostras fracionadas por densimetria (item 3.3.6), de acordo com a metodologia desenvolvida no laboratório PROTEE, e encontra-se resumida na Figura 3.4.

Para as extrações dos ácidos húmicos e fúlvicos das diferentes frações utilizou-se, respectivamente, $5 \mathrm{~mL}$ de $0.1 \mathrm{~mol} \mathrm{~L}{ }^{-1} \mathrm{HCl}$ e $5 \mathrm{~mL}$ de $0.01 \mathrm{~mol} . \mathrm{L}^{-1} \mathrm{NaOH}$. 


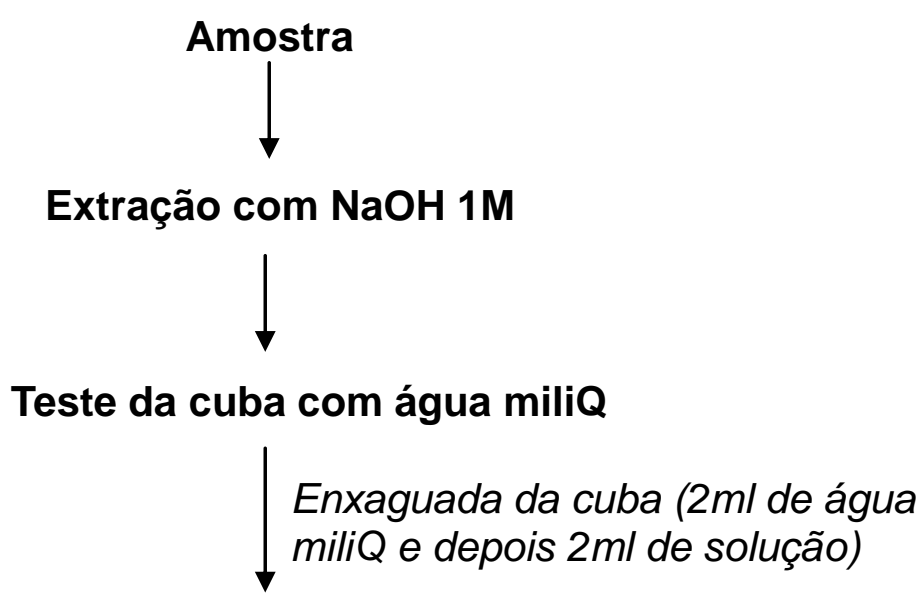

injeção de $2 \mathrm{ml}$ de solução com uma seringa possuindo um filtro<smiles>[13CH3]</smiles>

borbulhamento com $\mathrm{N}_{2}, 10 \mathrm{~min}$ ( eliminação do oxigênio da solução que poderia oxidar as ligações fluorescentes)

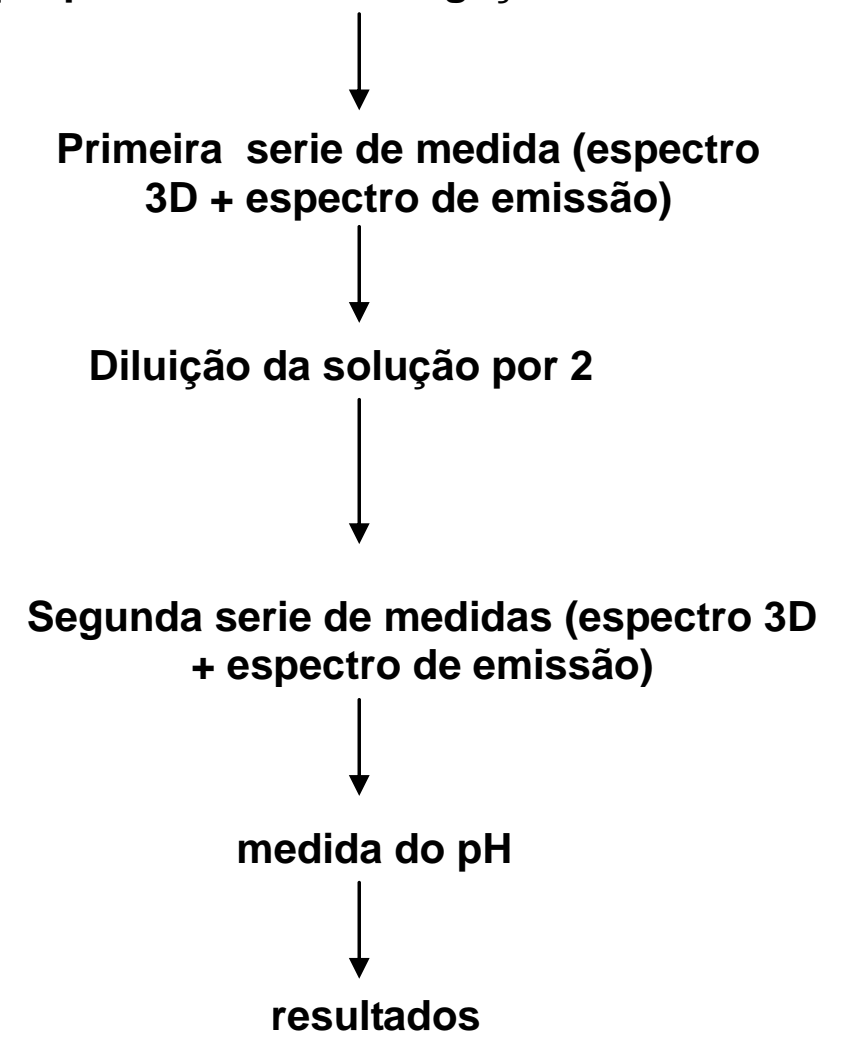

Figura 3.4 - Diagrama dos procedimentos de extração dos ácidos húmicos e fúlvicos analisados por fluorescência. 3D: tridimensional.

As matrizes de luminescência total (matrizes de excitação emissão (EEM) de fluorescência (Figura 3.5) das extrações foram medidas com um espectrômetro HITACHI 
F4500 nos intervalos de 250 a 450 nm (excitação) e 250 a 600 nm (emissão), com a fenda fixada em $5 \mathrm{~nm}$ para ambos intervalos. A velocidade de varredura foi de $2400 \mathrm{~nm} / \mathrm{min}$. Os resultados foram tratados pelo método PARAFAC para extrair as componentes independentes após difusão física e eliminação do efeito interno (Figura 3.6)(LUCIANI et al., 2009). As intensidades máximas de fluorescência foram divididas pelos teores de carbono da amostra para serem comparadas.

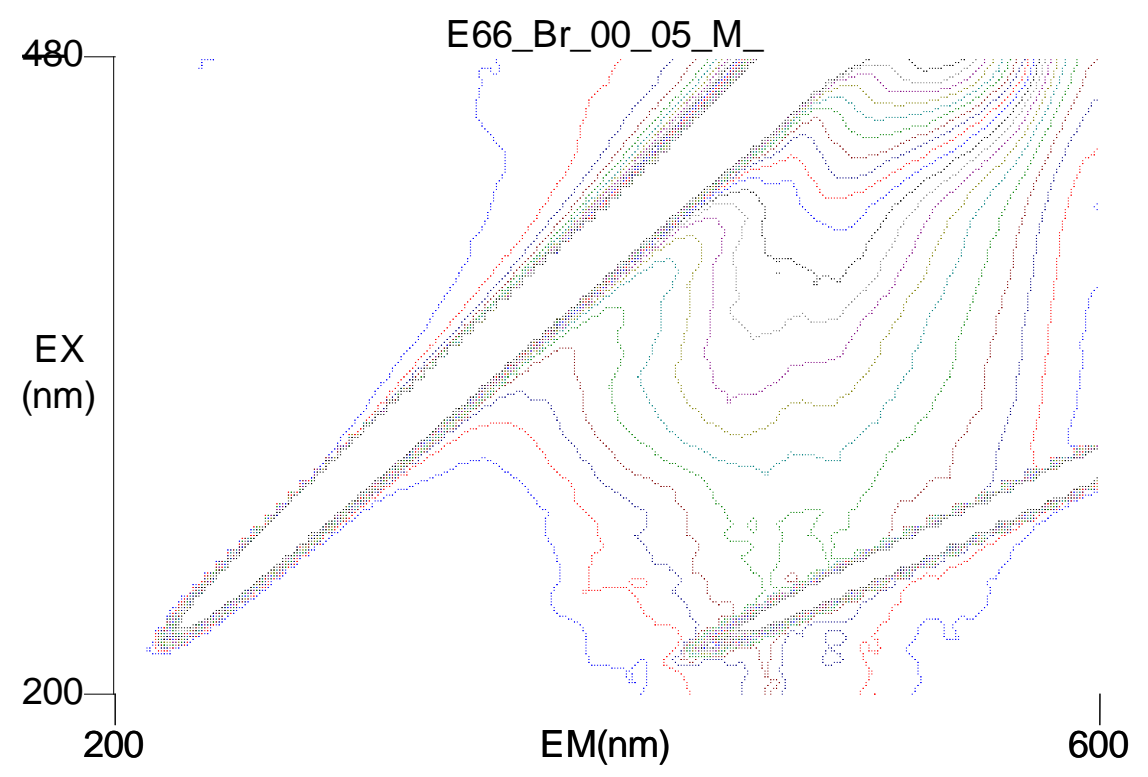

Figura 3.5 - Exemplo de matriz de excitação-emissão (EEM) do extrato da MOS de solo irrigado com efluente de estação de tratamento de esgoto. 

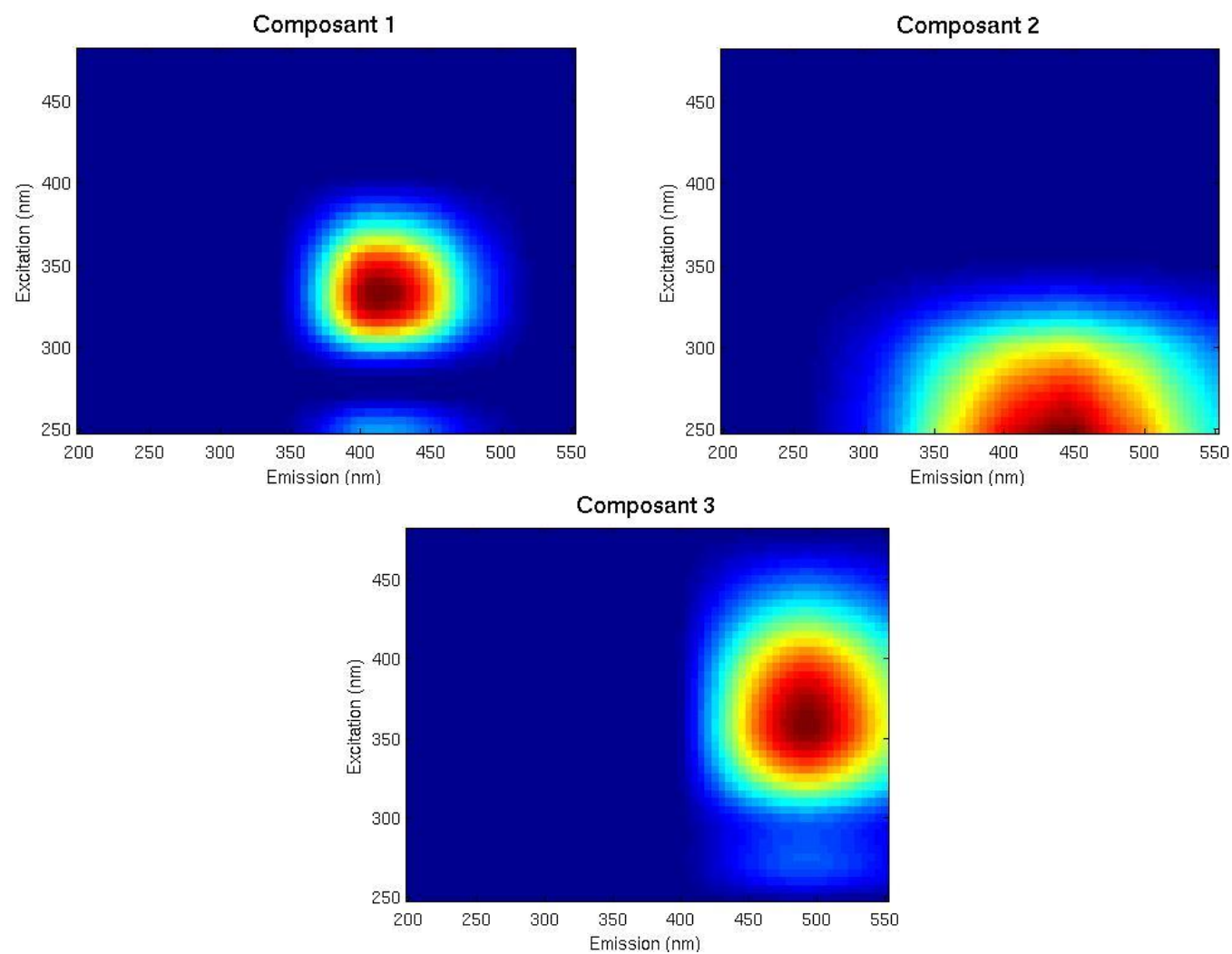

Figura 3.6 - Componentes 1, 2 e 3 obtidas pelo método PARAFAC e descritivas da fluorescência 3-D dos extratos da MOS.

\subsubsection{Solução do solo, efluente de estação de tratamento de esgoto e água potável}

As amostras líquidas foram analisadas para a determinação do $\mathrm{pH}$, da condutividade elétrica, do grau de humificação, dos cations e ânions, do carbono orgânico dissolvido (COD), carbono inorgânico dissolvido (CID) e carbono orgânico particulado (COP) nos laboratórios do NUPEGEL e PROTEE.

Foram realizadas cinco coletas de soluções sendo três durante as estações secas (junho de 2007, 2008, e 2009) e duas durante as estações chuvosas (dezembro 2007 e março 2008).

A solução do solo foi coletada, nos tratamentos SI, W100 e E66, utilizando-se cápsulas de cerâmica porosas (WAGNER, 1962) instaladas no meio das camadas 0-20, 20-40, 40-60, 60-80, 80-100 cm. As cápsulas foram assentadas em pó de sílica sobre um selo de bentonita 
utilizada para delimitar as camadas e outro selo próximo a superfície para evitar percolação preferencial (ASTM,1996). Sete dias antes da coleta uma pressão negativa de 80,0 kPa foi aplicada no seu interior com utilização de uma bomba de vácuo manual, com o objetivo de criar um gradiente de potencial negativo entre o solo e o interior de cápsula que decrescerá com a entrada de água até que o equilíbrio seja atingido. Entretanto, apesar de ser o sistema de extração de solução mais utilizado (AHMED et al., 2001), os volumes de solução coletados tem sido muito variáveis e, como também observado no presente trabalho, muitas vezes insuficientes para efetuar as análises (WAGNER, 1962; MENÉNDEZ et al., 2003). Desta forma, assim como para amostras de solo, uma amostra composta para cada camada das diferentes repetições foi obtida e submetida às análises.

O efluente e a água potável foram amostrados antes da entrada no sistema de irrigação.

Após a coleta todas as amostras de soluções foram mantidas numa temperatura de aproximadamente $4^{\circ} \mathrm{C}$. No laboratório, o pH e a condutividade elétrica foram medidos, nos equipamentos Digimed DM2 e DM3, e cada uma das amostras foi submetida aos seguintes procedimentos:

Uma alíquota foi filtrada em filtro de microfibra de vidro com poros de $0,45 \mu \mathrm{m}$ de diâmetro previamente calcinado a $500^{\circ} \mathrm{C}$ durante 6 horas, seco a $60^{\circ} \mathrm{C}$ durante 48 horas e pesado. O filtrado foi preservado com solução de $\mathrm{HgCl} 30 \mathrm{mmol} \mathrm{L}^{-1}$ e guardado em recipiente de vidro na geladeira para análise de COD e CID, por meio do equipamento Shimadzu TOC5000A acoplado ao módulo SSM-5000A, fluorescência UV-visível (equipamento HITACHI F4500) e cátions $\left(\mathrm{Na}^{+}, \mathrm{NH}^{+}, \mathrm{K}^{+}, \mathrm{Mg}^{2+}\right.$ e $\left.\mathrm{Ca}^{2+}\right)$ por cromatografia iônica líquida em equipamento Dionex DX-120.

Outra alíquota foi filtrada em filtro de éster-celulose com poros de 0,22 $\mu \mathrm{m}$ de diâmetro, preservada com Timol $\left(\mathrm{C}_{10} \mathrm{H}_{4} \mathrm{O}\right)$ e estocada em recipiente de polietileno de alta densidade para análise dos ânions $\left(\mathrm{Cl}^{-}, \mathrm{NO}_{3}{ }^{-}, \mathrm{NO}_{2}{ }^{-}, \mathrm{PO}_{4}{ }^{3-}, \mathrm{SO}_{4}{ }^{2-}\right)$ também por cromatografia 
iônica líquida.

\subsection{Análise estatística dos dados}

Os dados obtidos foram submetidos ao teste de Tukey (5\%) para comparação das médias. O programa estatístico utilizado foi o SYSTAT 9.0 (SAS INSTITUTE INC., 1999). A análise estatística da composição química das águas do solo de água do solo (matriz de correlações e análise de componentes principais) foi realizada com o progama StatistiXL 1.8. 


\section{Resultados e discussões}

\subsection{Mineralogia}

As análises mineralógicas apresentadas nas Tabelas 4.1 e 4.2 permitiram verificar que, sob o ponto de vista mineralógico o solo da área cultivada com capim Bermuda-Tifton 85 apresenta uma mineralogia relativamente simples e monótona em todas as camadas analisadas, caracterizada pela presença de quartzo, caulinita, gibbsita, goethita, hematita, magnetita e/ou maghemita. Não foram observadas diferenças mineralógicas entre os solos das diferentes parcelas dos tratamentos analisados (E66 e SI). As frações areia e silte, analisadas por DRX, são dominadas por quartzo e a fração argila é constituída por caulinita, ilita, hematita e magnetita e/ou maghemita.

Tabela 4.1 - Composição mineralógica das amostras brutas e frações granulométricas separadas representativas para os solos dos tratmentos E66 e SI.

\begin{tabular}{ccccc}
$\begin{array}{c}\text { Camada } \\
(\mathrm{cm})\end{array}$ & $\begin{array}{c}\text { Mineralogia }^{(1)} \\
\text { Amostra bruta }^{(3)}\end{array}$ & Areia $^{(2)}$ & Silte $^{(2)}$ & Argila $^{(2)}$ \\
\hline $0-5$ & $\mathrm{Q}^{(3)}, \mathrm{C}^{(3,4)}, \mathrm{G}^{(4)}, \mathrm{Go}^{(5)}, \mathrm{Hm}^{(5)}$ & $\mathrm{Q}$ & $\mathrm{Q}$ & $\mathrm{C}, \mathrm{I}, \mathrm{Hm}, \mathrm{M}$ \\
$5-10$ & $\mathrm{Q}, \mathrm{C}, \mathrm{G}, \mathrm{Go}, \mathrm{Hm}$ & $\mathrm{Q}$ & $\mathrm{Q}$ & $\mathrm{C}, \mathrm{I}, \mathrm{Hm}, \mathrm{M}$ \\
$10-20$ & $\mathrm{Q}, \mathrm{C}, \mathrm{C}, \mathrm{Go}, \mathrm{Hm}$ & $\mathrm{Q}$ & $\mathrm{Q}$ & $\mathrm{C}, \mathrm{I}, \mathrm{Hm}, \mathrm{M}$ \\
$20-40$ & $\mathrm{Q}, \mathrm{C}, \mathrm{G}, \mathrm{Go}, \mathrm{Hm}$ & $\mathrm{Q}$ & $\mathrm{Q}$ & $\mathrm{C}, \mathrm{I}, \mathrm{Hm}, \mathrm{M}$ \\
$40-60$ & $\mathrm{Q}, \mathrm{C}, \mathrm{G}, \mathrm{Go}, \mathrm{Hm}$ & $\mathrm{Q}$ & $\mathrm{Q}$ & C, I, Hm, M \\
$60-80$ & Q, C, G, Go, Hm & $\mathrm{Q}$ & $\mathrm{Q}$ & $\mathrm{C}, \mathrm{I}, \mathrm{Hm}, \mathrm{M}$ \\
$80-100$ & Q, C, G, Go, Hm & Q & Q & C, I, Hm, M \\
\hline
\end{tabular}

(1) $\mathrm{Q}=$ quartzo, $\mathrm{C}=$ caulinita, $\mathrm{G}=$ gibbsita, Go = Goethita, $\mathrm{Hm}=$ hematita, I = ilita, $\mathrm{M}$ = magnetita/maghemita, (2) analisadas por difratometria de raios-X (DRX), (3) identificados por difratometria de raios-X, (4) identificadas por análise térmica diferencial e gravimétrica (ATD-TG), (5) Identificadas por espectroscopia de reflectância difusa (ERD). SI: sem irrigação e sem fertilização; E66 - irrigação com EETE e adubação de $343 \mathrm{~kg}$ $\mathrm{ha}^{-1}$ ano $^{-1}$ de nitrato de amônio, $416 \mathrm{~kg} \mathrm{ha}^{-1}$ ano $^{-1}$ de $\mathrm{K}_{2} \mathrm{O}$ e $140 \mathrm{~kg} \mathrm{ha}^{-1}$ ano ${ }^{-1} \mathrm{P}_{2} \mathrm{O}_{5}$.

A partir dos difratatogramas de raios-X não foi possível identificar a gibssita e goethita. Sendo estes minerais identificados e quantificados, respectivamente, por meio da ATD-TG e por ER (Tabela 4.1 e 4.2). O teor de hematita no solo também foi determindao por EDR. 
Tabela 4.2 - Análise térmica diferencial e gravimétrica (ATD-TG) e espectroscopia por reflectância difusa (ERD) das amostras brutas dos solos dos tratamentos E66 e SI.

\begin{tabular}{|c|c|c|c|c|c|c|c|c|}
\hline & \multicolumn{4}{|c|}{ Tratamento SI } & \multicolumn{4}{|c|}{ Tratamento E66 } \\
\hline \multirow{2}{*}{ Camada } & \multicolumn{2}{|c|}{ ATD-TG } & \multicolumn{2}{|c|}{ ERD } & \multicolumn{2}{|c|}{ ATD-TG } & \multicolumn{2}{|c|}{ EDR } \\
\hline & Gibbsita & Caulinita & Goethit & Hematita & Gibbsita & Caulinita & Goethita & Hematita \\
\hline$(\mathrm{cm})$ & & \%-------- & & & ------- & & & \\
\hline $0-5$ & 3,67 & 12,60 & 21,0 & 31,2 & 3,48 & 12,54 & 24,1 & 39,2 \\
\hline $5-10$ & 2,94 & 12,05 & 17,8 & 35,3 & 2,32 & 12,52 & 29,0 & 41,9 \\
\hline $10-20$ & 3,08 & 13,29 & 24,7 & 40,1 & 2,24 & 11,07 & 22,6 & 38,5 \\
\hline $20-40$ & 2,95 & 17,38 & 24,6 & 40,3 & 2,25 & 14,96 & 24,0 & 39,6 \\
\hline $40-60$ & 3,01 & 17,79 & 29,3 & 45,4 & 2,58 & 17,36 & 22,7 & 39,6 \\
\hline $60-80$ & 2,47 & 16,29 & 27,7 & 42,0 & 2,66 & 16,29 & 24,7 & 39,8 \\
\hline $80-100$ & 2,40 & 15,89 & 29,2 & 45,5 & 1,96 & 15,89 & 27,4 & 42,4 \\
\hline
\end{tabular}

SI: sem irrigação e sem fertilização; E66 - irrigação com EETE e adubação de $343 \mathrm{~kg} \mathrm{ha}^{-1}$ ano ${ }^{-1}$ de nitrato de amônio, $416 \mathrm{~kg} \mathrm{ha}^{-1} \mathrm{ano}^{-1}$ de $\mathrm{K}_{2} \mathrm{O}$ e $140 \mathrm{~kg} \mathrm{ha}^{-1} \mathrm{ano}^{-1} \mathrm{P}_{2} \mathrm{O}_{5}$.

Não foram observadas diferenças estatísticas entre as médias nas diferentes camadas e entre os tratamentos SI e E66 tanto para os resultados de ATD-TG como para os de ERD. Entretanto, verifica-se uma tendência de aumento no teor de caulinita a partir da camada 2040 comparativamente as camadas superficiais, o que está de acordo com a textura determinada para este solo, media-arenosa na superfície e média argilosa em profundidade.

\section{2 Águas de percolação no solo}

O estudo das variações da composição química das águas de percolação no solo coletadas por meio de lisímetros de sucção não foi objetivo deste trabalho, sendo tal estudo já realizado em trabalhos anteriores (GLOAGUEN, 2005; FONSECA, 2005; NOGUEIRA, 2008). No âmbito deste trabalho, procurou-se verificar eventuais relações entre o COD e as outras espécies dissolvidas na solução do solo dos três tramentos, bem como entre o COD e a MOS das camadas de solo correspondentes às posições dos lisímetros.

As correlações entre espécies dissolvidas na solução do solo (dados completos no anexo) são apresentadas na Tabela 4.3. 
Tabela 4.3 - Matriz de corelação entre as espécies dissolvidas na solução do solo.

\begin{tabular}{cccccccccccccc}
\hline & Prof & $\mathrm{COD}$ & $\mathrm{Na}^{+}$ & $\mathrm{NH}_{4}^{+}$ & $\mathrm{K}^{+}$ & $\mathrm{Mg}^{2+}$ & $\mathrm{Ca}^{2+}$ & $\mathrm{F}^{-}$ & $\mathrm{Cl}^{-}$ & $\mathrm{NO}_{2}{ }^{-}$ & $\mathrm{NO}_{3}{ }^{-}$ & $\mathrm{PO}_{4}{ }^{2-}$ & $\mathrm{SO}_{4}{ }^{2-}$ \\
\hline Prof & 1,00 & & & & & & & & & & & & \\
$\mathrm{COD}$ & $-0,09$ & 1,00 & & & & & & & & & & & \\
$\mathrm{Na}^{+}$ & $-0,34$ & $-0,03$ & 1,00 & & & & & & & & & & \\
$\mathrm{NH}_{4}^{+}$ & $-0,10$ & $-0,40$ & $-0,02$ & 1,00 & & & & & & & & & \\
$\mathrm{~K}^{+}$ & 0,61 & $-0,02$ & 0,00 & $-0,13$ & 1,00 & & & & & & & & \\
$\mathrm{Mg}^{2+}$ & 0,20 & $-0,17$ & 0,23 & $-0,09$ & 0,38 & 1,00 & & & & & & & \\
$\mathrm{Ca}^{2+}$ & $-0,05$ & 0,03 & $-0,02$ & $-0,03$ & $-0,02$ & 0,18 & 1,00 & & & & & & \\
$\mathrm{~F}^{-}$ & $-0,22$ & 0,02 & 0,25 & 0,22 & 0,05 & 0,42 & 0,25 & 1,00 & & & & & \\
$\mathrm{Cl}^{-}$ & $-0,24$ & $-0,07$ & 0,38 & $-0,03$ & $-0,06$ & 0,46 & 0,01 & 0,61 & 1,00 & & & & \\
$\mathrm{NO}_{2}{ }^{-}$ & $-0,12$ & $-0,05$ & 0,44 & $-0,12$ & $-0,03$ & $-0,12$ & $-0,11$ & $-0,22$ & 0,14 & 1,00 & & & \\
$\mathrm{NO}_{3}^{-}$ & $-0,18$ & $-0,02$ & 0,52 & $-0,19$ & 0,02 & 0,01 & $-0,05$ & 0,01 & 0,33 & 0,93 & 1,00 & & \\
$\mathrm{PO}_{4}{ }^{2-}$ & 0,20 & $-0,06$ & $-0,16$ & $-0,24$ & 0,42 & 0,08 & 0,01 & 0,00 & $-0,09$ & $-0,12$ & $-0,03$ & 1,00 & \\
$\mathrm{SO}_{4}{ }^{2-}$ & $-0,25$ & 0,26 & 0,06 & $-0,23$ & $-0,09$ & $-0,05$ & $-0,11$ & 0,22 & 0,55 & $-0,07$ & 0,03 & $-0,05$ & 1,00 \\
\hline $\mathrm{P}^{2}$
\end{tabular}

Prof: profundidade; COD: carbono orgânico dissolvido.

Observa-se uma forte correlação $(0,93)$ entre os valores de $\mathrm{NO}_{2}^{-}$e $\mathrm{NO}_{3}^{-}$São observados coeficientes de correlação entre 0,52 e 0,61 entre a profundidade e o $\mathrm{K}^{+}, \mathrm{Na}^{+}$e $\mathrm{NO}_{3}{ }^{-}, \mathrm{Cl}^{-}$e $\mathrm{F}^{-}, \mathrm{Cl}^{-}$e $\mathrm{SO}_{4}{ }^{2-}$. Valores entre $|0,38|$ e $|0,46|$ são verificados entre o COD e $\mathrm{NH}_{4}{ }^{+}, \mathrm{K}^{+}$e $\mathrm{PO}_{4}{ }^{2-}, \mathrm{Na}^{+}$e $\mathrm{Cl}^{-}, \mathrm{Mg}^{2+}$ e $\mathrm{F}^{-}, \mathrm{Mg}^{2+}$ e $\mathrm{Cl}^{-}$. Estas correlações são coerentes com as obervações feitas nos estudos anteriores (op. cit.), sendo a maioria, relacionada às propriedades do efluente e da água de Lins (correlações entre $\mathrm{Na}^{+}$e $\mathrm{Cl}^{-} ; \mathrm{K}^{+}, \mathrm{Na}^{+} \mathrm{e} \mathrm{NO}_{3}{ }^{-} \mathrm{Cl}^{-}$e $\mathrm{SO}_{4}{ }^{2-}$; $\mathrm{COD}$ e $\mathrm{NH}_{4}{ }^{+}$; bem como as espécies do nitrogênio na atividade microbiana no solo). A correlação negativa de 0,40 entre o COD e o amônio pode parecer surpreendente pelos dos altos teores de $\mathrm{COD}$ e de $\mathrm{NH}_{4}{ }^{+}$no efluente. Entretanto, os estudos anteriores mostraram que o alto teor de $\mathrm{NH}_{4}{ }^{+}$estimula uma alta atividade microbiana, resultando numa rápida oxidação do amônio em nitrato e subsequente absorção desta espécie pelas plantas (GLOAGUEN, 2005).

A análise de componentes principais confirma essas observações. Os pesos das variáveis em relação aos dois primeiros eixos fatoriais, explicam 38,3\% da variância observada (Tabela 4.4 e Figura 4.1). O primeiro eixo fatorial é determinado, principalmente, 
pela profundidade, pelo cloro, sódio, nitrito e o nitrato, e o segundo eixo pelo magnésio e nitrito. Observa-se que o COD parece não ter peso significativo na discriminação estatística da projeção no plano dos dois primeiros eixos.

Tabela 4.4 - Peso dos eixos fatoriais na explicação da variância.

\begin{tabular}{cccccccccccccc}
\hline \multirow{2}{*}{ Valor } & PC & PC & PC & PC & PC & PC & PC & PC & PC & PC & PC & PC & PC \\
& 1 & 2 & 3 & 4 & 5 & 6 & 7 & 8 & 9 & 10 & 11 & 12 & 13 \\
\hline Peso & 2,8 & 2,2 & 2,0 & 1,6 & 1,1 & 0,9 & 0,7 & 0,6 & 0,4 & 0,3 & 0,2 & 0,1 & 0,0 \\
\% da variância & 21,6 & 16,7 & 15,4 & 12,6 & 8,5 & 6,6 & 5,4 & 4,9 & 3,4 & 2,1 & 1,7 & 0,8 & 0,2 \\
\% cumulativo & 21,6 & 38,3 & 53,7 & 66,3 & 74,8 & 81,4 & 86,8 & 91,8 & 95,2 & 97,2 & 98,9 & 99,8 & 100,0 \\
\hline
\end{tabular}

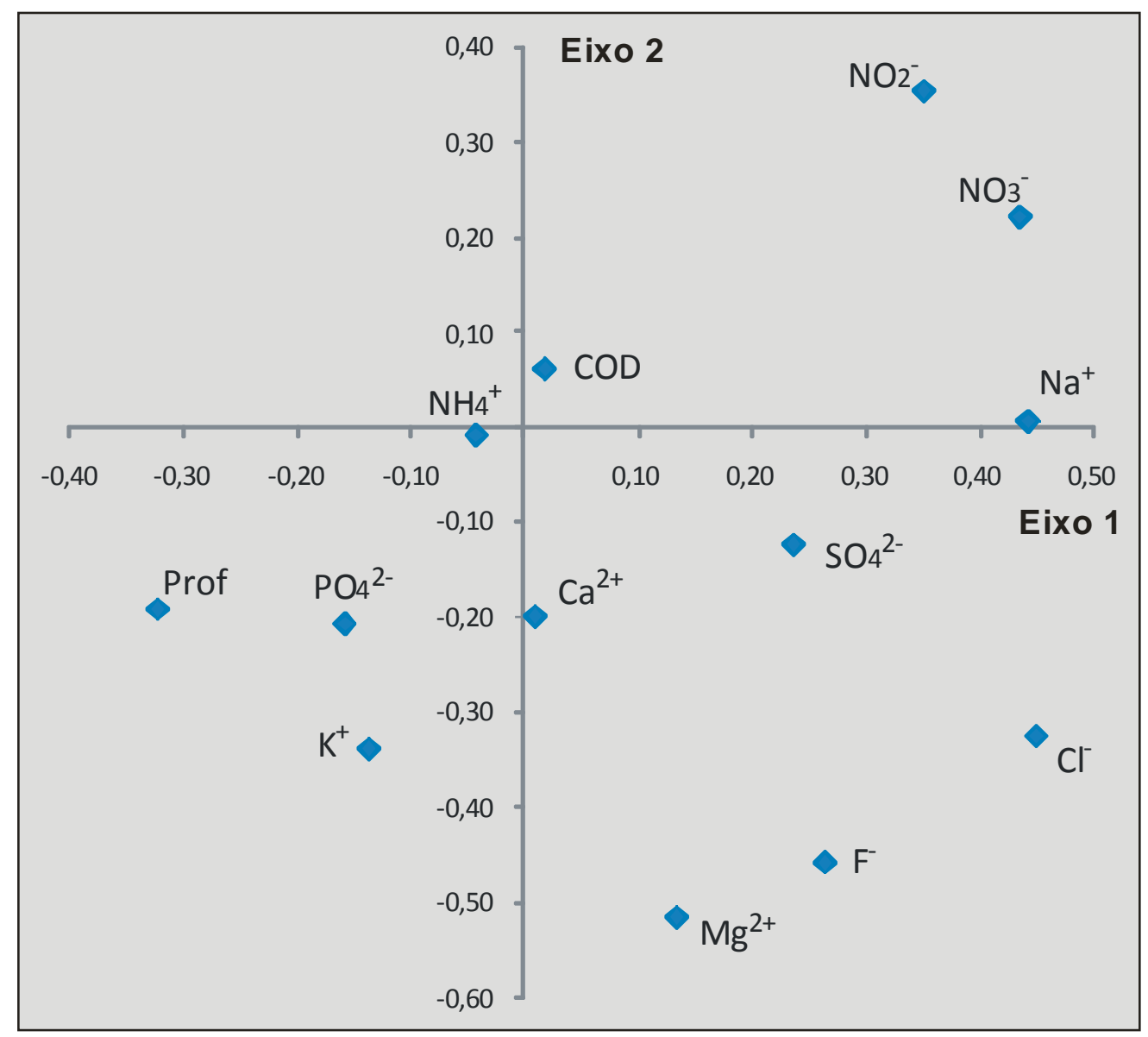

Figura 4.1 - Peso das variáveis em relação aos dois primeiros eixos da análise de componentes principais das espécies dissolvidas nas soluções do solo. COD: carbono orgânico dissolvido.

A Figura 4.2a apresenta a relação entre o COS e o COD da solução do solo, das amostras coletadas nas mesmas profundidades e épocas (junho de 2007 e junho de 2009). 
Observa-se uma fraca correlação negativa entre o COS e COD (Figura 4.2a), pelo fato que o COD não apresenta diminuição com a profundidade (Figura 4.2b), ao contrário do COS (Figura 4.2c). Desta forma, não houve uma relação direta entre o teor de matéria orgânica do solo e o COD da solução do solo numa determinada profundidade.
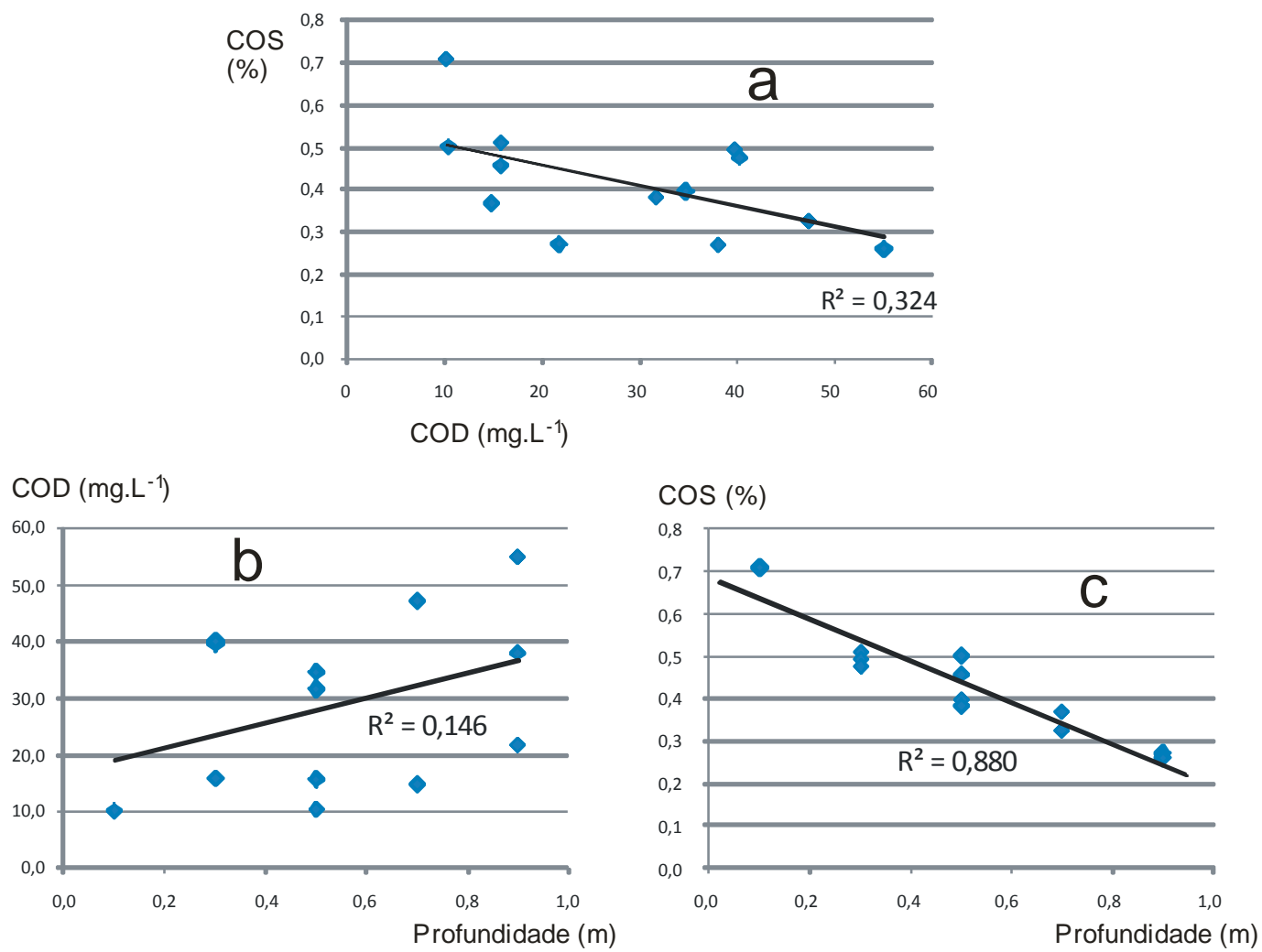

Figura 4.2 - Relação entre o carbono orgânico do solo (COS), e o carbono orgânico dissolvido (COD) da solução do solo (a); COD e COS com a profundidade (b) e (c), respectivamente.

\subsection{Teores de carbono no solo}

\subsubsection{Carbono no solo total}

A Figura 4.3 apresenta a evolução dos teores de carbono no solo para cada profundidade nos diferentes tratamentos entre Janeiro de 2003 e Junho de 2009 (FONSECA, 2005; NOGUERIA, 2008;SANTOS, 2008 e dados deste trabalho).

Os teores de carbono foram baixos para os três tratamentos (inferior a 1\%), com os 
valores decrescendo com a profundidade (de $1 \%$ nas camadas superficiais a $0,3 \%$ nas camadas mais profundas). Pode-se observar que nos primeiros $40 \mathrm{~cm}$ os teores de carbono do solo SI são, em geral, maiores que dos solos irrigados com exceção das amostras de Junho de 2005 . 

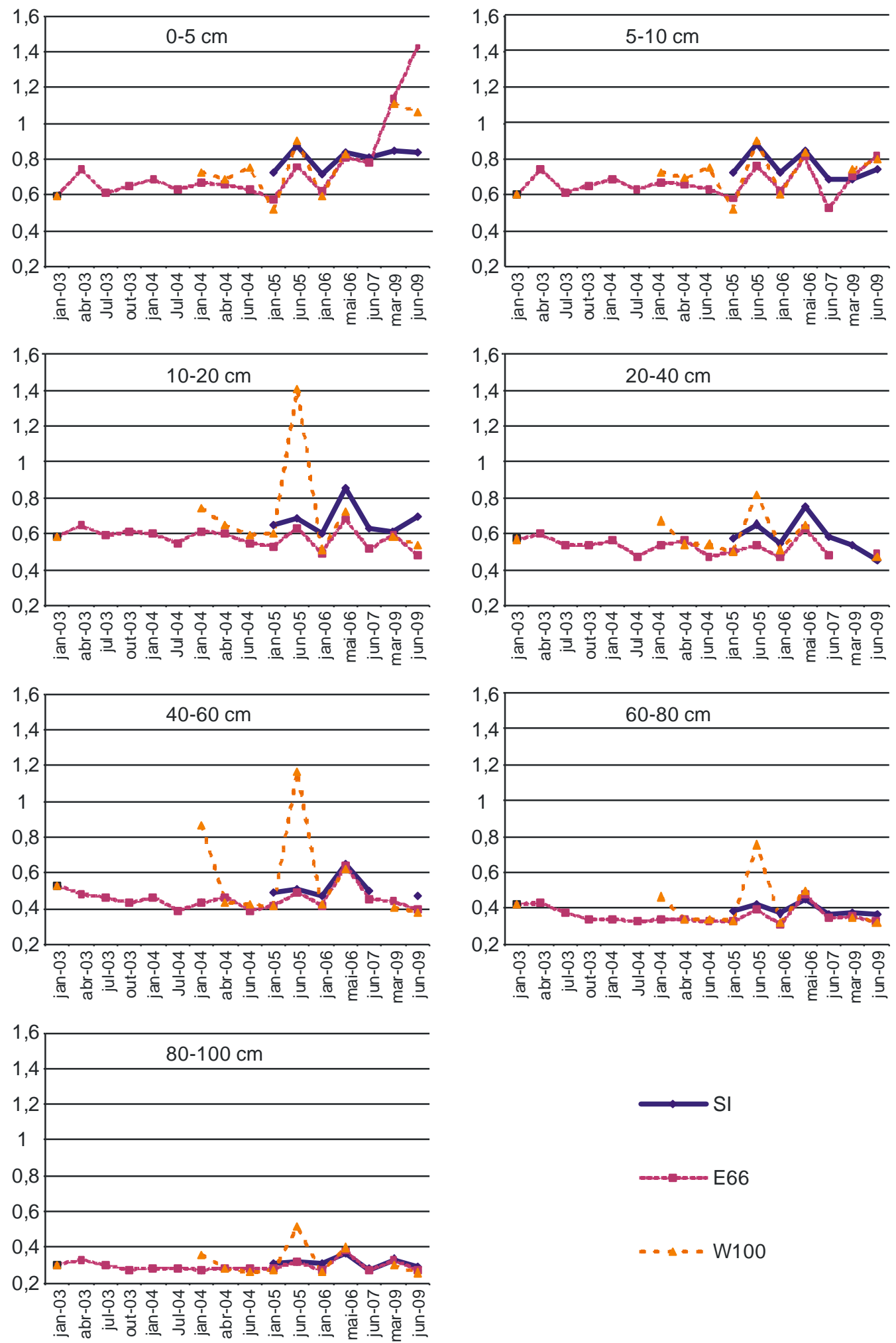

Figura 4.3 - Evolução dos teores de carbono no solo (porcentagem em massa) para as profundidades nos diferentes tratamentos entre Janeiro 2003 e Junho 2009. Os resultados de janeiro de 2003 a maio de 2006 foram extraídos de Fonseca, 2005, Nogueira, 2008 e Santos, 2008. SI: sem irrigação e sem fertilização; E66 - irrigação com EETE e adubação de $343 \mathrm{~kg} \mathrm{ha}^{-1}$ ano $^{-1}$ de nitrato de amônio, $416 \mathrm{~kg} \mathrm{ha}^{-1}$ ano $^{-1}$ de $\mathrm{K}_{2} \mathrm{O}$ e $140 \mathrm{~kg} \mathrm{ha}^{-1}$ ano $^{-1} \mathrm{P}_{2} \mathrm{O}_{5}$; W100 - irrigação com água potável e adição de $520 \mathrm{~kg} \mathrm{ha}^{-1}$ ano $^{-1}$ de nitrogênio via nitrato de amônio, 416 $\mathrm{kg} \mathrm{ha}^{-1} \mathrm{ano}^{-1}$ de $\mathrm{K}_{2} \mathrm{O}$ e $140 \mathrm{~kg} \mathrm{ha}^{-1}$ ano $^{-1} \mathrm{P}_{2} \mathrm{O}_{5}$. 
Os teores de carbono permaneceram relativamente estáveis até Junho de 2005. A partir desta data, os teores de carbono dos solos irrigados (E66 e W100) apresentaram um aumento brusco. Embora essa variação pareça um evento isolado, não foi possível identificar sua causa. Em Dezembro de 2008, ocorerram problemas no manejo do campo experimental os quais resultaram em um maior acúmulo de liteira que provocou um aumento dos teores de carbono nas camadas $0-5 \mathrm{~cm}$ dos solos tratados.

O menor estoque de $\mathrm{C}$ nos solos irrigados em relação ao solo sem irrigação pode ter origem em dois processos: (1) mineralização e lixiviação de uma matéria orgânica anterioramente estável, devido à sua exposição após a desestruturação dos complexos organominerais em razão dos altos teores de $\mathrm{Na}^{+}\left(132 \pm 7 \mathrm{mg} \mathrm{L}^{-1}\right.$; NOGUEIRA, 2008) no efluente (STEVENSON, 1994; ZECH et al, 1997; BALDOCK;NELSON, 2000; JIMÉNEZ \& LAL, 2006); (2) efeito "priming". O efeito "priming” foi descrito por Kuzyakov et al. (2000) como sendo um aumento da taxa de mineralização do $\mathrm{C}$ conseqüente do aumento da atividade microbiana resultado da maior presença de água no sistema. Este efeito pode ser definido como uma mudança de curta duração do "turnover" do C ou do N, em resposta a introdução de material de alto potencial energético no sistema. O fenômeno pode corresponder a uma aceleração (efeito priming positivo) ou uma redução (efeito priming negativo) da mineralização do $\mathrm{C}$ e do $\mathrm{N}$.

Fonseca (2005), apoiando-se na eficiência de conversão do $\mathrm{N}$ aplicado ao solo no período de abril 2003 a julho de 2004, descartou o efeito "priming" como explicação das mudanças por ele observas. No entanto, Nogueira (2008), monitorando a mesma área de julho de 2004 a fevereiro de 2006, determinou que até a seca de 2006, o efeito "priming" foi a principal causa das mudanças de $\mathrm{C}$ e $\mathrm{N}$ no solo. 


\subsubsection{Carbono nas diferentes frações densimétricas}

O rendimento da separação das frações por densimetria foi baixo, com quantidades extraidas inferiores a $1 \mathrm{~g}$ para a maioria das frações (Tabela 4.5). Por este motivo, não foi possível realizar todas as análises inicialmente previstas. Optou-se por realizar, para todas as frações, a extração da matéria orgânica com solução de $\mathrm{NaOH} 1 \mathrm{~mol} \mathrm{~L}^{-1}$ e a caracterização dos extratos por fluorescência. A análise da composição isotópica e do grau de húmificação por fluorescência induzida por laser foram realizadas nas frações de densidade $>2$.

Tabela 4.5 - Fracionamento densimétrico da matéria orgânica do solo (MOS) (g).

\begin{tabular}{cccccc}
$\mathrm{d}^{(1)}$ & 1,6 liv $^{(2)}$ & 1,6 occ $^{(3)}$ & $1,6-1,8$ & $1,8-2,0$ & $>2$ \\
\hline E66 0-5 & $\mathrm{ND}^{(5)}$ & $\mathrm{ND}$ & $\mathrm{ND}$ & $\mathrm{ND}$ & $\mathrm{ND}$ \\
E66 5-10 & 0,08495 & 0,02319 & 0,03446 & 0,02486 & 31,83254 \\
E66 10-20 & 0,07915 & 0,03439 & 0,05363 & 0,07053 & 31,76230 \\
E66 20-40 & 0,04625 & 0,01193 & 0,02945 & 0,04467 & 31,86770 \\
E66 40-60 & 0,04567 & 0,02668 & 0,04514 & 0,03301 & 31,84950 \\
E66 60-80 & 0,00000 & 0,0647 & 0,06976 & 0,00000 & 31,86554 \\
E66 80-100 & 0,02112 & 0,00000 & 0,01946 & 0,62046 & 31,35691 \\
\hline SI 0-5 & 0,20052 & 0,02883 & 0,02079 & 0,01772 & 31,73214 \\
SI 5-10 & 0,11175 & 0,01483 & 0,01672 & 0,01166 & 31,84504 \\
SI 10-20 & 0,07902 & 0,03832 & 0,01933 & 0,02957 & 31,83376 \\
SI 20-40 & 0,07884 & 0,01083 & 0,00654 & 0,04104 & 31,86275 \\
SI 40-60 & 0,05585 & 0,01192 & 0,06656 & 0,04363 & 31,82204 \\
SI 60-80 & 0,02070 & 0,02179 & 0,02858 & 0,01580 & 31,91313 \\
SI 80-100 & 0,02637 & 0,02001 & 0,02167 & 0,05465 & 31,87730 \\
\hline
\end{tabular}

(1)d: densidade; (2)liv: matéria orgânica livre da fração mineral não decomposta ou pouca descomposta; (3)occ: matéria orgânica intra-agregados; (4) 0-5 representam as diferentes camadas de solo; (5) não determinado. SI: sem irrigação e sem fertilização; E66 - irrigação com EETE e adubação de $343 \mathrm{~kg} \mathrm{ha}^{-1}$ ano ${ }^{-1}$ de nitrato de amônio, $416 \mathrm{~kg} \mathrm{ha}^{-1} \mathrm{ano}^{-1}$ de $\mathrm{K}_{2} \mathrm{O}$ e $140 \mathrm{~kg} \mathrm{ha}^{-1} \mathrm{ano}^{-1} \mathrm{P}_{2} \mathrm{O}_{5}$.

A observação visual das frações permitiu uma primeira avaliação da origem da matéria orgânica. Como se esperava, as frações 1,6 liv eram, principalmente, compostas por restos de plantas e matéria orgânica fresca. As frações de densidade superior a 2 eram, principalmente, constituídas pela da fase mineral. As outras frações eram compostas por fragmentos de folhas e raiz recobertos pela fase mineral. Outros elementos, provavelmente minerais, foram observados porém não identificados.

A figura 4.4 mostra a repartição do carbono entre as diferentes frações densimétricas 
para as amostras coletadas em junho 2007 dos solos dos tratamentos SI e E66. Observa-se que, independentemente do tratamento, mais de $60 \%$ do carbono do solo é estreitamente associado a fase mineral (fração de densidade superior a 2). Ressalta-se que esta fração, além da matéria orgânica humificada, compõe-se de matéria orgânica pouca humificada de tipo polissacarídeos associada aos microrganismos. Este resultado concorda com aqueles obtidos por Christensen (1986) que, num estudo para determinar a estabilidade da matéria orgânica associada com varias frações minerais de solos europeus, mostrou que mais de 50\% do carbono dos solos estavam associados com as argilas. Roscoe et al. (2001), estudando a dinâmica da matéria orgânica de um oxisolo do Cerrado, encontraram resultados semelhante com 89 a 91\% do carbono orgânico concentrado fração mineral.

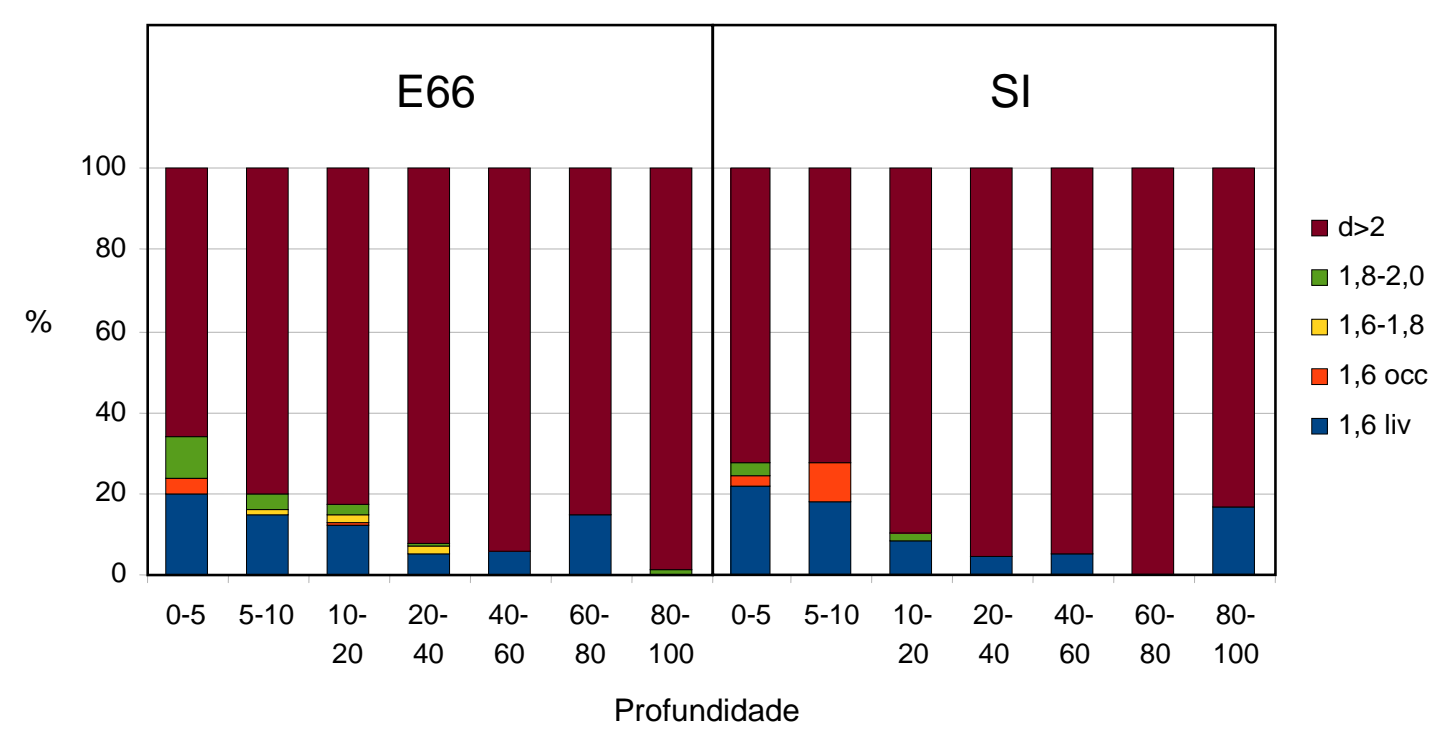

Figura 4.4 - Teores relativos de carbono (\%) nas diferentes frações densimétricas da MOS. d: densidade; liv: matéria orgânica livre da fração mineral não decomposta ou pouca descomposta; occ: matéria orgânica intra-agregados; profundidade em $\mathrm{cm}$. SI: sem irrigação e sem fertilização; E66 - irrigação com EETE e adubação de $343 \mathrm{~kg} \mathrm{ha}^{-1}$ ano $^{-1}$ de nitrato de amônio, $416 \mathrm{~kg} \mathrm{ha}^{-1}$ ano $^{-1}$ de $\mathrm{K}_{2} \mathrm{O}$ e $140 \mathrm{~kg}$ ha $^{-1}$ ano $^{-1} \mathrm{P}_{2} \mathrm{O}_{5}$.

A fração 1,6 liv, é composta, predominantemente, por fragmentos vegetais pouco decompostos, estando, portanto, mais sujeita a variações aletatórias, decorrentes, por 
exemplo, da presença de fragmentos de raízes nas amostras. Estas variações poderiam ser responsáveis pelas diferenças observadas entre as camadas 60-80 e 80-100 para ambos tratamentos SI e E66. Desta forma, é pertinente analisar os teores de C contidos nas frações densimétricas retirando-se a contribuição da fração 1,6liv (Figura 4.5).

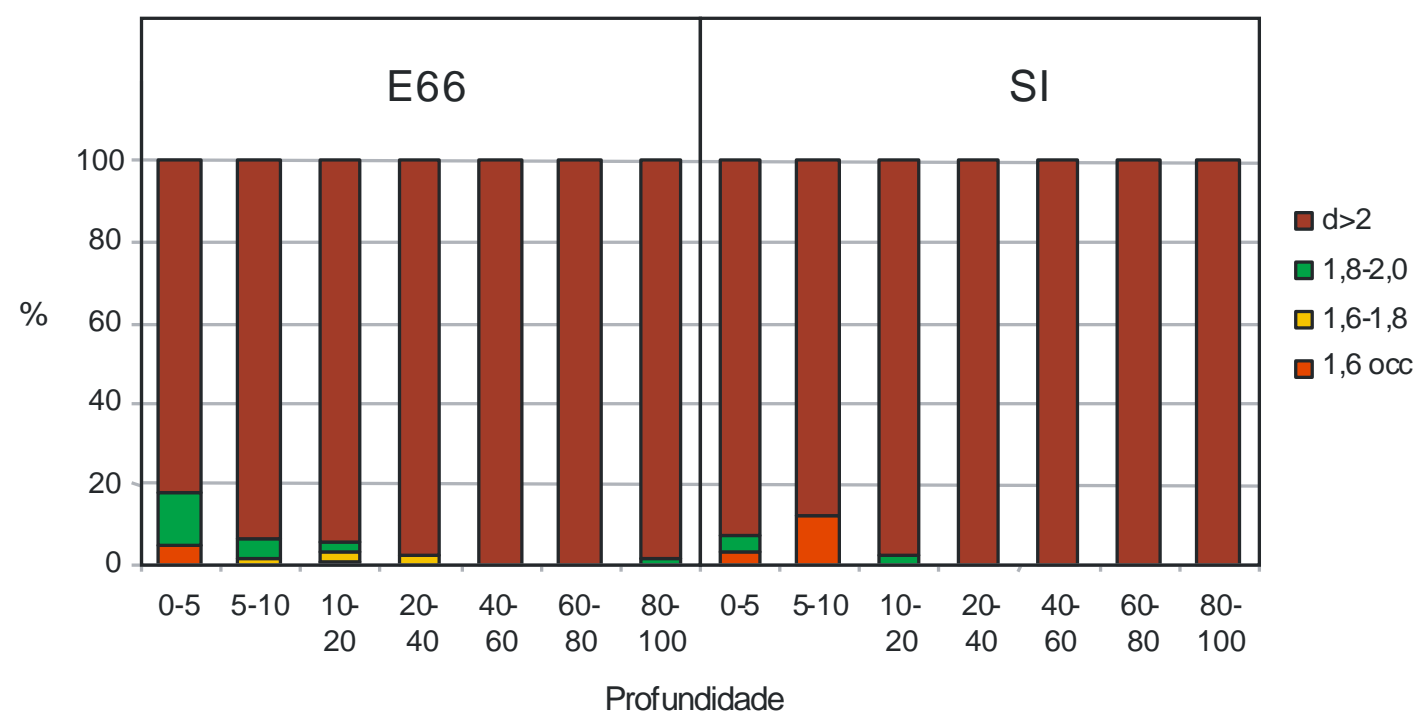

Figura 4.5 - Teores de carbono (\%) nas diferentes frações frações densimétricas da MOS, retirando-se a fração 1,6 liv . d: densidade; occ: matéria orgânica intraagregados de densidade <1,6; profundidade em cm. SI: sem irrigação e sem fertilização; E66 - irrigação com EETE e adubação de $343 \mathrm{~kg} \mathrm{ha}^{-1} \mathrm{ano}^{-1} \mathrm{de}$ nitrato de amônio, $416 \mathrm{~kg} \mathrm{ha}^{-1} \mathrm{ano}^{-1} \mathrm{de} \mathrm{K}_{2} \mathrm{O}$ e $140 \mathrm{~kg} \mathrm{ha}^{-1} \mathrm{ano}^{-1} \mathrm{P}_{2} \mathrm{O}_{5}$.

Observa-se que a porcentagem de carbono contido nas frações mais densas 1,8 a 2 e $>2$, estreitamente ligadas à fração mineral, é maior no solo irrigado que no solo não irrigado. Essa observação concorda com aquelas previamente realizadas sobre a desestruração dos agregados nos solos irrigados. 


\subsection{Composição isotópica do carbono}

\subsubsection{Composição isotópica do carbono no solo total}

O perfil da composição isotópica do $\mathrm{C}$ com a profundidade (Figura 4.6) mostra diferenças relacionadas aos tratamentos e uma relativa estabilidade ao longo do período experimental. Até $40 \mathrm{~cm}$, os solos irrigados apresentaram composições isotópicas com valores mais negativos que o solo não irrigado, com exeção para as profundidades 0-5 e 5-10 cm em junho de 2007. 


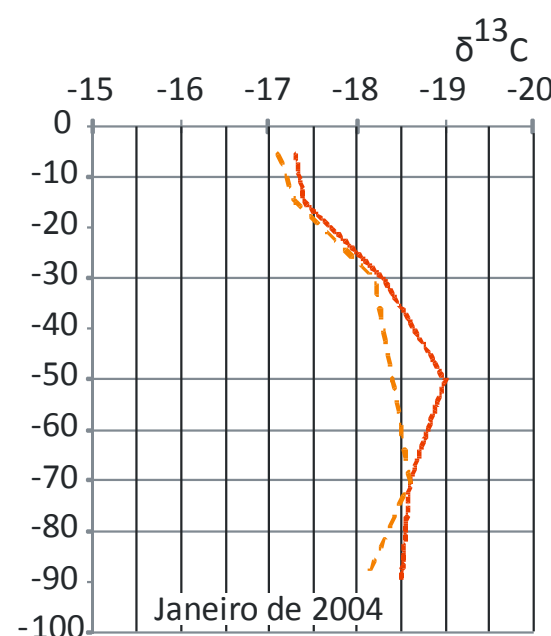

Profundidade $(\mathrm{cm})$

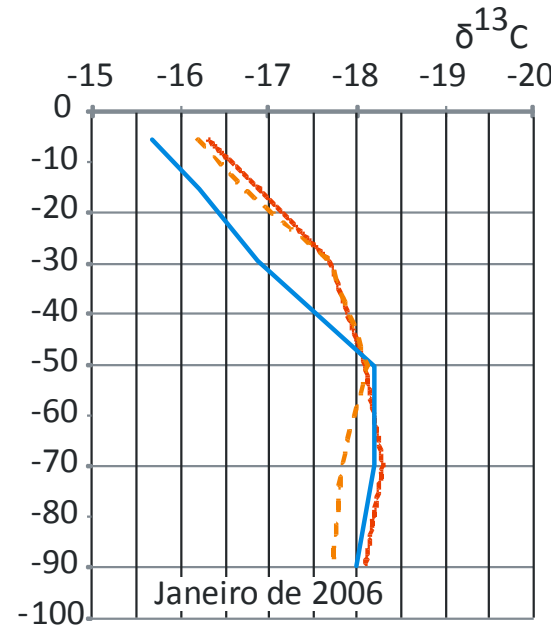

Profundidade $(\mathrm{cm})$

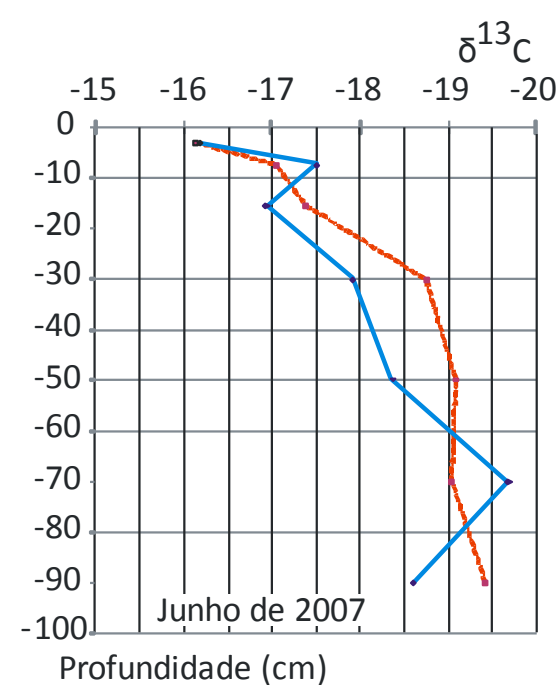

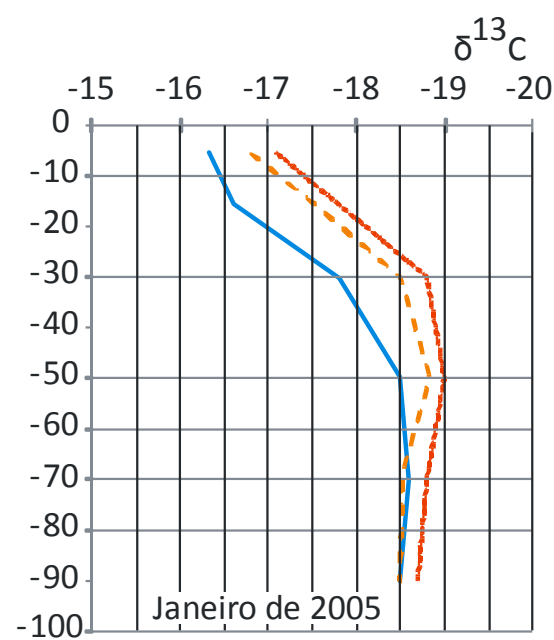

Profundidade $(\mathrm{cm})$

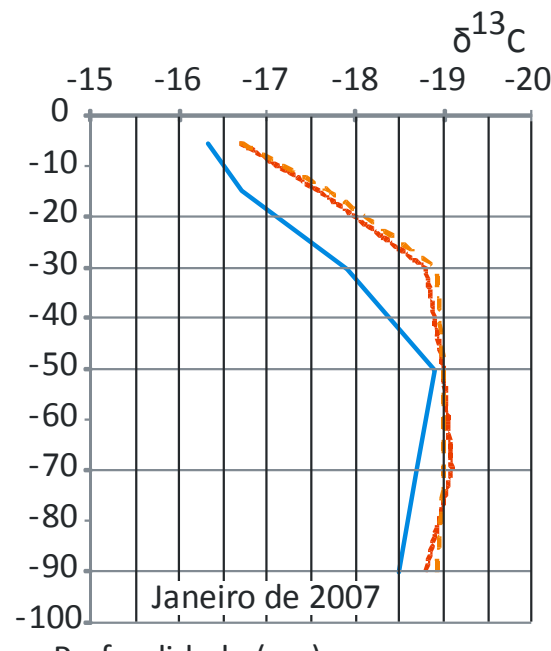

Profundidade $(\mathrm{cm})$

Figura 4.6 - Composição isotópica $\left(\delta^{13} \mathrm{C}\right)$ da matéria orgânica do solo total. Os resultados de janeiro de 2004 a janeiro de 2007 foram extraídos de Nogueira (2008). SI: sem irrigação e sem fertilização; E66 - irrigação com EETE e adubação de 343 $\mathrm{kg} \mathrm{ha}^{-1}$ ano $^{-1}$ de nitrato de amônio, $416 \mathrm{~kg} \mathrm{ha}^{-1}$ ano $^{-1}$ de $\mathrm{K}_{2} \mathrm{O}$ e $140 \mathrm{~kg} \mathrm{ha}^{-1}$ ano $^{-1}$ $\mathrm{P}_{2} \mathrm{O}_{5}$; W100: irrigação com água potável e adição de $520 \mathrm{~kg} \mathrm{ha}^{-1} \mathrm{ano}^{-1} \mathrm{de}$ nitrogênio via nitrato de amônio, $416 \mathrm{~kg} \mathrm{ha}^{-1}$ ano $^{-1}$ de $\mathrm{K}_{2} \mathrm{O}$ e $140 \mathrm{~kg} \mathrm{ha}^{-1}$ ano $^{-1}$ $\mathrm{P}_{2} \mathrm{O}_{5}$. 
Os valores semelhantes entre os solos irrigados com EETE e água evidenciam que não houve influência do efluente, cuja composição isotópica do carbono (-23,8 \%o, Tabela 3.1) é mais negativa do que a da MOS (ver Figura 4.6) ou do capim (-13\%o; NOGUEIRA, 2008). Isto pode ser explicado pela pequena contribuição do $\mathrm{C}$ orgânico oriundo do EETE (menos de 5,3\% dos aportes totais de C; NOGUEIRA, 2008).

Os valores mais negativos de $\delta^{13} \mathrm{C}$ da $\mathrm{MOS}$ nos dois solos irrigados, restritos aos horizontes superficiais, são muito provavelmente devido à irrigação. Werth e Kuzyakov (2010) mostraram que os microrganismos tendem a consumir e mineralizar uma MOS de $\delta^{13} \mathrm{C}$ menos negativa, resultando em uma MOS residual mais negativa. Isto reforça a hipótese do favorecimento da atividade microbiana pela irrigação, conforme citado na literatura (FRIEDEL et al, 2000; RAMIREZ-FUENTES et al,2002)

\subsubsection{Composição isotópica na fração densimétrica superior a dois}

Na Figura 4.7 apresenta-se uma comparação das composições isotópicas do C da MOS total e da fração de densidade superior a 2 dos solos dos tratamentos SI e E66. Embora todos os perfis apresentem valores mais negativos com a profundidade, a MOS total apresenta sistematicamente valores inferiores aos da fração de densidade $d>2$ correspondente. Pode-se também observar que a diferença entre a MOS total e a fração d $>2$ é maior no solo irrigado que no não irrigado. Esta diferença é coerente com a hipótese de consumo preferencial da MOS de $\delta^{13} \mathrm{C}$ menos negativa da fração $\mathrm{d}>2$, favorecido pela dispersão dos agregados em razão da alta concentração em Na nas águas de irrigação (WERTH E KUZYAKOV; 2010). A hipótese de um enriquecimento da fração mineral em matéria orgânica oriunda do capim é difícil de sustentar, uma vez que a fração d>2 é mais resistente à degradação que as demais frações. 


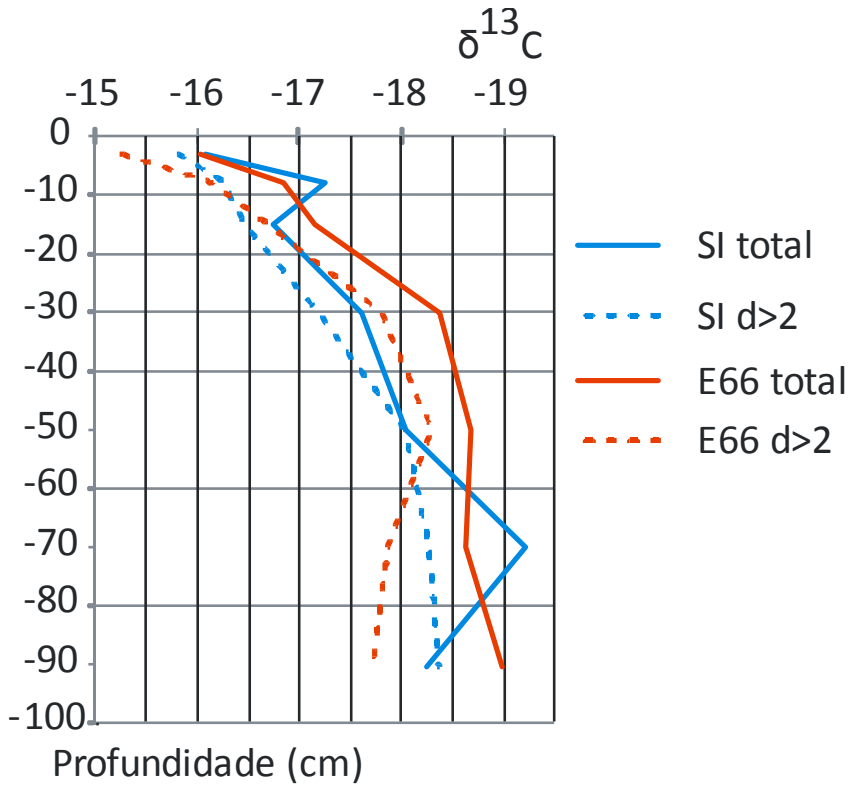

Figura 4.7 - Composição isotópica $\left(\delta^{13} \mathrm{C}\right)$ da matéria orgânica do total e da fração $d>2$ dos solos dos tratamentos SI e E66 (amostragem de Junho de 2007). d: densidade; SI: sem irrigação e sem fertilização; E66 - irrigação com EETE e adubação de $343 \mathrm{~kg} \mathrm{ha}^{-1}$ ano $^{-1}$ de nitrato de amônio, $416 \mathrm{~kg} \mathrm{ha}^{-1} \mathrm{ano}^{-1}$ de $\mathrm{K}_{2} \mathrm{O}$ e $140 \mathrm{~kg} \mathrm{ha}^{-1}$ ano $^{-1} \mathrm{P}_{2} \mathrm{O}_{5}$; W100: irrigação com água potável e adição de $520 \mathrm{~kg} \mathrm{ha}^{-1} \mathrm{ano}^{-1} \mathrm{de}$ nitrogênio via nitrato de amônio, $416 \mathrm{~kg} \mathrm{ha}^{-1} \mathrm{ano}^{-1} \mathrm{de} \mathrm{K}_{2} \mathrm{O}$ e $140 \mathrm{~kg} \mathrm{ha}^{-1}$ ano $^{-1}$ $\mathrm{P}_{2} \mathrm{O}_{5}$.

\subsection{Fluorescência induzida por laser (LIF)}

\subsubsection{LIF do solo total}

A partir dos resultados obtidos por espectroscopia induzida por laser (FIL) e do valor da concentração do carbono orgânico total (COT) no solo foi calculado o índice de húmificação $(\mathrm{IH})$ das amostras de solo total e da fração com densidade superior a 2 para os diferentes tratamentos e camadas do solo. Os resultados são apresentados na Tabela 4.6 e na Figura 4.8. 
Tabela 4.6 - Índice de humificação (IH) para as amostras de solo total (junho 2007).

\begin{tabular}{|c|c|c|c|c|c|c|c|}
\hline camada $(\mathrm{cm})$ & $0-5$ & $5-10$ & $10-20$ & $20-40$ & $40-60$ & $60-80$ & $80-100$ \\
\hline \multicolumn{8}{|c|}{$\mathrm{IH}$} \\
\hline $\mathrm{E} 6^{(1)}$ & $600,3^{\mathrm{a}}$ & $969,4^{\mathrm{b}}$ & $1044,2^{\mathrm{c}}$ & $1169.8^{d}$ & $1569,9^{\mathrm{e}}$ & $2162,7^{f}$ & $2926,5^{\mathrm{g}}$ \\
\hline SI & $603,9^{\mathrm{a}}$ & $836,3^{\mathrm{b}}$ & $978,5^{\mathrm{c}}$ & $1232,7^{\mathrm{d}}$ & $1494,5^{\mathrm{e}}$ & $2271,1^{\mathrm{f}}$ & $3037,5^{\mathrm{g}}$ \\
\hline
\end{tabular}

(1)Tratamentos; SI: sem irrigação e sem fertilização; E66 - irrigação com EETE e adubação de 343 kg ha-1 ano1 de nitrato de amônio, $416 \mathrm{~kg}$ ha-1 ano-1 de $\mathrm{K}_{2} \mathrm{O}$ e $140 \mathrm{~kg}$ ha-1 ano-1 $\mathrm{P}_{2} \mathrm{O}_{5}$; Letras iguais nas colunas não diferem estatisticamente pelo teste de Tukey $(\mathrm{P}<0,05)$.

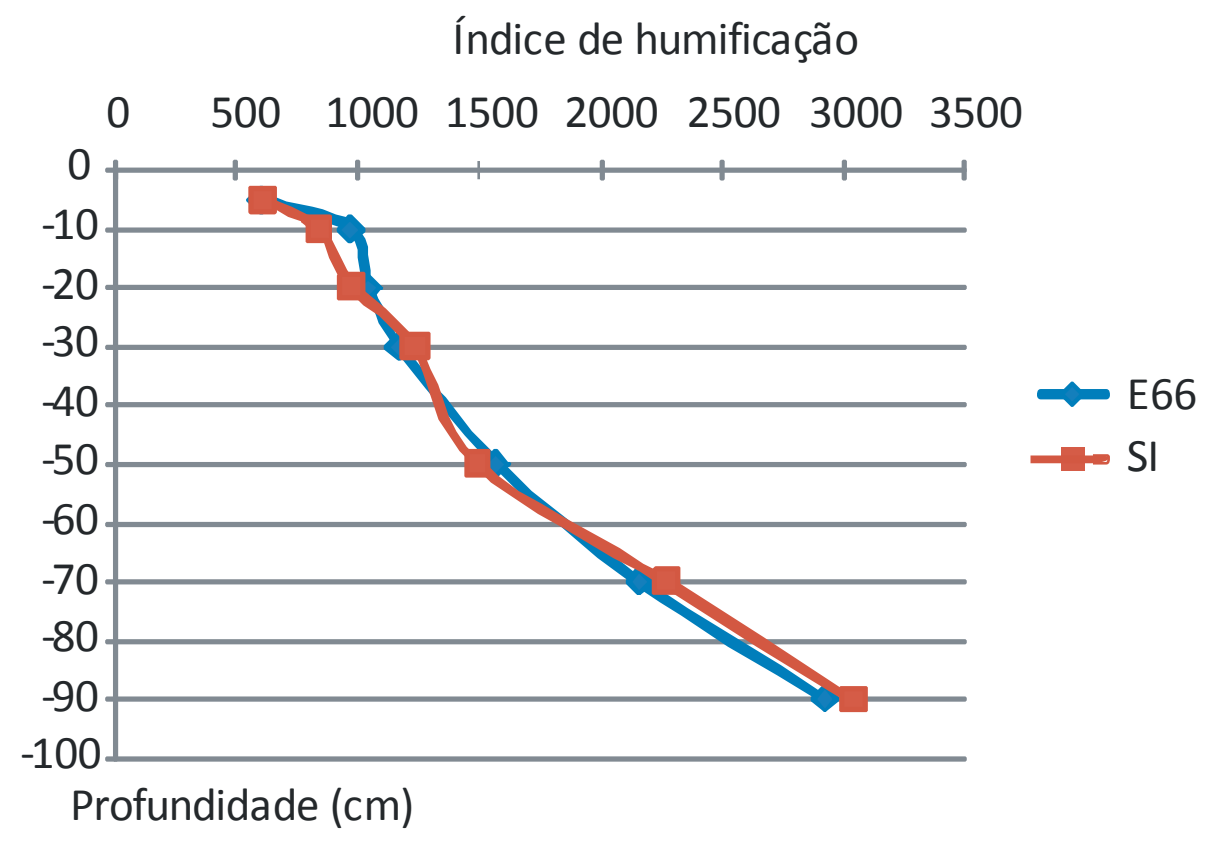

Figura 4.8 - Índice de humificação da MOS total (Junho 2007). SI: sem irrigação e sem fertilização; E66 - irrigação com EETE e adubação de $343 \mathrm{~kg} \mathrm{ha}^{-1} \mathrm{ano}^{-1}$ de nitrato de amônio, $416 \mathrm{~kg} \mathrm{ha}^{-1} \mathrm{ano}^{-1} \mathrm{de} \mathrm{K}_{2} \mathrm{O}$ e $140 \mathrm{~kg} \mathrm{ha}^{-1} \mathrm{ano}^{-1} \mathrm{P}_{2} \mathrm{O}_{5}$.

Não foram observadas diferenças estatísticas entre os valores de IH para as amostras de solo total entre os tratamentos. Resultado semelhante foi obtido por Santos (2008) que concluiu que a espectroscopia induzida por laser (FIL) não foi sensível para detectar alterações no grau de humificação que, possivelmente, ocorreram nos solos. Entretanto, como também observado por Santos (2008), há uma tendência de aumento progressivo do grau de humificação com a profundidade. Isto concorda com as conclusões de numerosos trabalhos, que mostraram que a humificação medida, por exemplo, pelo grau de condensação, bem como a idade média e a estabilidade da MOS, aumenta com a profundidade (STEVENSON, 1994; ZECH et al, 1997; BALDOCK;NELSON, 2000). As camadas superficiais apresentaram um 
estoque maior de matéria orgânica mais jovem, menos humificada, de "turnover" mais rápido devido, concomitantemente, à entrada mais rápida e maior degradação microbiana.

\subsubsection{LIF na fração densimétrica superior a dois}

Comparando-se os valores do índice de humificação para o solo total e para a fração densimétrica superior a 2 (Tabela 4.7 e Figura 4.9), verifica-se que nas camadas superficiais (até $10 \mathrm{~cm}$ de profundidade) estes valores não diferem estatisticamente. Entretanto, a partir de 10 cm os IH são distintos, sendo o índice de humificação da fração densimétrica superior a 2 significativamente menor que o obtido para o solo total. Isto poderia ser explicado pelo fato

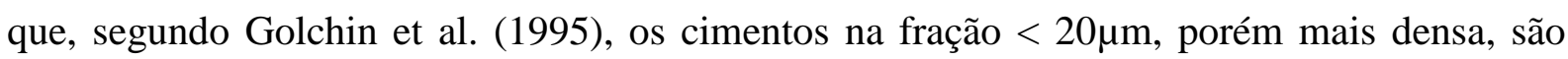
sobretudo de tipo mucilagem (polissacarídeos), o que aumenta a razão da matéria pouco humificada.

Tabela 4.7 - Comparação entre os valores do índice de humificação (IH) para as amostras de solo total e da fração densimétrica superior a 2 para o tratamento SI (junho de 2007).

\begin{tabular}{cccccccc}
\hline camada $(\mathrm{cm})$ & $0-5$ & $5-10$ & $10-20$ & $20-40$ & $40-60$ & $60-80$ & $80-100$ \\
\hline & & \multicolumn{7}{c}{ IH } & & & & \\
\hline SI(1) & $603,9 \mathrm{a}$ & $836,3 \mathrm{~b}$ & 978,5 & 1232,7 & 1494,5 & 2271,1 & 3037,5 \\
SI d 2 & $616,1 \mathrm{a}$ & $892,1 \mathrm{~b}$ & 689,9 & 857,1 & 947,9 & 1985,9 & 1799,3 \\
\hline
\end{tabular}

(1)Tratamentos; SI sem irrigação e sem fertilização; d densidade.Letras iguais nas colunas não diferem estatisticamente pelo teste de Tukey $(\mathrm{P}<0,05)$.

İndice de humificaçä̃o

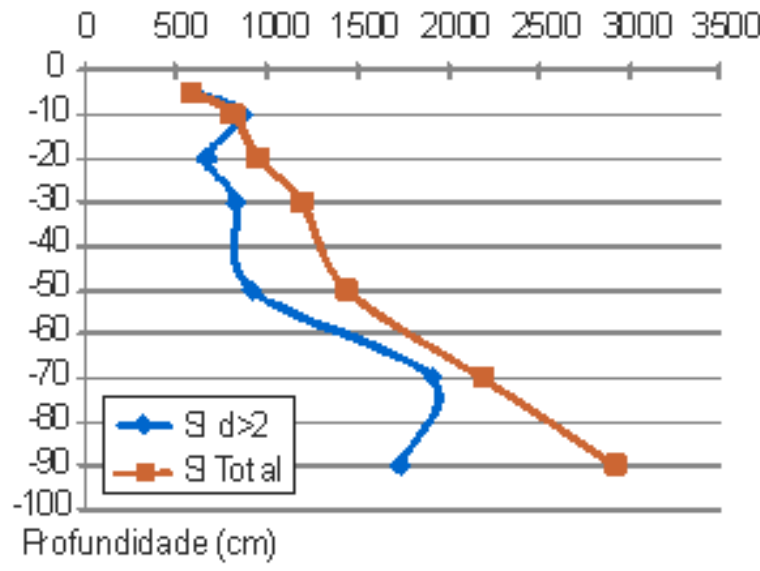

Figura 4.9 - Índice de humificação da MOS total e da fração d>2 para o tratamento SI (Junho 2007). d: dendidade; SI sem irrigação e sem fertilização. 
Na Tabela 4.8 e Figura 4.10 são apresentados os resultados da comparação dos valores de IH para as frações de densidade superior a 2 para os diferentes tratamentos. Verifica-se que somente as camadas de 40-60 e 80-100 cm apresentaram valores estatisticamente iguais. Nas demais profundidades os IH da fração d $>2$ do solo irrigado são estatisticamante maiores. Essa evolução da MOS pode estar ligada à alteração da atividade microbiana sob efeito do efluente, resultando numa aceleração da degradação da matéria orgânica mais lábil como, por exemplo, dos cimentos polissacarídeos dos agregados organo-minerais. Estes processos podem ser favorecidos pela dispersão dos agregados pelo efeito da sodicidade do efluente (GONÇALVEZ, 2005). Um outro processo citado por Santos (2008), seria que a irrigação com águas residuárias favoreceria a formação de substância húmicas solúveis que tenderiam a se acumular em profundidade.

Tabela 4.8 - Comparação entre os valores do índice de humificação (IH) para as amostras de solo da fração de densidade superior a 2 para os tratametos SI e E66.

\begin{tabular}{|c|c|c|c|c|c|c|c|}
\hline camada $(\mathrm{cm})$ & $0-5$ & $5-10$ & $10-20$ & $20-40$ & $40-60$ & $60-80$ & $80-100$ \\
\hline \multicolumn{8}{|c|}{$\mathrm{IH}$} \\
\hline $\mathrm{E}^{2} 6^{(1)}$ & 1335,5 & 2501,2 & 1696,8 & 1016,9 & $1475,5^{\mathrm{a}}$ & 1728,5 & $2679,2^{b}$ \\
\hline SI & 616,1 & 892,1 & 689,9 & 857,1 & $947,9^{\mathrm{a}}$ & 1985,9 & $1799,3^{b}$ \\
\hline
\end{tabular}

(1)Tratamentos; SI: sem irrigação e sem fertilização; E66 - irrigação com EETE e adubação de 343 kg ha-1 ano1 de nitrato de amônio, $416 \mathrm{~kg}$ ha-1 ano-1 de $\mathrm{K}_{2} \mathrm{O}$ e $140 \mathrm{~kg}$ ha-1 ano-1 $\mathrm{P}_{2} \mathrm{O}_{5}$. Letras iguais nas colunas não diferem estatisticamente pelo teste de Tukey $(\mathrm{P}<0,05)$. 
Índice de humificação

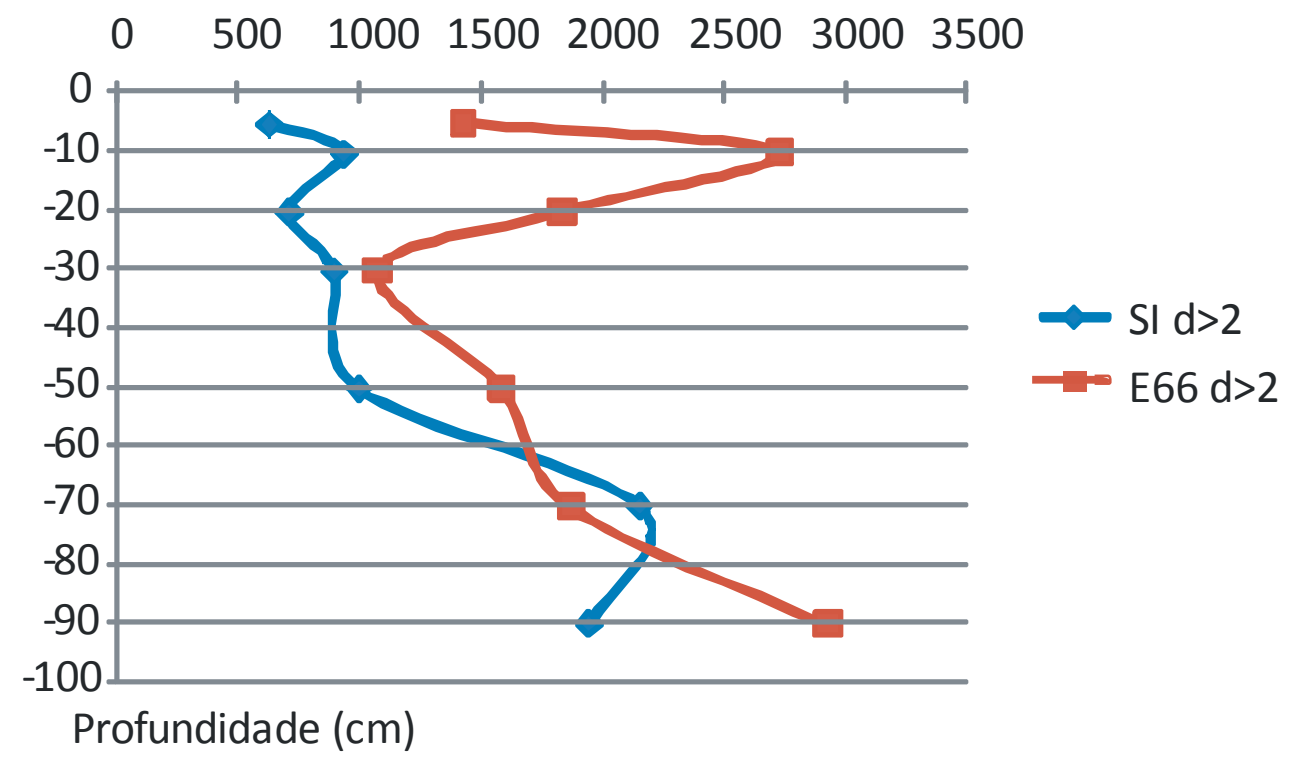

Figura 4.10 - Índice de humificação da fração d $>2$ da MOS dos solos dos tratamentos SI e E66 (Junho 2007). d densidade; SI: sem irrigação e sem fertilização; E66 irrigação com EETE e adubação de $343 \mathrm{~kg} \mathrm{ha}^{-1}$ ano $^{-1}$ de nitrato de amônio, 416 $\mathrm{kg} \mathrm{ha}^{-1} \mathrm{ano}^{-1}$ de $\mathrm{K}_{2} \mathrm{O}$ e $140 \mathrm{~kg} \mathrm{ha}^{-1}$ ano $^{-1} \mathrm{P}_{2} \mathrm{O}_{5}$.

\subsubsection{Evolução do IH durante o período experimental}

Nas Tabelas 4.9, 4.10 e 4.11 e nas Figuras 4.11, 4.12 e 4.13 são apresentadas as evoluções dos valores de IH para o solo total durante o período experimental para os solos dos tratamentos SI, E66 e W100, respectivamente.

Tabela 4.9 - Evolução do índice de humificação (IH) para as amostras de solo total no período experimental para o tratamento SI.

\begin{tabular}{rccccccc}
\hline camada $(\mathrm{cm})$ & $0-5$ & $5-10$ & $10-20$ & $20-40$ & $40-60$ & $60-80$ & $80-100$ \\
\hline \multicolumn{7}{c}{ IH } \\
\hline Junho 2007 & $11327,3^{\text {a }}$ & $13622,1^{\mathrm{b}}$ & $14735,0^{\mathrm{c}}$ & $16157,2^{\mathrm{d}}$ & 20517,0 & $27352,5^{\mathrm{e}}$ & 35024,6 \\
Maio 2009 & $10097,1^{\mathrm{a}}$ & $12787,4^{\mathrm{b}}$ & $13981,3^{\mathrm{c}}$ & $14209,5^{\mathrm{d}}$ & & 22967,8 & 26065,7 \\
Junho 2009 & $9727,5^{\mathrm{a}}$ & $11219,2^{\mathrm{b}}$ & $13841,4^{\mathrm{c}}$ & 22729,2 & 20091,6 & $25751,6^{\mathrm{e}}$ & 31773,4 \\
\hline
\end{tabular}




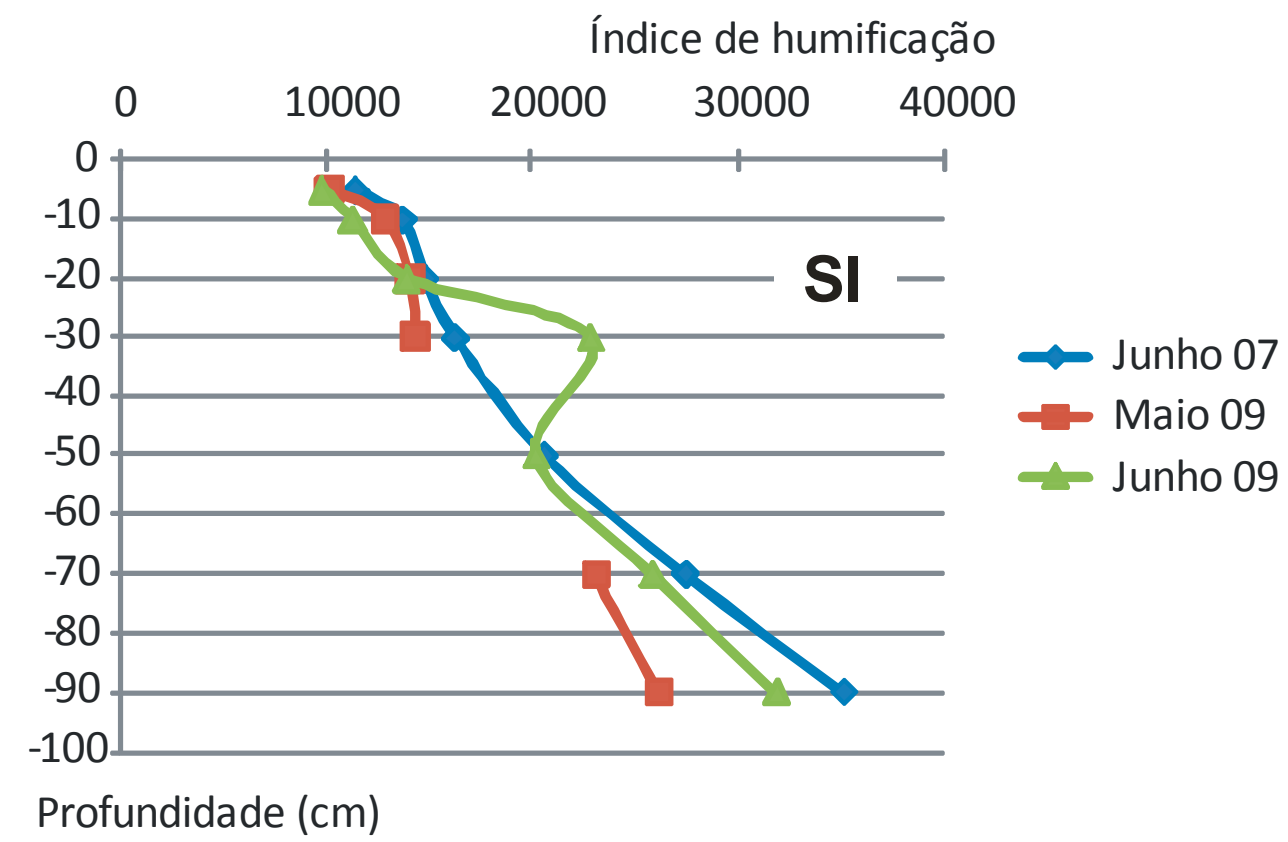

Figura 4.11 - Evolução temporal do índice de humificação para o solo do tratamento SI (solo total). SI sem irrigação e sem fertilização.

Tabela 4.10 - Evolução do índice de humificação (IH) para as amostras de solo total no período experimental para o tratamento E66.

\begin{tabular}{cccccccc}
\hline camada (cm) & $0-5$ & $5-10$ & $10-20$ & $20-40$ & $40-60$ & $60-80$ & $80-100$ \\
\hline \multicolumn{7}{c}{ IH } \\
\hline Junho 2007 & 11010,0 & 15914,5 & $16989,0^{\mathrm{c}}$ & 19052,7 & $21518,3^{\mathrm{d}}$ & $29124,2^{\mathrm{e}}$ & $34860,2^{\mathrm{f}}$ \\
Maio 2009 & $6637,1^{\text {a }}$ & $10422,7^{\mathrm{b}}$ & $11038,0^{\mathrm{c}}$ & & $18414,2^{\mathrm{d}}$ & 24065,7 & 25286,4 \\
Junho 2009 & $6766,8^{\mathrm{a}}$ & $9943,3^{\mathrm{b}}$ & $20506,3^{\mathrm{c}}$ & 18718,1 & $23965,1^{\mathrm{d}}$ & $29953,6^{\mathrm{e}}$ & $33614,3^{\mathrm{f}}$ \\
\hline
\end{tabular}

E66 - irrigação com EETE e adubação de $343 \mathrm{~kg} \mathrm{ha}^{-1} \mathrm{ano}^{-1}$ de nitrato de amônio, $416 \mathrm{~kg} \mathrm{ha}^{-1}$ ano $^{-1}$ de $\mathrm{K}_{2} \mathrm{O}$ e 140 $\mathrm{kg} \mathrm{ha}^{-1}$ ano $^{-1} \mathrm{P}_{2} \mathrm{O}_{5}$. Letras iguais nas colunas não diferem estatisticamente pelo teste de Tukey $(\mathrm{P}<0,05)$. 


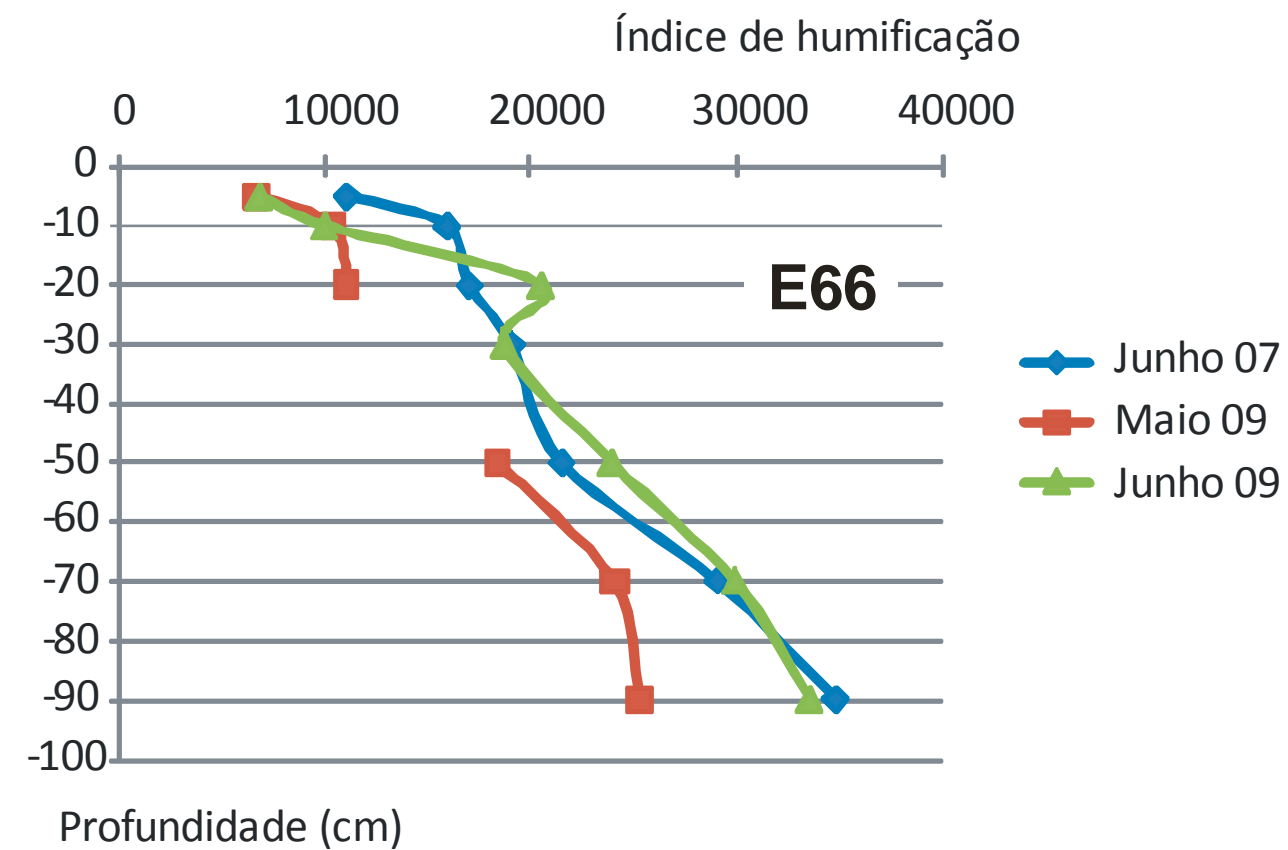

Figura 4.12 - Evolução temporal do índice de humificação para o solo do tratamento E66 (solo total). E66 - irrigação com EETE e adubação de $343 \mathrm{~kg} \mathrm{ha}^{-1} \mathrm{ano}^{-1}$ de nitrato de amônio, $416 \mathrm{~kg} \mathrm{ha}^{-1}$ ano $^{-1}$ de $\mathrm{K}_{2} \mathrm{O}$ e $140 \mathrm{~kg} \mathrm{ha}^{-1}$ ano $^{-1} \mathrm{P}_{2} \mathrm{O}_{5}$.

Tabela 4.11 - Evolução do índice de humificação (IH) para as amostras de solo total no período experimental para o tratamento W100.

\begin{tabular}{|c|c|c|c|c|c|c|c|}
\hline camada $(\mathrm{cm})$ & $0-5$ & $5-10$ & $10-20$ & $20-40$ & $40-60$ & $60-80$ & $80-100$ \\
\hline \multicolumn{8}{|c|}{$\mathrm{IH}$} \\
\hline Maio 2009 & $6390,1^{\mathrm{a}}$ & $10007,5^{b}$ & 12823,0 & & 19392,9 & 22791,5 & 26176,3 \\
\hline Junho 2009 & $8261,3^{\mathrm{a}}$ & $12392,1^{b}$ & 17315,0 & 19079,6 & 23420,5 & 28425,7 & 37506,1 \\
\hline
\end{tabular}




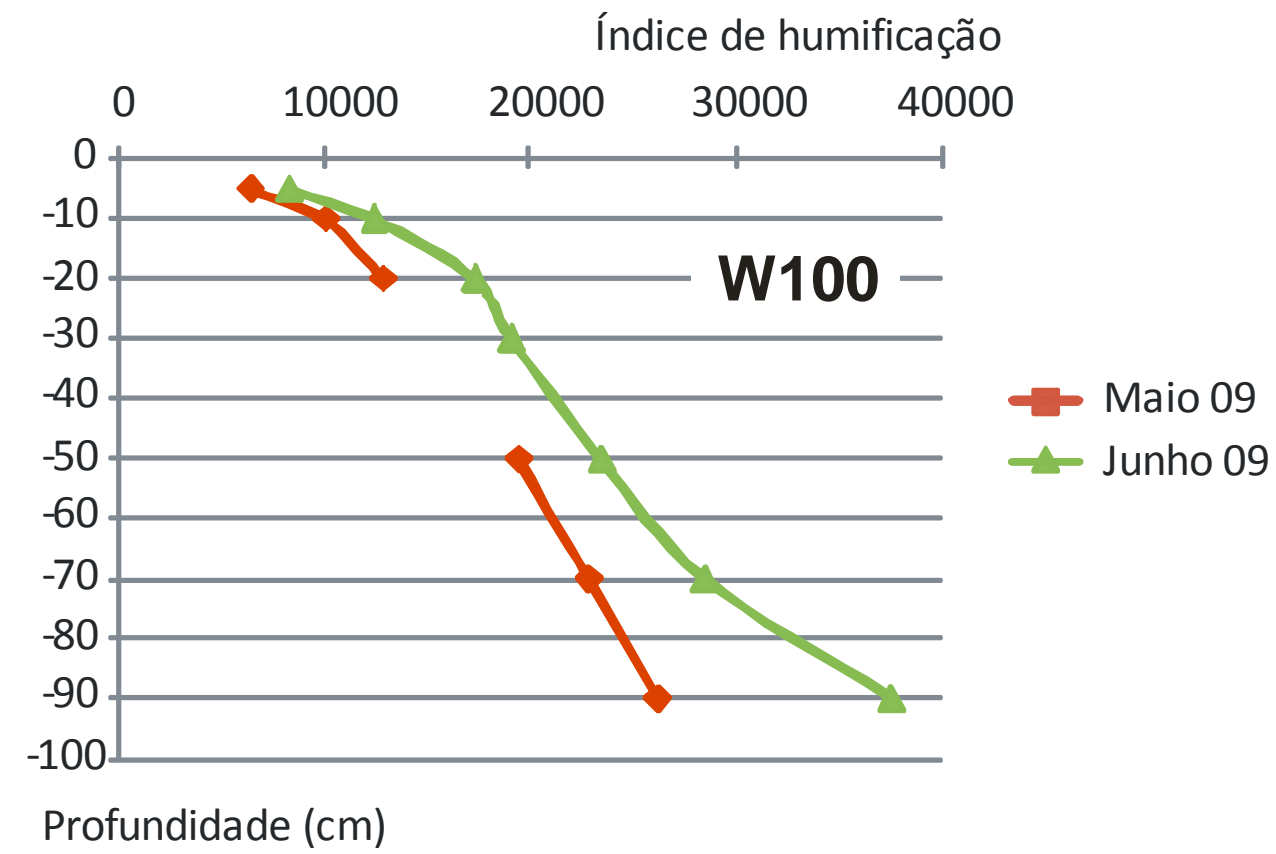

Figura 4.13 - Evolução temporal do índice de humificação para o solo W100 (solo total). W100: irrigação com água potável e adição de $520 \mathrm{~kg} \mathrm{ha}^{-1} \mathrm{ano}^{-1}$ de nitrogênio via nitrato de amônio, $416 \mathrm{~kg} \mathrm{ha}^{-1}$ ano $^{-1} \mathrm{de} \mathrm{K}_{2} \mathrm{O}$ e $140 \mathrm{~kg} \mathrm{ha}^{-1} \mathrm{ano}^{-1} \mathrm{P}_{2} \mathrm{O}_{5}$.

A evolução temporal do IH apresenta feições similares para os solos dos três tratamentos. As curvas de junho de 2007 e de junho de 2009 são similares, com exceção de valores mais elevados na profundidade de 20 a $30 \mathrm{~cm}$, nos tratamentos SI e E66. Considerando o solo do tratamento W100, a ausência dos valores para junho de 2007 não permite uma conclusão, no entanto, a curva de junho de 2009 apresenta um ombro na profundidade de $20 \mathrm{~cm}$, o que poderia indicar comportamento semelhante aos demais tratmentos (ver tambem a figura 4.16). Comparando os valores de IH de junho e maio de 2009 verifica-se que, abaixo da camada $10-20 \mathrm{~cm}$, os valores de IH são menores em maio para os solos dos três tratamentos.

Quais fatores poderiam dar origem as variações observadas? O estado fenológico da cultura pode ser descartado, considerando que se trata de capim e que o corte e a sua remoção foram realizados bimestralmente. A variação de temperatura média parece desprezível, sobretudo quando se trata de variações em profundidade. A origem mais provável, portanto, 
se encontra na diminuição da pluviosidade iniciada em fevereiro de 2009 (ver Figura 3.2) e que, apesar da irrigação, poderia resultar em uma inversão do fluxo vertical da solução do solo, fenômeno que foi observado por Gonçalvez (2005) e Gloaguen (2006). A variação do IH com a umidade do solo já foi evidenciada por Hentschel et al. (2007). No caso deste experimento, o aumento do IH com a diminuição do fluxo de solução proveniente da parte superior do solo, poderia estar relacionado à diminuição da entrada de compostos móveis pouco humificados em profundidade..

Ressalta-se que áreas agrícolas irrigadas com esgoto bruto durante 25, 65 e 80 anos não apresentaram variações significativas do quociente metabólico (FRIEDEL et al., 2000). Porém, a atividade metabólica dos microrganismos aeróbios é controlada por fatores sazonais tais como, a difusão do oxigênio no solo, fator afetado pela quantidade de poros preenchidos com água (JONES et al., 2005; MOREIRA; SIQUEIRA, 2006), o volume de água no solo (THOMSEN et al., 1999) e a temperatura (SOLLINS et al., 1996). Nogueira (2008) monitorou a atividade dos microrganismos da camada $0-5 \mathrm{~cm}$ durante 2,5 anos por meio da respiração heterotrófica, do quociente metabólico e do grau de saturação de água no solo. Os resultados mostraram variações sazonais dos três parâmetros, sendo as variações do grau de saturação de água no solo aquelas que apresentaram as maiores diferenças entre os tratamentos. Os resultados obtidos, no entanto, não permitiram concluir que as variações da atividade microbiológica foram suficientes para explicar as diferenças observadas entre os tratamentos. Os processos de mineralização poderiam ter sido temporariamente compensados pelos processos de maior estabilização do C nos microagregados, decorrente da decomposição de raízes mortas (TRUJILLO et al., 2006) ou da maior liberação de exsudatos pelas raízes (KASTOVSKA; SANDRUCKOVA, 2007). Em experimentos com gramíneas perenes, Hütsch et al. (2002) determinaram que até $20 \%$ do C fixado fotossinteticamente são exsudatos das raízes para o solo durante a fase vegetativa. 
As Tabelas 4.12, 4.13 e 4.14 e as Figuras 4.14, 4.15 e 4.16 apresentam a comparação dos valores de IH do solo de cada tratamento para as diferentes épocas de amostragem.

Tabela 4.12 - Índices de humificação (IH) para as amostras de solos coletadas em junho 2007 para os tratamentos Si e E66.

\begin{tabular}{cccccccc}
\hline camada $(\mathrm{cm})$ & $0-5$ & $5-10$ & $10-20$ & $20-40$ & $40-60$ & $60-80$ & $80-100$ \\
\hline \multicolumn{7}{c}{ IH } \\
\hline SI $^{(1)}$ & $11327,3^{\mathrm{a}}$ & $13622,1^{\mathrm{b}}$ & $14735,0^{\mathrm{c}}$ & $16157,2^{\mathrm{d}}$ & $20517,0^{\mathrm{e}}$ & $27352,5^{\mathrm{f}}$ & $35024,6^{\mathrm{g}}$ \\
E66 & $11010,0^{\mathrm{a}}$ & $15914,5^{\mathrm{b}}$ & $16989,0^{\mathrm{c}}$ & $19052,7^{\mathrm{d}}$ & $21518,3^{\mathrm{e}}$ & $29124,2^{\mathrm{f}}$ & $34860,2^{\mathrm{g}}$ \\
\hline
\end{tabular}

(1)Tratamentos. SI: sem irrigação e sem fertilização; E66 - irrigação com EETE e adubação de 343 kg ha-1 ano1 de nitrato de amônio, $416 \mathrm{~kg} \mathrm{ha}^{-1}$ ano $^{-1}$ de $\mathrm{K}_{2} \mathrm{O}$ e $140 \mathrm{~kg} \mathrm{ha}^{-1}$ ano $^{-1} \mathrm{P}_{2} \mathrm{O}_{5}$; SI (controle) - ausência de irrigação e de adubação. Letras iguais nas colunas não diferem estatisticamente pelo teste de Tukey $(\mathrm{P}<0,05)$.

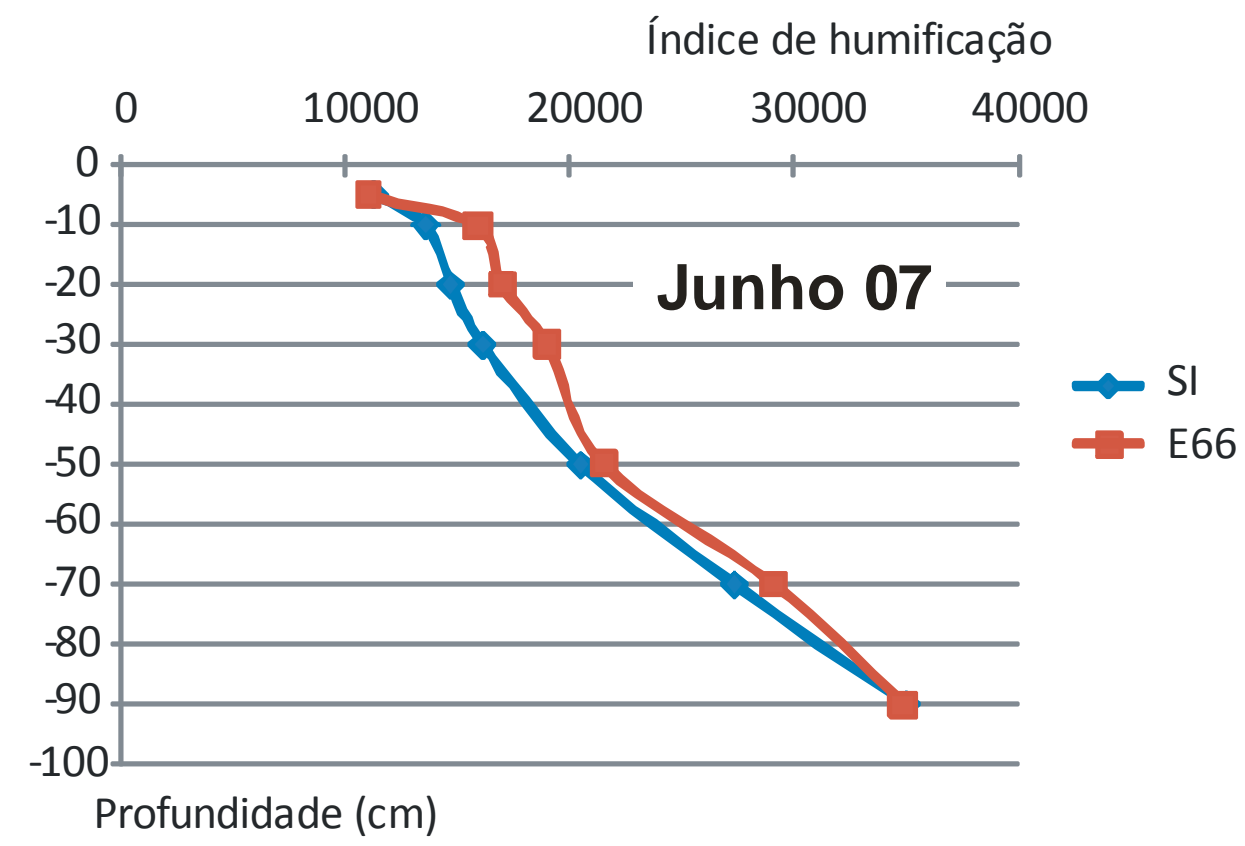

Figura 4.14 - Comparação dos índices de humificação (IH) entre os tratamentos Si e E66 (Junho de 2007, solo total). SI: sem irrigação e sem fertilização; E66 - irrigação com EETE e adubação de $343 \mathrm{~kg} \mathrm{ha}^{-1}$ ano $^{-1}$ de nitrato de amônio, $416 \mathrm{~kg} \mathrm{ha}^{-1}$ $\mathrm{ano}^{-1}$ de $\mathrm{K}_{2} \mathrm{O}$ e $140 \mathrm{~kg} \mathrm{ha}^{-1} \mathrm{ano}^{-1} \mathrm{P}_{2} \mathrm{O}_{5}$.

Tabela 4.13 - Índices de humificação (IH) para as amostras de solos coletadas em maio 2009 para os tratamentos Si, E66 e W100.

\begin{tabular}{cccccccc}
\hline camada $(\mathrm{cm})$ & $0-5$ & $5-10$ & $10-20$ & $20-40$ & $40-60$ & $60-80$ & $80-100$ \\
\hline \multicolumn{7}{c}{ IH } \\
\hline SI & $10097,1^{(1)}$ & $12787,4^{\mathrm{a}}$ & $13981,3^{\mathrm{g}}$ & 14209,5 & & $22967,8^{\mathrm{b}}$ & $26065,7^{\mathrm{c}}$ \\
$\mathrm{E} 66$ & $6637,1^{\mathrm{d}}$ & $10422,7^{\text {ae }}$ & $11038,0^{\mathrm{f}}$ & & 18414,2 & $24065,7^{\mathrm{b}}$ & $25286,4^{\mathrm{c}}$ \\
$\mathrm{W} 100$ & $6390,1^{\text {d }}$ & $10007,5^{\mathrm{e}}$ & $12823,3^{\mathrm{fg}}$ & & 19392,9 & $22791,5^{\mathrm{b}}$ & $26176,3^{\mathrm{c}}$ \\
\hline
\end{tabular}

(1)Tratamentos. SI: sem irrigação e sem fertilização; E66 - irrigação com EETE e adubação de $343 \mathrm{~kg} \mathrm{ha}^{-1} \mathrm{ano}^{-1}$ de nitrato de amônio, $416 \mathrm{~kg} \mathrm{ha}^{-1}$ ano $^{-1}$ de $\mathrm{K}_{2} \mathrm{O}$ e $140 \mathrm{~kg} \mathrm{ha}^{-1}$ ano ${ }^{-1} \mathrm{P}_{2} \mathrm{O}_{5}$; W100: irrigação com água potável e adição de $520 \mathrm{~kg} \mathrm{ha}^{-1}$ ano $^{-1}$ de nitrogênio via nitrato de amônio, $416 \mathrm{~kg} \mathrm{ha}^{-1}$ ano $^{-1}$ de $\mathrm{K}_{2} \mathrm{O}$ e $140 \mathrm{~kg} \mathrm{ha}^{-1} \mathrm{ano}^{-1}$ $\mathrm{P}_{2} \mathrm{O}_{5}$. Letras iguais nas colunas não diferem estatisticamente pelo teste de Tukey $(\mathrm{P}<0,05)$. 
$\mathrm{IH}$

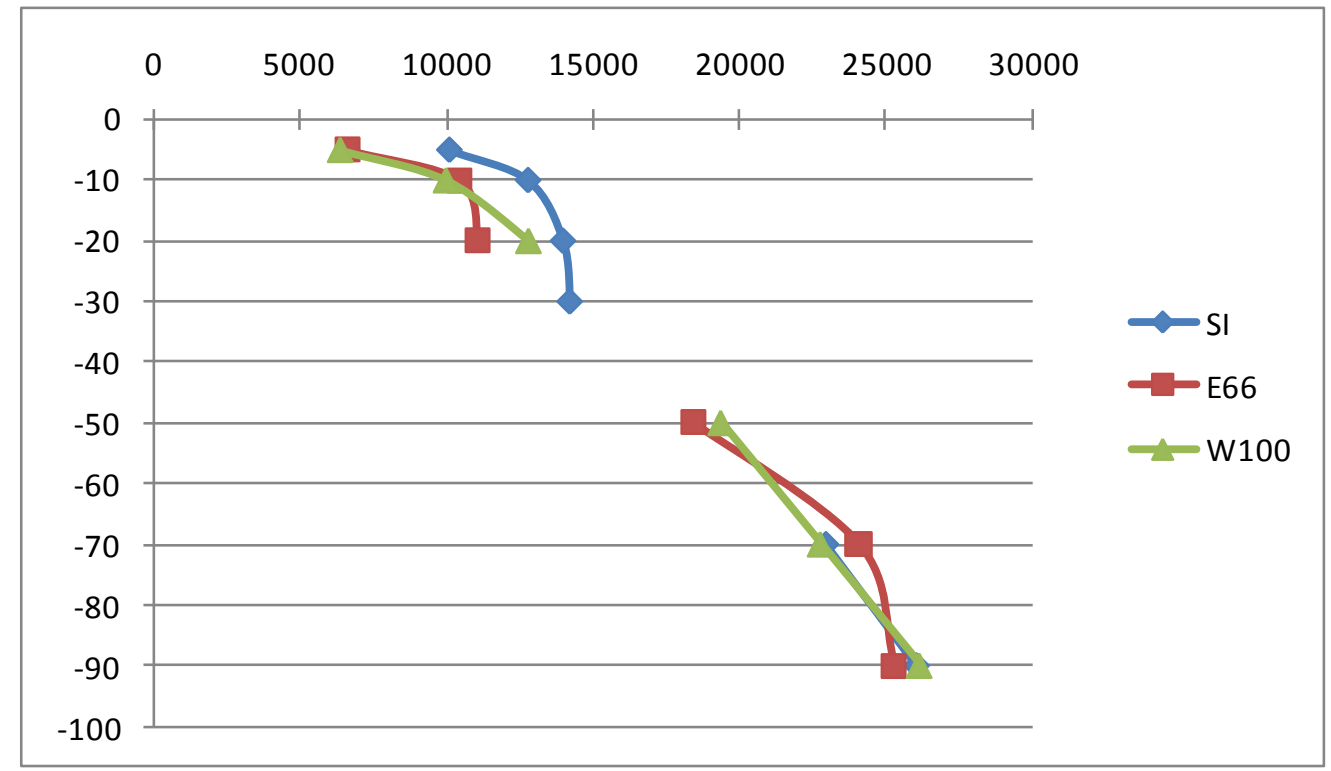

Profundidade $(\mathrm{cm})$

Figura 4.15 - Comparação dos índices de humificação (IH) entre os tratamentos Si, E66 e W100 (Maio de 2009; solo total). SI: sem irrigação e sem fertilização; E66 irrigação com EETE e adubação de $343 \mathrm{~kg} \mathrm{ha}^{-1}$ ano $^{-1}$ de nitrato de amônio, 416 $\mathrm{kg} \mathrm{ha}^{-1}$ ano $^{-1}$ de $\mathrm{K}_{2} \mathrm{O}$ e $140 \mathrm{~kg} \mathrm{ha}{ }^{-1}$ ano $^{-1} \mathrm{P}_{2} \mathrm{O}_{5}$; W100: irrigação com água potável e adição de $520 \mathrm{~kg} \mathrm{ha}^{-1}$ ano $^{-1}$ de nitrogênio via nitrato de amônio, 416 $\mathrm{kg} \mathrm{ha}^{-1} \mathrm{ano}^{-1}$ de $\mathrm{K}_{2} \mathrm{O}$ e $140 \mathrm{~kg} \mathrm{ha}^{-1}$ ano $^{-1} \mathrm{P}_{2} \mathrm{O}_{5}$.

Tabela 4.14 - Índices de humificação (IH) para as amostras de solos coletadas em de junho 2009 para os tratamentos Si, E66 e W100.

\begin{tabular}{|c|c|c|c|c|c|c|c|}
\hline camada $(\mathrm{cm})$ & $0-5$ & $5-10$ & $10-20$ & $20-40$ & $40-60$ & $60-80$ & $80-100$ \\
\hline \multicolumn{8}{|c|}{$\mathrm{IH}$} \\
\hline $\mathrm{SI}^{(1)}$ & $9727,5^{\mathrm{a}}$ & $11219,2^{b}$ & 13841,4 & 22729,2 & 20091,6 & 25751,6 & $31773,4^{\mathrm{g}}$ \\
\hline E66 & $6766,8^{\mathrm{a}}$ & $9943,3^{\mathrm{b}}$ & $20506,3^{\mathrm{c}}$ & $18718,1^{\mathrm{d}}$ & $23965,1^{\mathrm{e}}$ & $29953,6^{f}$ & $33614,3^{\mathrm{g}}$ \\
\hline W100 & $8261,3^{\mathrm{a}}$ & $12392,1^{\mathrm{b}}$ & $17315,0^{\mathrm{c}}$ & $19079,6^{\mathrm{d}}$ & $23420,5^{\mathrm{e}}$ & $28425,7^{f}$ & 37506,1 \\
\hline
\end{tabular}

(1)Tratamentos. SI: sem irrigação e sem fertilização; E66 - irrigação com EETE e adubação de $343 \mathrm{~kg} \mathrm{ha}^{-1}$ ano $^{-1}$ de nitrato de amônio, $416 \mathrm{~kg} \mathrm{ha}^{-1}$ ano ${ }^{-1}$ de $\mathrm{K}_{2} \mathrm{O}$ e $140 \mathrm{~kg} \mathrm{ha}^{-1}$ ano $^{-1} \mathrm{P}_{2} \mathrm{O}_{5}$; W100: irrigação com água potável e adição de $520 \mathrm{~kg} \mathrm{ha}^{-1}$ ano $^{-1}$ de nitrogênio via nitrato de amônio, $416 \mathrm{~kg} \mathrm{ha}^{-1}$ ano $^{-1} \mathrm{de} \mathrm{K}_{2} \mathrm{O}$ e $140 \mathrm{~kg} \mathrm{ha}^{-1}$ ano $^{-1}$ $\mathrm{P}_{2} \mathrm{O}_{5}$; $\mathrm{SI}$ (controle) - ausência de irrigação e de adubação. Letras iguais nas colunas não diferem estatisticamente pelo teste de Tukey $(\mathrm{P}<0,05)$. 
$\mathrm{IH}$

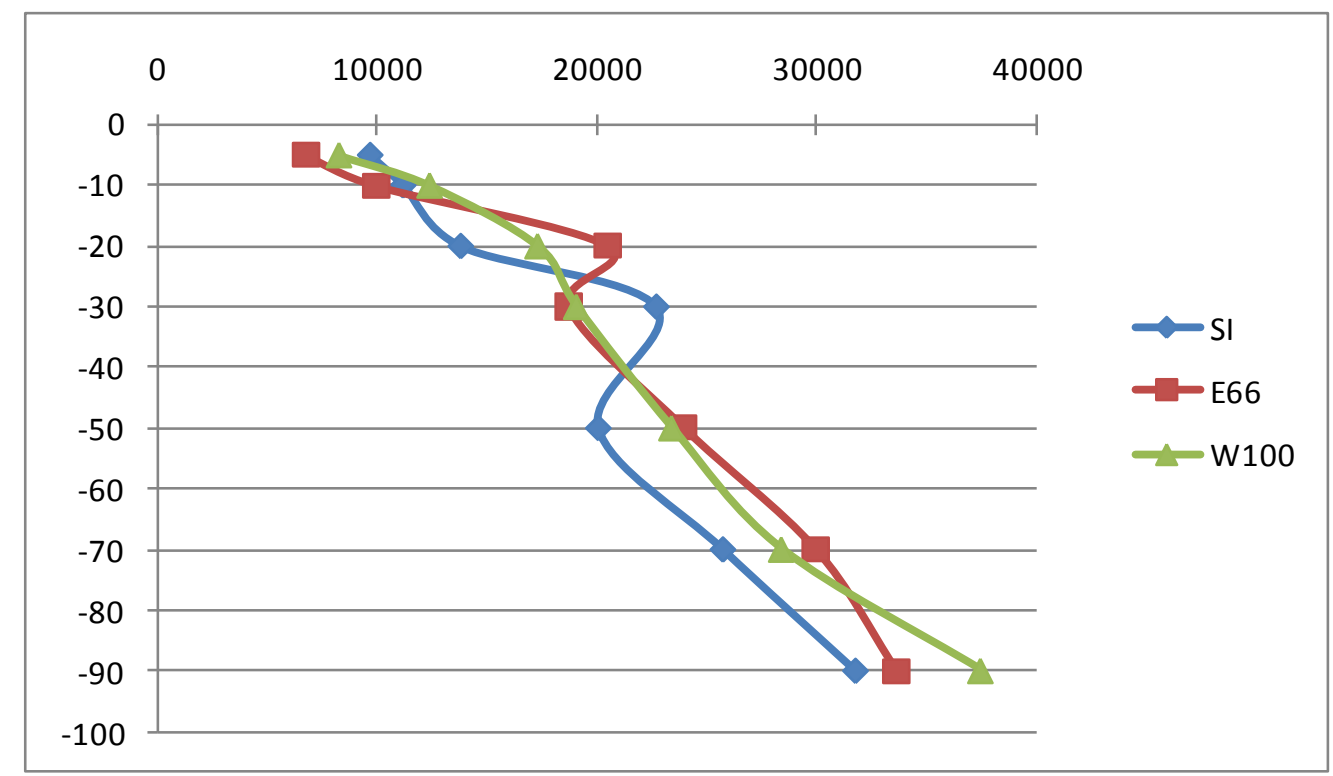

Profundidade $(\mathrm{cm})$

Figura 4.16 - Comparação dos índices de humificação $(\mathrm{IH})$ entre os tratamentos Si, E66 e W100 (Junho de 2009, solo total).. SI: sem irrigação e sem fertilização; E66 irrigação com EETE e adubação de $343 \mathrm{~kg} \mathrm{ha}^{-1}$ ano $^{-1}$ de nitrato de amônio, 416 $\mathrm{kg} \mathrm{ha}^{-1}$ ano $^{-1}$ de $\mathrm{K}_{2} \mathrm{O}$ e $140 \mathrm{~kg} \mathrm{ha}^{-1}$ ano $^{-1} \mathrm{P}_{2} \mathrm{O}_{5}$; W100: irrigação com água potável e adição de $520 \mathrm{~kg} \mathrm{ha}^{-1}$ ano $^{-1}$ de nitrogênio via nitrato de amônio, 416 $\mathrm{kg} \mathrm{ha}^{-1} \mathrm{ano}^{-1}$ de $\mathrm{K}_{2} \mathrm{O}$ e $140 \mathrm{~kg} \mathrm{ha}^{-1} \mathrm{ano}^{-1} \mathrm{P}_{2} \mathrm{O}_{5}$.

Como já foi observado, os valores de IH da primeira coleta foram estatisticamente idênticos (Tabela 4.12). Na coleta de maio de 2009, os valores de IH dos solos irrigados foram estatisticamente iguais e para as camadas 60-80 e 80-100 não foram observadas diferenças significativas para as amostras de solos dos três tratamentos. Os valores de IH dos solos amostrados em junho de 2009 são estatisticamente iguais para todas as camadas dos solos dos tratamentos W100 e E66, exceto para a última. Os valores de IH das duas primeiras camadas são estatisticamente idênticos para todos os tratamentos.

Verifica-se, portanto, que a irrigação com efluente ou com água, não alterou de maneira significativa os IH medidos a partir do solo total. Ressalta-se, no entanto, que ocorreram diferenças significativas nos valores de IH para as amostras de solo da fração d>2 do tratamento E66 quando comparado ao solo do SI (Tabela 4.8; Figura 4.10), não refletindo, entretanto, nos valores de IH do solo total. 


\subsubsection{Relações entre o IH e a composição isotópica do carbono}

A Figura 4.17 mostra a comparação entre os resultados de IH e a composição isotópica do carbono $\left(\delta^{13} \mathrm{C}\right)$ dos extratos obtidos para as amostras de solos totais e para as frações $\mathrm{d}>2$ dos tratamentos SI e E66.

Com exceção da camada 80-100 cm de ambos os solos e da fração d> 2 do solo E66, os resultados do $\mathrm{IH}$ e do $\delta^{13} \mathrm{C}$ apresentaram uma boa correlação. $\mathrm{O} \delta^{13} \mathrm{C}$ torna-se mais negativo com o aumento do índice de humificação. Esta variação é coerente com a hipótese. já mencionada, na qual os microrganismos tendem a consumir e mineralizar uma MOS de $\delta^{13} \mathrm{C}$ menos negativa (WERTH; KUZYAKOV, 2010).

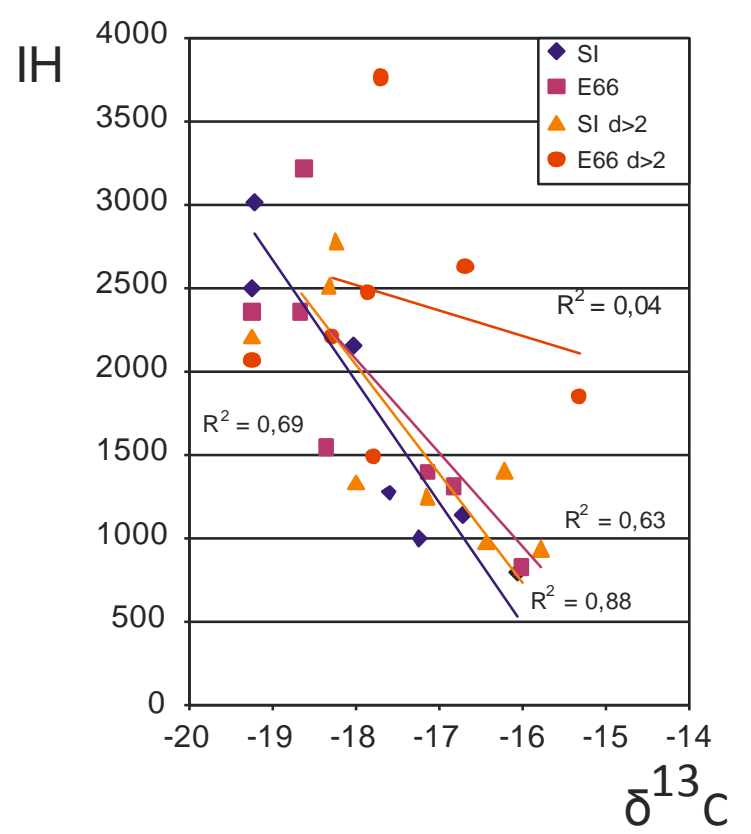

Figura 4.17 - Comparação entre o índeice de humificação (IH) determinado por fluorescência induzida por laser (LIF) e a composição isotópica $\left(\delta^{13} \mathrm{C}\right)$. d: densidade. SI: sem irrigação e sem fertilização; E66 - irrigação com EETE e adubação de $343 \mathrm{~kg} \mathrm{ha}^{-1}$ ano $^{-1}$ de nitrato de amônio, $416 \mathrm{~kg} \mathrm{ha}^{-1} \mathrm{ano}^{-1}$ de $\mathrm{K}_{2} \mathrm{O}$ e $140 \mathrm{~kg} \mathrm{ha}^{-1}$ ano $^{-1} \mathrm{P}_{2} \mathrm{O}_{5}$. 


\subsection{Fluorescência tridimensional (3D)}

\subsubsection{Fluorescência 3D dos extratos de solo total}

O tratamento dos espectros tridimensionais de fluorescência dos extratos de solos foram analisados com o emprego do PARAFAC. Para efetuar a comparação, a contribuição da intensidade de cada componente $\mathrm{c}_{\mathrm{i}}$ foi dividida pelos teores de carbono total da amostra, determinando-se assim o índice "c $c_{i} /$ COT". Foram identificadas três componentes. A componente 1, com comprimentos de onda de excitação de 250 nm e de emissão de 375 nm, corresponde as componentes tipo proteína. A componente $2(260 / 450 \mathrm{~nm})$ é típica das componentes do tipo A identificadas por Coble (1996) e associadas aos ácidos fúlvicos. A componente $3(350 / 450 \mathrm{~nm})$ corresponde a componente C de Coble (1996) e é usualmente associado às substâncias húmicas.

Os resultados mostraram a predominância da componente 2 de caráter fúlvico nos extratos de ambos os solos e em todas as profundidades (Figura. 4.18). As feições da componente 1 de caráter proteico no solo do tratamento E66 mostram uma relativa estabilidade até $40 \mathrm{~cm}$, um aumento ao redor de 40-80 cm e em seguida observa-se uma diminuição. O solo tratamento SI apresenta feições da componente 1 muito parecidas, com exceção de valores mais baixos nas camadas superiores, 0-5 e 5-10 cm. Sendo a componente 1 característica da atividade microbiana na época da amostragem, esses dados mostram uma fraca atividade nas camadas superiores do solo do tratamento SI, devido, provavelmente, ao baixo grau de umidade destas camadas não irrigadas. Em ambos os solos, o máximo da componente 1 observado de 40 a $80 \mathrm{~cm}$ de profundidade, pode estar relacionado ao máximo de atividade microbiana na época da amostragem. Uma outra hipótese seria que a matéria orgânica pouca humificada oriunda da atividade microbiana é mais facilmente extraída e, portanto, mais facilmente lixiviada das camadas superficias, se acumulando em profundidade média. 
A componente 2 de caráter fúlvico mostrou variações mais aleatórias com a profundidade em ambos os solos. A componente 3, de caráter húmico, apresentou valores mais elevados no solo E66 nas profundidades de 0 a $40 \mathrm{~cm}$ em comparação ao solo SI. A partir de $40 \mathrm{~cm}$ os os resultados foram semelhantes em ambos os solos.

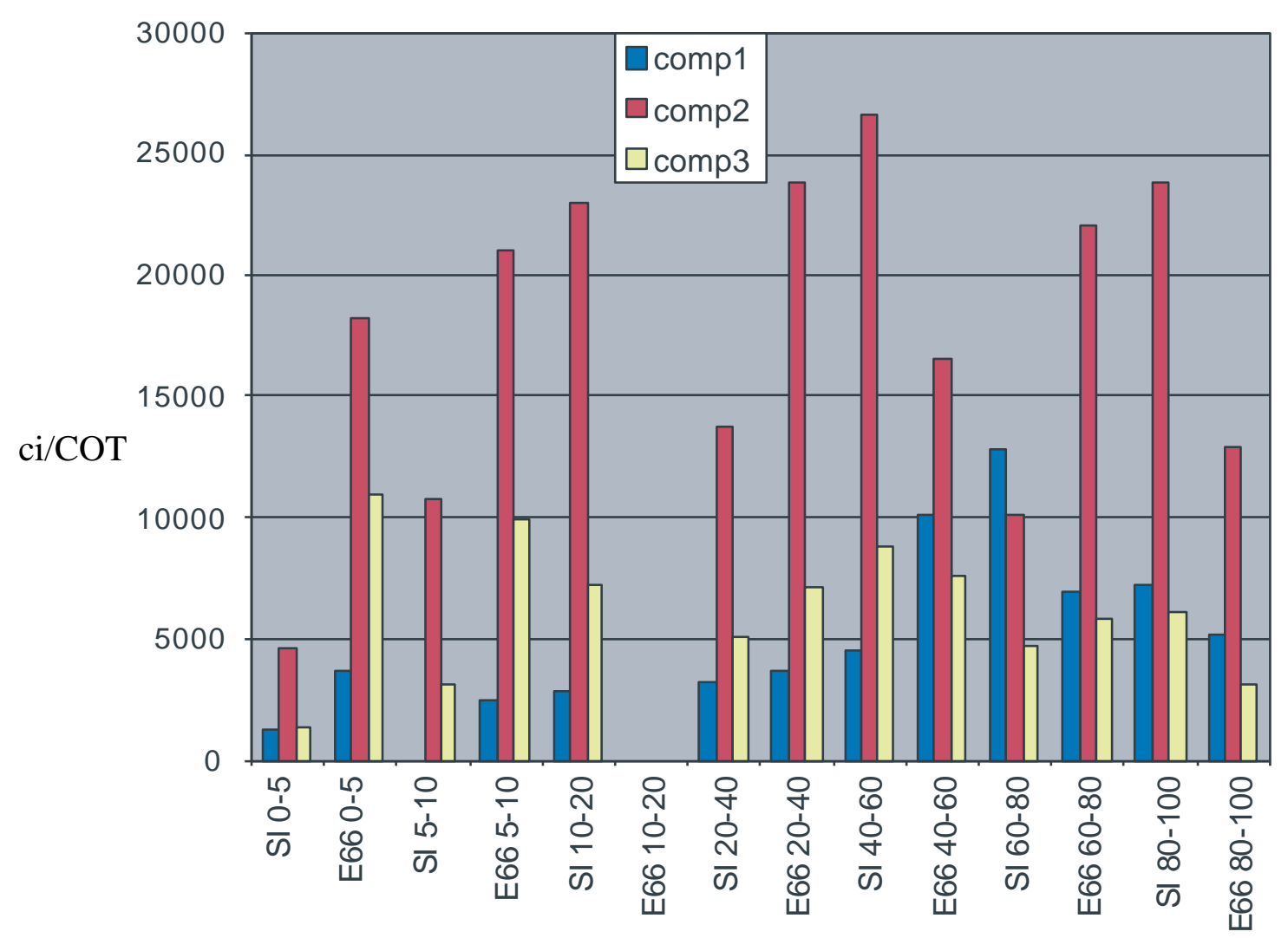

Figura 4.18 - Índice ci /COT dos componentes 1, 2 e 3 dos extratos de solo total (Junho de 2007). comp: componente. SI: sem irrigação e sem fertilização; E66 - irrigação com EETE e adubação de $343 \mathrm{~kg} \mathrm{ha}^{-1}$ ano $^{-1}$ de nitrato de amônio, $416 \mathrm{~kg} \mathrm{ha}^{-1}$ ano $^{-1}$ de $\mathrm{K}_{2} \mathrm{O}$ e $140 \mathrm{~kg} \mathrm{ha}^{-1}$ ano $^{-1} \mathrm{P}_{2} \mathrm{O}_{5}$. Eixo X: representa a profundidade das diferentes camadas de solos em $\mathrm{cm}$.

Na Figura 4.19 são apresentadas as intensidades de fluorescência das três componentes, no intuito de dar uma idéia da quantidade total de fluoróforos nos extratos e da quantidade de fluoróforos das componentes 2 e 3 correspondentes às substâncias fúlvicas e húmicas. 


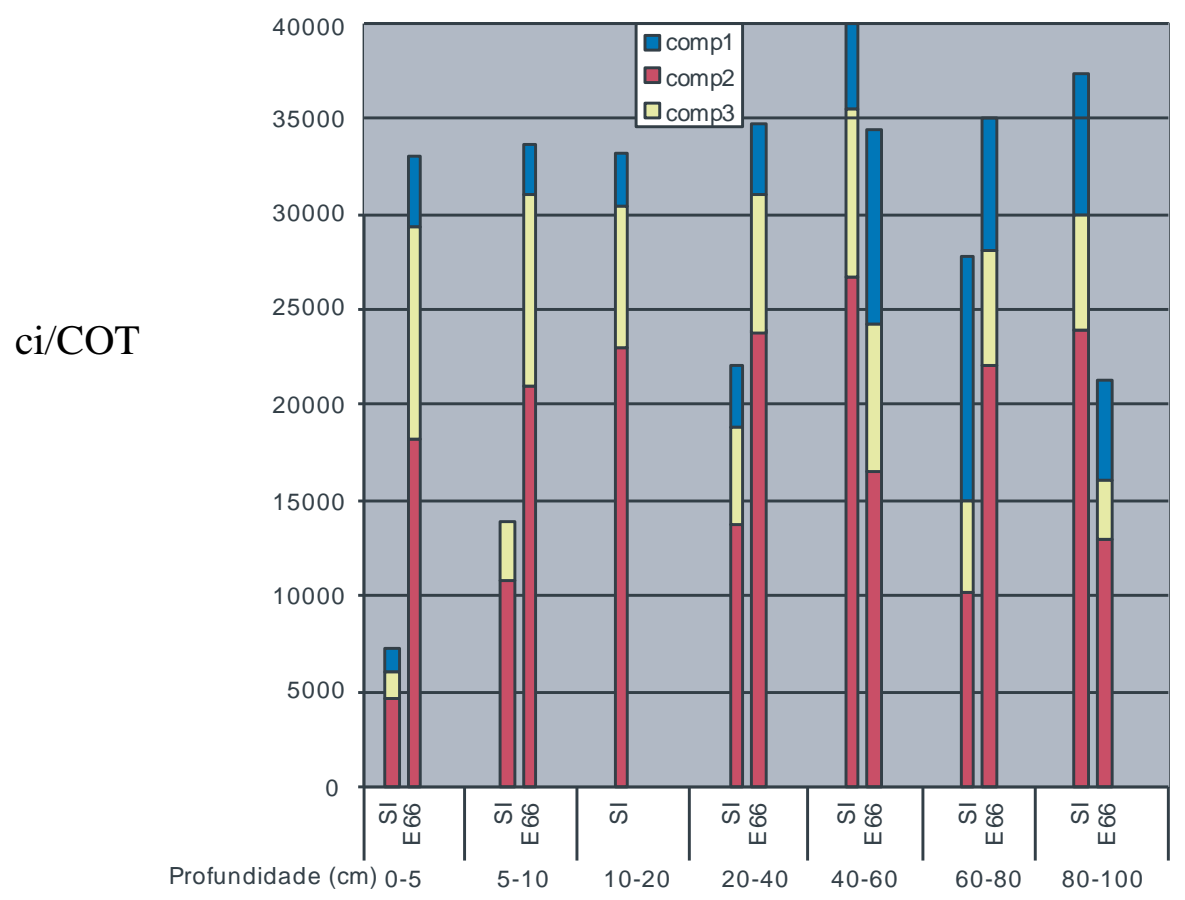

Figura 4.19 - Contribuições à fluorescência ci /COT das componentes 1, 2 e 3 dos extratos de MOS (Junho de 2007). comp: componente. SI: sem irrigação e sem fertilização; E66 - irrigação com EETE e adubação de $343 \mathrm{~kg} \mathrm{ha}^{-1} \mathrm{ano}^{-1} \mathrm{de}$ nitrato de amônio, $416 \mathrm{~kg} \mathrm{ha}^{-1} \mathrm{ano}^{-1}$ de $\mathrm{K}_{2} \mathrm{O}$ e $140 \mathrm{~kg} \mathrm{ha}^{-1} \mathrm{ano}^{-1} \mathrm{P}_{2} \mathrm{O}_{5}$.

Observa-se que a fluorescência total é, sobretudo, controlada pelas substâncias fúlvicas e húmicas. A fluorescência apresentou-se relativamente estável da superfície até 80 cm de profundidade no solo E66, e diminuiu em 80-100 cm. No solo SI apresentou-se mais baixa nas camadas superiores e com maiores variações em profundidade. Estas diferenças podem resultar das variações de umidade e de fluxo de soluções na coluna de solo.

Relacionando a contribuição $c_{2}$ à intensidade Ia relativa aos compostos de tipo fúlvico, e a contribuição $c_{3}$ à intensidade Ic relativa aos compostos de tipo húmico, pode-se considerar a razão $\mathrm{Ia} / \mathrm{Ic}=\mathrm{c}_{2} / \mathrm{c}_{3}$ como representativa da razão fúlvico/húmico. A razão Ia/Ic dos extratos dos solos mostrou uma relativa estabilidade com a profundidade no solo SI, e um aumento no solo irrigado E66 (Figura 4.20). As duas curvas, porém, apresentam variações importantes na faixa $30-70 \mathrm{~cm}$. Sendo o Ia teoricamente relacionado às substâncias fúlvicas e o Ic às substâncias húmicas, esperava-se uma diminuição da razão Ia/Ic com a profundidade, bem como um aumento da quantidade total de fluoróforos, o que seria coerente com as variações 
do índice de humificação, este aumentando progressivamente com a profundidade (ver figura 4.8). Entretanto, a diminuição da razão Ia/Ic com a profundidade foi verificada somente no solo SI, exceto para o ponto mais profundo $(80-100 \mathrm{~cm})$, e o contrário foi observado para o solo E66 (Figura 4.21).

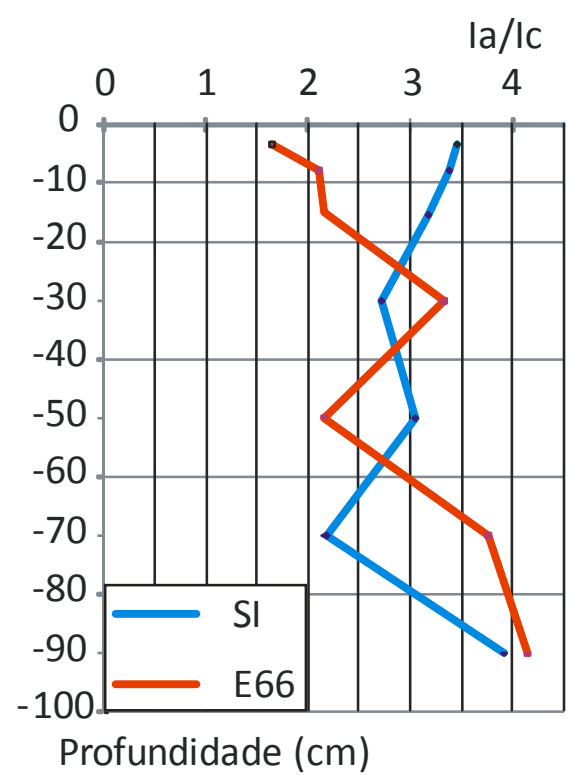

Figura 4.20 - Razão Ia/Ic (intensidade relativa aos compostos de tipo fúlvico/intensidade relativa aos compostos de tipo húmico) dos extratos de solo total (Junho de 2007). SI: sem irrigação e sem fertilização; E66 - irrigação com EETE e adubação de $343 \mathrm{~kg} \mathrm{ha}^{-1}$ ano $^{-1}$ de nitrato de amônio, $416 \mathrm{~kg} \mathrm{ha}^{-1}$ ano $^{-1}$ de $\mathrm{K}_{2} \mathrm{O}$ e $140 \mathrm{~kg} \mathrm{ha}^{-1} \mathrm{ano}^{-1} \mathrm{P}_{2} \mathrm{O}_{5}$.

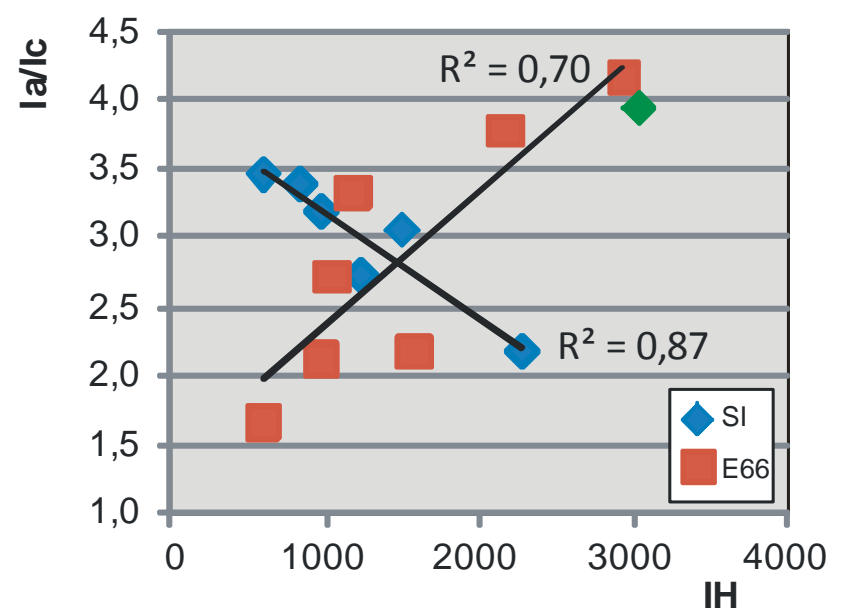

Figura 4.21 - Comparação da razão Ia/Ic (intensidade relativa aos compostos de tipo fúlvico/intensidade relativa aos compostos de tipo húmico) dos extratos de solo total (Junho de 2007) e do IH (índice de humificação) do solo total. SI: sem irrigação e sem fertilização; E66 - irrigação com EETE e adubação de $343 \mathrm{~kg}$ $\mathrm{ha}^{-1}$ ano $^{-1}$ de nitrato de amônio, $416 \mathrm{~kg} \mathrm{ha}^{-1}$ ano $^{-1}$ de $\mathrm{K}_{2} \mathrm{O}$ e $140 \mathrm{~kg} \mathrm{ha}^{-1}$ ano $^{-1}$ $\mathrm{P}_{2} \mathrm{O}_{5}$. O ponto de cor verde pertence ao conjunto do solo SI e não foi considerado no cálculo da correlação. 
Uma provável explicação seria que a extração da MOS mais humificada das camadas mais profundas não foi completa, uma vez que tal matéria orgânica, como já ressaltado por Stevenson (1994), é de difícil extração. Se a fração mais humificada, mais condensada, sofreu uma extração incompleta, o extrato apresentaria um grau de humificação inferior ao real.

Entretanto, não se pode descartar, a dificuldade de relacionar nos espectros de fluorescência as componentes 2 e 3 com os picos de tipo A e de tipo C, bem como a relação entre os picos de tipo A e de tipo $\mathrm{C}$ com a abundância relativa de compostos fúlvicos e húmicos. As bases da interpretação usual referem-se aos estudos relacionados, sobretudo, à matérias orgânicas dissolvidas em águas naturais ou à extratos aquosos de MOS (ZSOLNAY et al., 1999). A relação com as propriedades de matérias orgânicas extraídas dos solos por extração alcalina é ainda pouco estudada (SIERRA et al, 2005).

\subsubsection{Fluorescência 3D das frações densimétricas}

Os valores obtidos para cada componente de fluorescência das frações densimétricas são apresentados nas Figures 4.22 a 4.24 .

A componente 1 (Figura 4.22 apresenta uma contribuição à fluorescência inferior em média de 2 e 4 vezes em relação às das componentes 3 e 2 (Figuras 4.23 e 4.24), respectivamente. A fração $d>2$ tem a maior intensidade de fluorescência, com variações com a profundidade similares nos solos dos tratamentos SI e E66, a saber: valores médios de 0 a 10 cm, mínimos de 10 a $40 \mathrm{~cm}$ e aumentando com a profundidade para atingir os valores máximos entre $80-100 \mathrm{~cm}$. A soma das frações $\mathrm{d}>2$ e $1,8<\mathrm{d}<2$ segue o mesmo padrão. As frações $1,6<\mathrm{d}<1,8$ e 1,6 occ apresentaram valores insignificantes, exceto nos extratos de E66 5-10 e 10-20. A fração 1,6 livre está sempre presente com valores baixos, exceto nos extratos de E66 10-20, SI 20-40 e SI 60-80. 


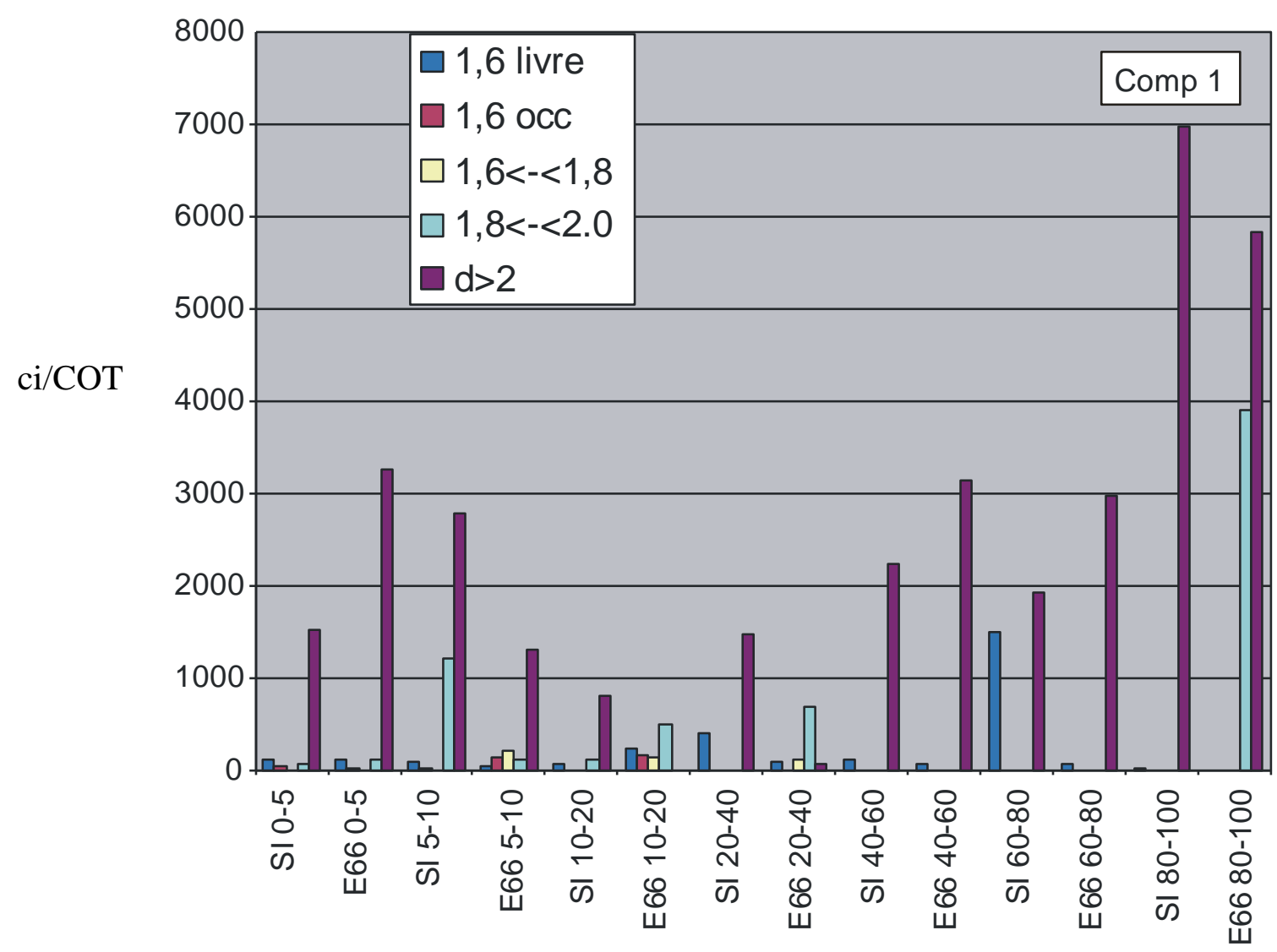

Figura 4.22 - Índice ci /COT da componente 1 dos extratos de solo das frações densimétricas separadas (Junho de 2007). comp: componente; d: densidade; livre: matéria orgânica livre da fração mineral não decomposta ou pouca descomposta; occ: matéria orgânica intra-agregados. SI: sem irrigação e sem fertilização; E66 irrigação com EETE e adubação de $343 \mathrm{~kg} \mathrm{ha}^{-1}$ ano $^{-1}$ de nitrato de amônio, 416 $\mathrm{kg} \mathrm{ha}{ }^{-1}$ ano $^{-1}$ de $\mathrm{K}_{2} \mathrm{O}$ e $140 \mathrm{~kg} \mathrm{ha}^{-1}$ ano $^{-1} \mathrm{P}_{2} \mathrm{O}_{5}$. Eixo $\mathrm{X}$ : representa a profundidade das diferentes camadas de solos em $\mathrm{cm}$.

As componentes 2 e 3 (Figuras 4.23 e 4.24) apresentaram variações relativas muito semelhantes às da componente 1 . As maiores diferenças foram observadas nas variações das contribuições da fração $d>2$. Para a componente 2 foram observadas no perfil SI, contribuições menores nas camadas mais superficiais e aumento progressivo com a profundidade e no perfil E66, verificou-se contribuições mais elevadas nos níveis superficiais e diminuição com a profundidade. Para a componente 3 os valores foram elevados tanto em superfície como em profundidade. As variações das componentes 2 e 3 da fração d>2 são coerentes com aquelas do índice de humificação da fração d>2 da MOS dos solos dos tratamentos SI e E66 (Figura 4.10). Embora a matéria orgânica mais humificada, segundo 
Roscoe et al. (2001), encontra-se na fração 1,6 occ, esta fração não apresentou elevadas contribuições de fluorescência $c_{i} / C O T$, provavelmente porque esta matéria orgânica é de mais difícil extração (STEVENSON, 1994).

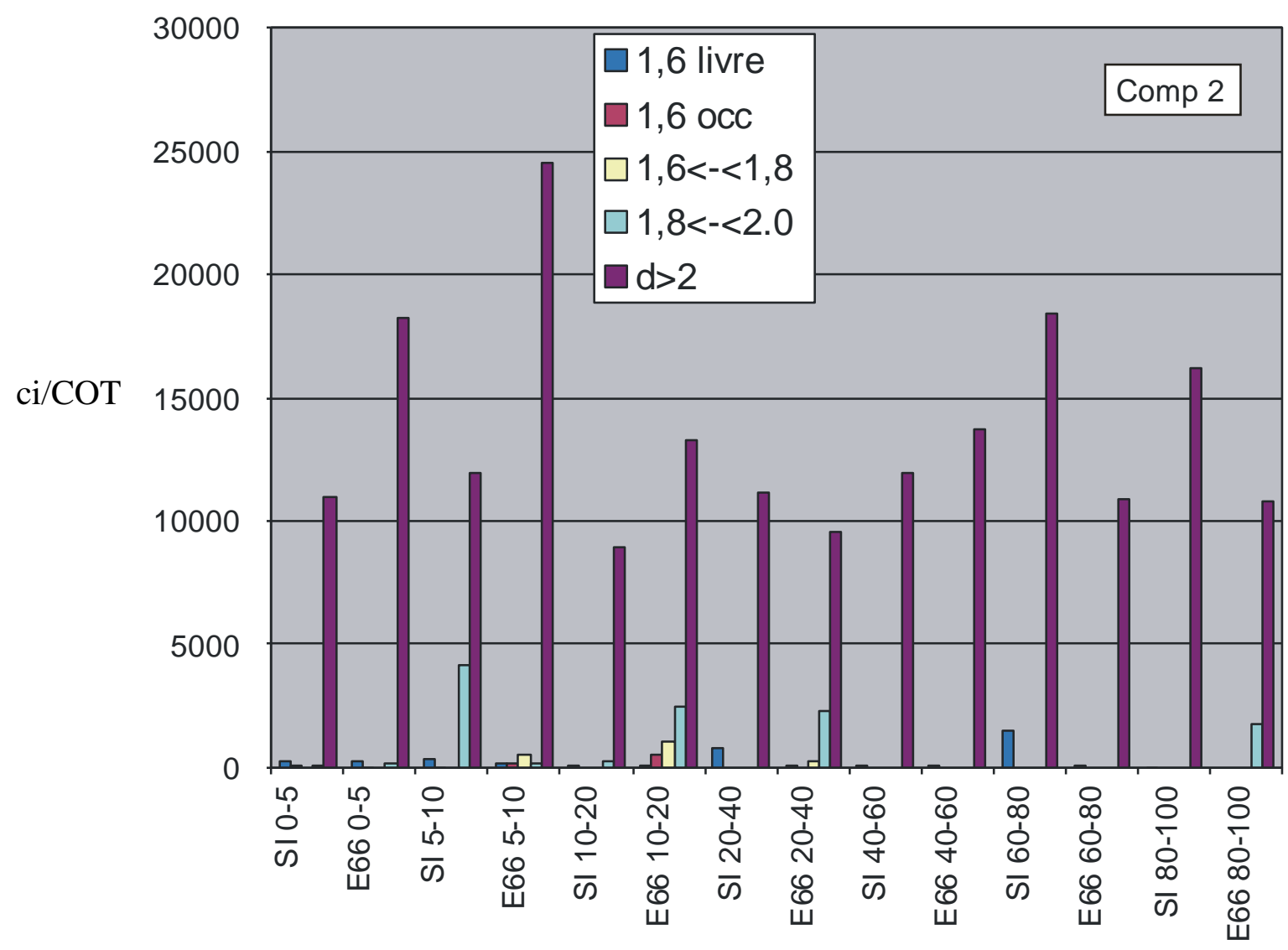

Figura 4.23 - Índice ci /COT da componente 2 dos extratos de solo das frações densimétricas separadas (Junho de 2007). comp: componente; d: densidade; livre: matéria orgânica livre da fração mineral não decomposta ou pouca descomposta; occ: matéria orgânica intra-agregados. SI: sem irrigação e sem fertilização; E66 irrigação com EETE e adubação de $343 \mathrm{~kg} \mathrm{ha}^{-1}$ ano ${ }^{-1}$ de nitrato de amônio, 416 $\mathrm{kg} \mathrm{ha}$ ano $^{-1}$ de $\mathrm{K}_{2} \mathrm{O}$ e $140 \mathrm{~kg} \mathrm{ha}^{-1} \mathrm{ano}^{-1} \mathrm{P}_{2} \mathrm{O}_{5}$. Eixo $\mathrm{X}$ : representa a profundidade das diferentes camadas de solos em $\mathrm{cm}$. 


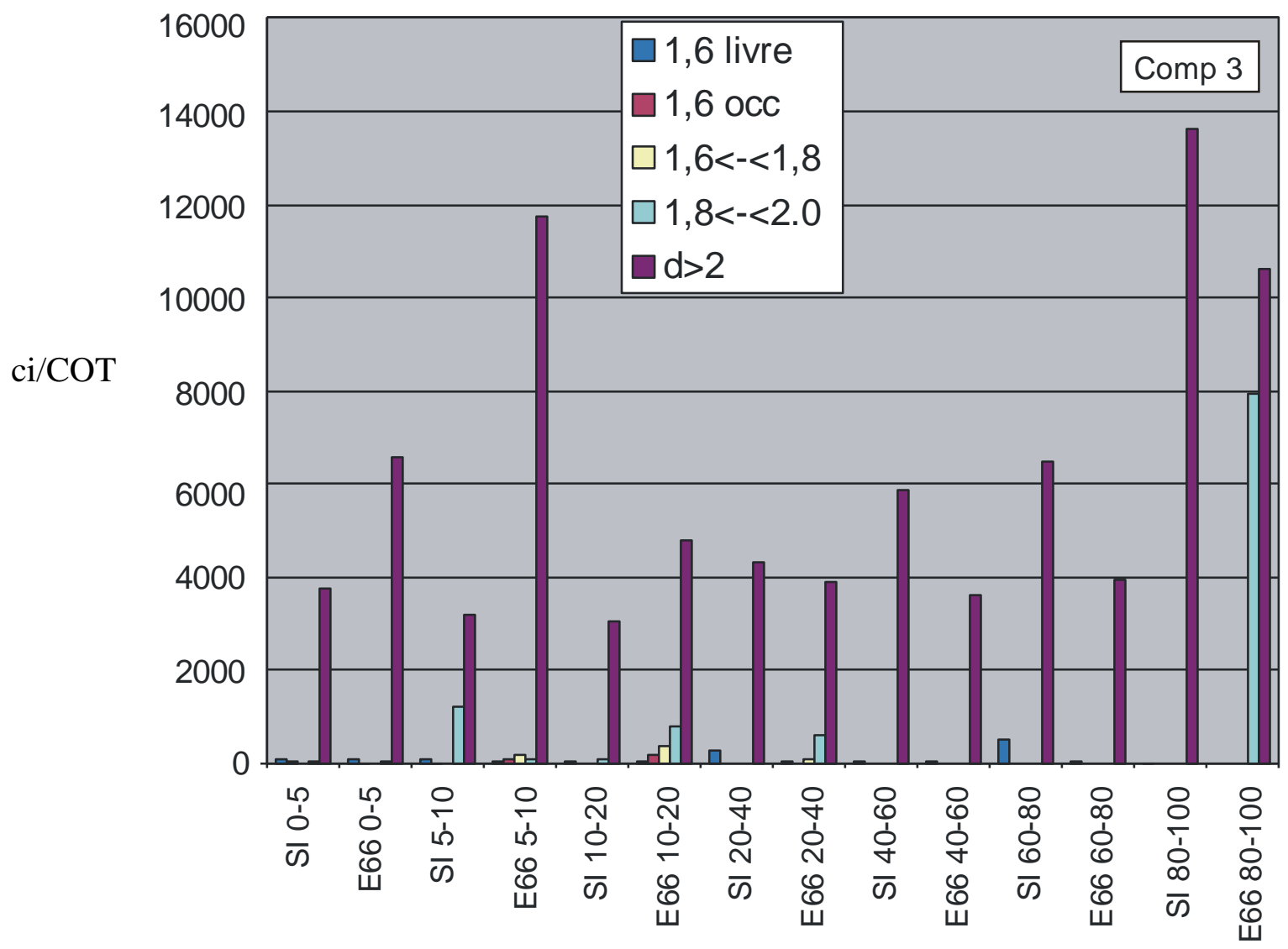

Figura 4.24 - Índice ci /COT da componente 3 dos extratos de solo das frações densimétricas separadas (Junho de 2007). comp: componente; d: densidade; livre: matéria orgânica livre da fração mineral não decomposta ou pouca descomposta; occ: matéria orgânica intra-agregados. SI: sem irrigação e sem fertilização; E66 irrigação com EETE e adubação de $343 \mathrm{~kg} \mathrm{ha}^{-1}$ ano ${ }^{-1}$ de nitrato de amônio, 416 $\mathrm{kg} \mathrm{ha}$ ano $^{-1}$ de $\mathrm{K}_{2} \mathrm{O}$ e $140 \mathrm{~kg} \mathrm{ha}^{-1}$ ano $^{-1} \mathrm{P}_{2} \mathrm{O}_{5}$. Eixo X: representa a profundidade das diferentes camadas de solos em $\mathrm{cm}$.

As observações realizadas a partir dos dados de fluorescência 3D, permitiram concluir que: (i) a maior diferença entre o solo $\mathrm{Si}$ e o solo E66 refere-se à contribuição de fluorescência da fração d>2, devida, sobretudo, às frações fúlvicas e húmicas, sendo no solo Si maior em profundidade, e no solo E66 maior nas camadas superficiais, coerente, portanto, com os dados de IH; (ii) a incoerência aparente entre os dados de IH e a fluorescência das frações densimétricas e a razão Ia/Ic do extrato de solo total é, provavelmente, devida a extração não homogênea da matéria orgânica destas frações; (iii) a maior contribuição relativa à componente 1 , característica de matéria protéica oriunda da atividade microbiana recente, ocorre em profundidade, indicando uma provável transferência de matéria orgânica mais lábil. 
Essa hipótese é reforçada pelo fato da fluorescência da fração 1,6 livre ser maior nos níveis de 20 a 60 que na superfície.

\subsection{Razão C/N da matéria orgânica do solo}

Os resultados apresentados por Coble (1996), bem como os de fluoerescência 3-D do presente estudo, mostraram que as componentes protéicas apresentam maior fluorescência quando excitadas com comprimento de onda de 250 à $275 \mathrm{~nm}$. No método utilizado por Milori et al. (2006) e aqui empregado para determinação do IH, as amostras são irradiadas por uma luz monocromática em 458nm, que corresponde ao comprimento de onda de excitação das estruturas cuja concentração aumenta com o grau de humificação (MILORI et al., 2002).

Isto leva ao questionamento se a LIF permite obter o comportamento das componentes protéicas como foi avaliado a partir da fluorescência 3-D. No intuito de obter dados complementares em relação a este problema foi determinada a razão $\mathrm{C} / \mathrm{N}$.

Os resultados obtidos (Figura 4.2r) variaram de 11 a 13,5 para as amostras de solo total, e de 10,5 a 9 para as frações de densidade >2, o que é coerente com os dados encontrados na literatura para o tipo de solo estudado (LEHMANN et al, 2001; NOGUEIRA, 2008). Observa-se um leve acréscimo da razão C/N com a profundidade para os solos totais, e o contrário para as frações d>2. Estas observações são de difícil interpretação, tendo em vista os numerosos processos que podem alterar a razão $\mathrm{C} / \mathrm{N}$ durante o processo de humificação, tais como a razão $\mathrm{C} / \mathrm{N}$ da matéria orgânica fresca ou o tipo de atividade microbiana, bactérias versus fungos, por exemplo (GOLCHIN et al., 1997; ZECH et al., 1997). 
$\mathrm{C} / \mathrm{N}$

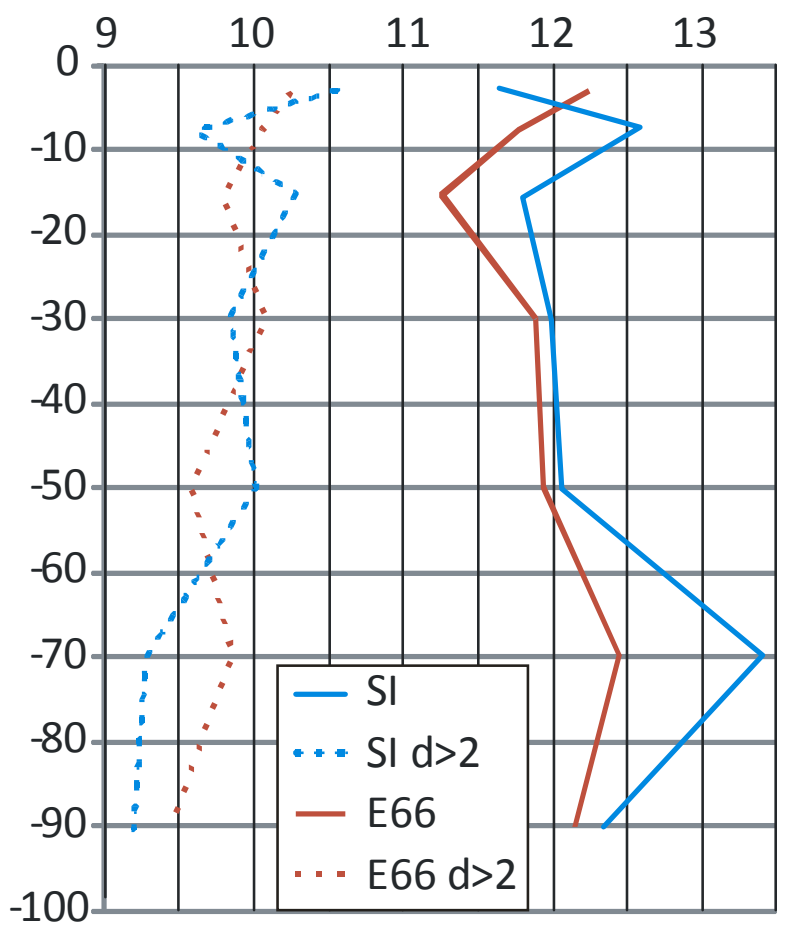

Profundidade $(\mathrm{cm})$

Figura 4.25 - Razão C/N para as amostras de solo total (SI e E66) e para as amostras da fração densimétrica superior a 2 (SI d>2 e E66 d>2) (amostragem de junho 2007) . d: densidade; SI: sem irrigação e sem fertilização; E66 - irrigação com EETE e adubação de $343 \mathrm{~kg} \mathrm{ha}^{-1}$ ano $^{-1}$ de nitrato de amônio, $416 \mathrm{~kg} \mathrm{ha}^{-1}$ ano $^{-1}$ de $\mathrm{K}_{2} \mathrm{O}$ e $140 \mathrm{~kg} \mathrm{ha}^{-1}$ ano $^{-1} \mathrm{P}_{2} \mathrm{O}_{5}$.

Na Figura 4.26 apresenta-se o resultado da comparação entre a razão C/N e o índice de humificacão determinado por fluorescência induzida por laser. Os valores relativos às frações de densidade>2 apresentaram boa correlação com a razão C/N. O mesmo não foi observado quando a comparação foi realizada entre a razão $\mathrm{C} / \mathrm{N}$ e os solos totais, cujas correlações não foram significativas. Entretanto, para se concluir que a partir do IH medido pelo método de Milori et al. (2006) é possível obter-se resultados satisfatórios em relação as componentes protéicas, seria necessário superar as eventuais dificuldades de extração no protocolo de fracionamento da MOS. 


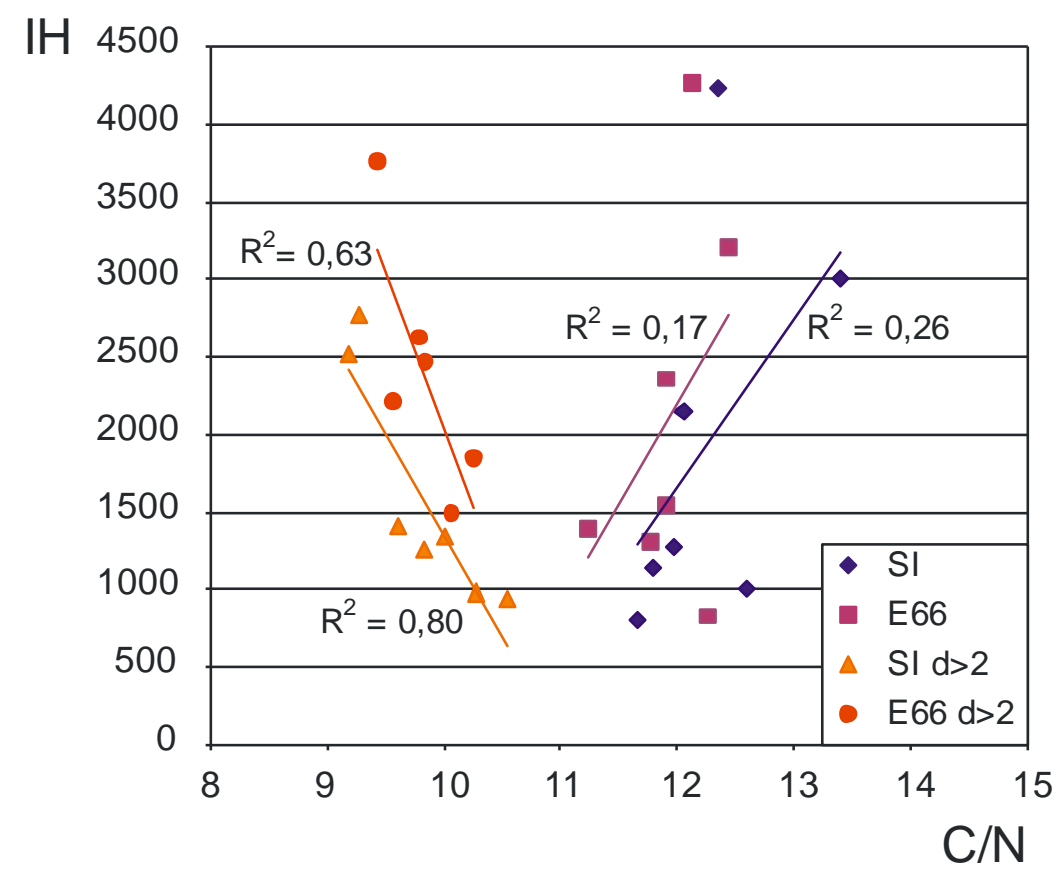

Figura 4.26 - Comparação entre a razão C/N e o índice de humificação (IH) determinado por fuorescência induzida por laser (LIF). d: densidade; SI: sem irrigação e sem fertilização; E66 - irrigação com EETE e adubação de $343 \mathrm{~kg} \mathrm{ha}^{-1} \mathrm{ano}^{-1}$ de nitrato de amônio, $416 \mathrm{~kg} \mathrm{ha}^{-1} \mathrm{ano}^{-1}$ de $\mathrm{K}_{2} \mathrm{O}$ e $140 \mathrm{~kg} \mathrm{ha}^{-1} \mathrm{ano}^{-1} \mathrm{P}_{2} \mathrm{O}_{5}$.

Comparação semelhante foi realizada entre a composição isotópica do carbono e a razão C/N (Figura 4.27). Os resultados mostraram uma correlação positiva igual a 0,67 no caso do extrato do solo total do tratamento SI. Esta correlação, no entanto, parece ter pouco significado, sendo devida, sobretudo, a um ponto mais afastado do conjunto de dados. 


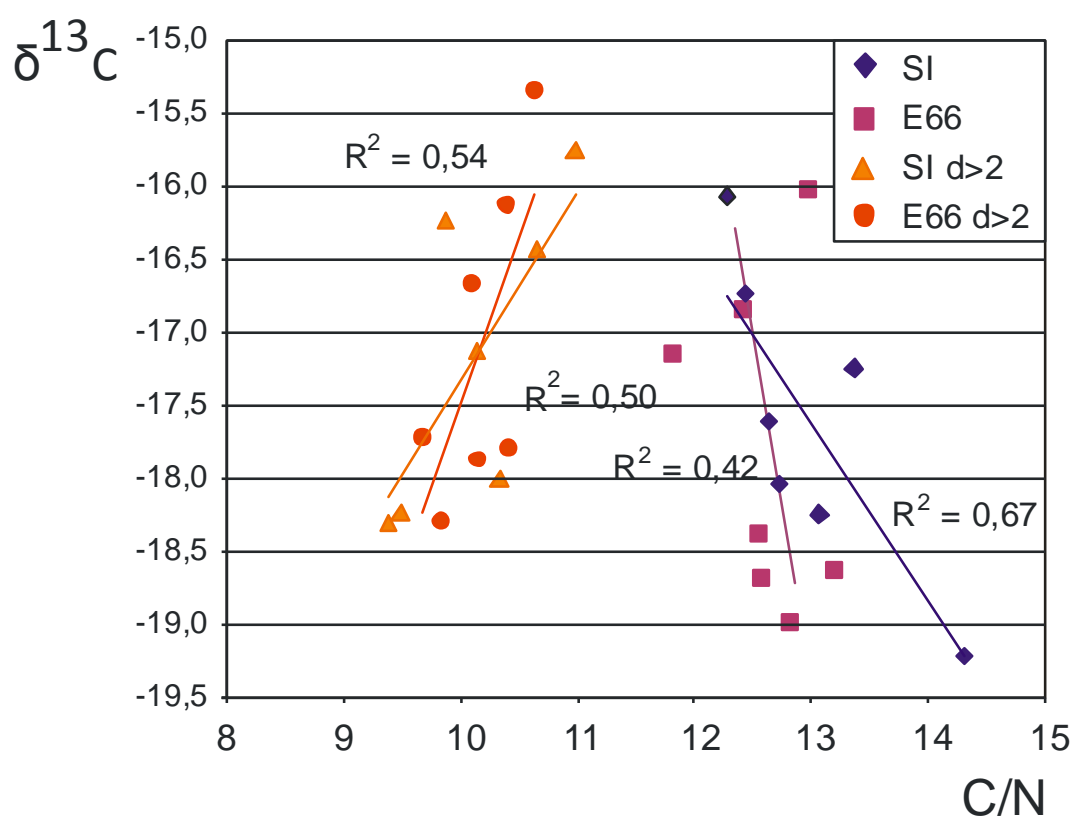

Figura 4.27 - Comparação entre a razão $\mathrm{C} / \mathrm{N}$ e a composição isotópica $\left(\delta^{13} \mathrm{C}\right)$. d: densidade; SI: sem irrigação e sem fertilização; E66 - irrigação com EETE e adubação de $343 \mathrm{~kg} \mathrm{ha}^{-1}$ ano $^{-1}$ de nitrato de amônio, $416 \mathrm{~kg} \mathrm{ha}^{-1}$ ano $^{-1}$ de $\mathrm{K}_{2} \mathrm{O}$ e $140 \mathrm{~kg} \mathrm{ha}^{-1}$ ano $^{-1} \mathrm{P}_{2} \mathrm{O}_{5}$. 


\section{Síntese dos Resultados}

- A mineralogia dos solos estudados é simples, dominada pela presença de quartzo, caulinita, gibbsita, goethita, hematita, e magnetita e/ou maghemita. Não foram observadas diferenças estatísticas entre os solos dos tratamentos SI e E66 para os teores de caulinita, gibbsita, goethita e hematita.

- Verificou-se um menor estoque de $\mathrm{C}$ nos solos irrigados em relação ao solo não irrigado, o que poderia ter origem em três processos: (i) mineralização e lixiviação de uma matéria orgânica anteriormente estável, devido à sua exposição após a desestruturação dos complexos organominerais em razão dos altos teores de $\mathrm{Na}^{+}$no efluente bem como na água potável; (ii) solubilização maior e consequente lixiviação da MOS devido aos valores de $\mathrm{pH}$ mais elevados das soluções do solo induzidos pelo efluente bem como pela água potável; (iii) efeito priming;

- A maior parte do carbono nos solos (mais de 60\%) está associada à fase mineral;

- O carbono contido nas frações mais densas de 1,8 a 2 e >2, estreitamente ligadas à fração mineral, é maior no solo não irrigado que no solo irrigado. Esta observação reforça a hipótese de desestruturação dos agregados nos solos irrigados, em razão do caráter sódico das águas de irrigação;

- A fração de d<1,6 livre é maior nos horizontes superficiais e em profundidade, o que indica uma provável lixiviação dos compostos mais solúveis;

- O índice de humificação (IH) do solo total não apresentou diferenças significativas entre o solo do tratamento SI e do E66. Em ambos os casos há um aumento com a profundidade, o que era esperado devido ao aumento do grau de condensação, da idade média e da estabilidade da MOS; 
- $\mathrm{O}$ IH da fração densimétrica superior a 2 foi significativamente menor que para o solo total, o que poderia ser explicado pelo fato dos cimentos na fração granulométrica < $20 \mu \mathrm{m}$ serem, sobretudo, de tipo mucilagem (polissacarídeos), o que aumenta a razão da matéria pouco humificada;

- A evolução temporal do IH mostra, em ambos os solos, um aumento em profundidade associado, provavelmente, à diminuição do fluxo de solução proveniente da parte superior do solo. O processo seria uma diminuição dos aportes, em profundidade, de compostos móveis pouco humificados;

- Observa-se um aumento significativo do IH da fração densimétrica d>2 do solo E66 em comparação ao SI, não refletindo no valores de IH do solo total. Dois processos poderiam dar origem a essa diferença: (i) a alteração da atividade microbiana sob efeito do efluente, resultando numa aceleração da degradação da matéria orgânica mais lábil, menos humificada. Este processo poderia ser favorecido pela dispersão dos agregados em razão da sodicidade do efluente; (ii) irrigação com águas residuárias favoreceria a formação de substâncias húmicas solúveis que tenderiam a se acumular em profundidade;

- Considerando a fluorescência tem-se que, a maior diferença entre o solo do tratamento SI e do E66 está na intensidade de fluorescência da fração densimétrica d>2, devida sobretudo às frações fúlvicas e húmicas, sendo, no solo SI maior em profundidade, e no solo E66 maior nas camadas superficiais. Esta observação é coerente com os dados de IH e as variações da razão C/N;

- A correlação entre a razão $\mathrm{C} / \mathrm{N}$ e o índice de humificacão determinado por fluorescência induzida por laser é boa considerando-se as frações d>2 e ruim considerando-se os solos totais. Isto indica que: (i) o IH medido pelo método de Milori 
et al. (2006) forneceria resultados satisfatórios em relação as componentes protéicas; (ii) que a extração da MOS da fração d $>2$ foi, provavelmente, incompleta

- A MOS total dos dois solos irrigados apresentou nas camadas superficiais valores mais negativos de $\delta^{13} \mathrm{C}$. A MOS das frações $\mathrm{d}>2$ apresentou sistematicamente valores superiores aos do solo total correspondente, sendo esta diferença maior no solo irrigado que no não irrigado. O processo responsável poderia ser uma maior mineralização da MOS de $\delta^{13} \mathrm{C}$ menos negativa pelos microrganismos, eventualmente favorecida pela dispersão dos agregados. 


\section{Conclusão Geral}

A irrigação com efluente de estação de tratamento de esgoto promoveu mudanças tanto qualitativas como quantitativas na matéria orgânica do solo em relação ao tratamento sem irrigação. Essas mudanças, no entanto, parecem estar mais associadas à própria irrigação do que às propriedades específicas do efluente. Esta constatação se deve ao fato que não foram observadas diferenças nítidas entre o comportamento da matéria orgânica do solo irrigado com efluente de estação de tratamento de esgoto e a do solo irrigado com água potável.

Em consequência, a diminuição do estoque de carbono dos solos irrigados, o aumento do grau de humificação da matéria orgânica do solo ligada à fração mineral e a lixiviação e acumulação nas camadas mais profundas no perfil de solo das substâncias húmicas solúveis são, principalmente, provenientes da desestabilização dos agregados do solo, devido aos altos teores de sódio nas águas de irrigação. Portanto, o problema não é o efluente em si, mas sim a sodicidade.

Desta forma, o manejo adequado do solo para preservar, a longo prazo, suas qualidades agronômicas deverá, obrigatoriamente, manter a estabilidade estutural do solo, o que propiciará uma boa condutividade hidráulica.

As técnicas de fluorescência de matéria orgânica empregadas parecem ser sensíveis para monitorar as variações da MOS, no entanto, ainda é necessário se conhecer melhor a relação entre os sinais observados nos espectros e as propriedades agronômicas. 


\section{Referências Biliográficas}

AHMED, M.; SHARMA, M.L.; RICHARDS, Q.D.; AL-KALBANI, M.S. Sampling soil water in sandy soils: comparative analysis of some common methods. Communications in Soil Science and Plant Analysis, v.32, p.1677-1686, 2001.

AIKEN, G.R. Isolation and concentration techniques for aquatic humic substances In: Humic Substances in Soil, Sediment, and Water, New York, USA: Wiley, 1985, p. 363-385.

AL-LAHHAM, O.; EL ASSI, N.M.; FAYYAD, M. Impact of treated wastewater irrigation on quality attributes and contamination of tomato fruit. Agricultural Water Management. v.61, p.51-62, 2003.

ALI, I.; MORIN, S.; BARRINTON, S.; WHALEN, J.; BONNELL, R.; MARTINEZ, J. Surface Irrigation of Dairy Farm Effluent, Part I: Nutrient and Bacterial Load. Biosystems Engineering, v.95, n.4, p.547-556, 2006.

ALI, I.; MORIN, S.; BARRINTON, S.; WHALEN, J.; BONNELL, R.; MARTINEZ, J. Surface Irrigation of Dairy Farm Effluent, Part II: System Design and Operation. Biosystems Engineering, v.96, n.1, p.65-77, 2007

ALVIM, J.A.; BOTREL, M.A.; MARTINS, C.E.; CÓSER,A.C.; RESENDE, H.; VILELA, D. Efeito de doses de nitrogênio e de intervalos entre cortes sobre a produção de matéria seca e teor de proteína bruta do tifton 85. In: Reunião da sociedade brasileira de zootecnia, 35, Botucatu, 1998. Anais. Botucatu: SBZ, 1998. p.492-494.

AMERICAN SOCIETY FOR TESTING AND MATERIALS - ASTM. 1996. ASTM Publication Code Number (PCN): 03-418196-38, USA, 255 p.

ANDERSON, D. W., PAUL, E. A., AND ST. ARNAUD, R. J. Extraction and characterization of humus with reference to clay-associated humus. Canadian Journal of Soil Science, v.54, p.317-23, 1974.

ARANDACIREROL, N.; HERRERA-SILVEIRA, J. A.; COMIN, F. A.Nutrient water quality in a tropical coastal zone with groundwater discharge, northwest Yucatán, Mexico. Estuarine, Coastal and Shelf Science, v.68, p.445-454, 2006.

ASANO, T.; PETTYGROVE, G.S. Using reclaimed municipal wastewater for irrigation. California Agriculture, v.41, n.3/4, p.15-18, 1987. 
AYERS, R.S.; WESTCOT, D.S. Water quality for agriculture. Rome: Food and Agriculture Organization, 1985. 174p. (Irrigation and Drainage Paper, 29).

AZEVEDO, W. R.; FAQUIN, V.; FERNANDES, L. A. Boron adsorption in lowland soils from Southern of the State of Minas Gerais, Brazil. Pesquisa Agropecuária Brasileira, v.36, n.7, p.957-964, 2001.

BAGARELlO, V.; IOVINO, M.; PALAZZOLO, E.; PANNO, M.; REYNOLDS, W.D. Field and laboratory approaches for determining sodicity effects on saturated soil hydraulic conductivity. Geoderma, v.130, n.1-2, p.1-13, 2006.

BALDOCK, J. A.; NELSON, P. Soil organic matter. In: Handbook of soil science. Boca Raton, Fla: CRC Press, 2000. p.B25-B84. 0849331366.

BARRIE, A.; PROSSER, S.J. Automated analysis of light-element stable isotopes by isotope ratio mass spectrometry. In: Mass spectrometry of soils. New York: Marcel Dekker, 1996, capítulo 1, p.1-46. 0824796993.

BOND, W.J. Effluent irrigation - an environmental challenge for soil science. Australian Journal Of Soil Research, v.36, p.543-555, 1998.

BOUTTON, T.W. Stable carbon isotope ratios of soil organic matter and their use as indicators of vegetation and climate change. In: Mass spectrometry of soils. New York: Marcel Dekker, 1996, capítulo 2, p.47-82. 0824796993.

BOUWER, H.; CHANEY, R.L. Land treatment of wastewater. Advances in Agronomy, v.26, p.133-176, 1974.

BRADY, N.C.; WEIL, R.R. The nature and properties of soils. 13. ed. Upper Saddle River, N.J. : Prentice Hall , 2002. 960 p. 0130167630.

BRIGGS, L.J.; McCALL, A.G. (1904) An artificial root for inducing capillary movement of soil moisture. Science, v.20, p.566-569.

BURTON G. W.; GATES R.N.; HILL G.M. Registration of 'Tifton 85' Bermudagrass. Crop Science, v.33, p.644-645, 1993.

BURTON, G.W. Tifton 85 Bermudagrass - early history of its creation, selection, and evaluation. Crop Science, v.41, p.5-6, 2001. 
CAMERON, K.C.; DI, H.J.; McLAREN, R.G. Is soil an appropriate dumping ground for our wastes? Australian Journal Of Soil Research, v.35, p.995-1035, 1997.

CAMARGO, O.A.; MONIZ, A.C.; JORGE, J.A.; VALADARES, J.M.A.S. Métodos de análise química, mineralógica, e física de solos do instituto agronômico de Campina. Boletim técnico do Instituto Agronômico de Campinas, n.106, p.94, 1986.

CAMPBELL, N.A.; Biologie, 3. ed. Saint-laurent, Quebec: De Boeck, 1995. 1190 p. 2804120848.

CARNEVALLI, R.A.; DA SILVA S.C.; PEDREIRA, C.G.S.; FAGUNDES, J.L.; DE CARVALHO, C.A.B.;SBRISSIA, A.F.; PINTO, L.F.M.; UEBELE, M.C.; PASSANEZI, M.M. Pasture and animal responses of Tifton 85 swards grazed by sheep under continuous stocking. In: International symposium on grassland ecophysiology and grazing ecology, Curitiba, 1999. Curitiba: UFPR, 1999. p.357361.

CASTRO, R.S.; BORGES AZEVEDO, C.M.S.; BEZERRA-NETO, F. Increasing cherry tomato yield using fish effluent as irrigation water in Northeast Brazil. Scientia Horticulturae, v.110, p.44-50, 2006.

CHAPMAN, P.J.; WILLIAMS, B.L.; HAWKINS A. Dissolved organic Nitrogen in a peaty podzol: influence of temperature and vegetation cover. In: Sustainable management of soil organic matter. Wallingforg, UK: CAB International, 2001. p.247-255. 0851994652.

CHOI W.J.; HAN, G.H.; LEE, S.M.; LEE G.T.; YOON, K.S.; CHOI, S.M.; RO, H.M. Impact of land-use types on nitrate concentration and $\delta^{15} \mathrm{~N}$ in unconfined groundwater in rural areas of Korea. Agriculture, Ecosystems and Environment, v.120, p.259-268, 2007.

CHRISTENSEN, B.T. Decomposability of organic matter in particle size fractions from field soils with straw incorporation. Soil Biology and Biochemistry, v.3, p.429-435, 1987.

CLOERN, J.E. Our evolving conceptual model of the coastal eutrophication problem. Marine Ecology Progress Series, v.210, p.223-253, 2001.

COBLE G. P. Characterization of marine and terrestrial DOM in seawater using excitationemission matrix spectroscopy. Marine Chemistry, v.51, p.325-346 1996. 
DAI, K.H.; JOHNSON, C.E. Applicability of solid-state ${ }^{13} \mathrm{C}$ CP/MAS NMR analysis on spodosols: chemical removal of magnetic materials. Geoderma, v.93, p.289-310, 1990.

DARBAN, A.K.;FORIERO A.;YONG, R.N. Concentration eff ects of EDTA and chloride on the retention of trace metals in clays. Engineering Geology, v.57, p.81-94, 2000.

DAVIDSON, L.; PONT, D.; BOLTON, K.; HEADLEY, T. Dealing with nitrogen in subtropical Australia: Seven case studies in the diffusion of ecotechnological innovation. Ecological Engeneering, v.28, p.213-223, 2006.

DERRY, C.; ATTWATER, R.; BOOTH, S. Rapid health-risk assessment of effluent irrigation on an Australian university campus. International Journal of Hygiene and Environnemental Health, v.209, p.159-171, 2006.

ELLIOT, E.T.; COLEMAN, D.C. Let the soil do the work for us. Ecological Bulletins, v.39, p.23-32, 1988.

EMPRESA BRASILEIRA DE PESQUISA AGROPECUÁRIA. Sistema brasileiro de classificação de solos. Rio de Janeiro: Centro Nacional de Pesquisa de Solos, 1999. $412 \mathrm{p}$.

EMONGOR, V.E.; RAMOLEMANA, G.M. Treated sewage effluent (water) potential to be used for horticultural production in Botswana. Physics and Chemistry of the Earth, v.29, p.1101-1108, 2004.

FAGUNDES, J.L.; DA SILVA, S.C.; PEDREIRA, C.G.S; SBRISSIA, A.F.; CARNEVALLI, R.A.; DE CARVALHO, C.A.B.; PINTO, L.F.M. Índice de área foliar, interceptação luminosa e acúmulo de forragem em pastagens de Cynodon spp. sob diferentes intensidades de pastejo. Scientia Agricola, v.56, n.4, p.1141-1150, 1999.

FEIGIN, A.; BIELORAI, H.; DAG, Y.; KIPNIS, T.; GISKIN, M. The nitrogen factor in the management of effluent-irrigated soils. Soil Science, v.125, p.248-254, 1978.

FEIGIN, A.; RAVINA, I.; SHALHEVET, J. Irrigation with treated sewage effluent: management for environmental protection. Berlin: Springer-Verlag, 1991. 224 p. $354050804 X$.

FERRI, M.V.W.; GOMES, J.; DICK, D.P.; SOUZA, R.F.; VIDAL, R.A. Sorção do herbicida acetochlor em amostras de solo, ácidos húmicos e huminas de argissolo submetido à semeadura direta e ao preparo convencional. Revista Brasileira de Ciência do Solo, v.29, p.705-714, 2005. 
FETTER, C. W. Contaminant Hydrogeology. New York, Macmillan Publishing Company. 1993. $457 \mathrm{p}$.

FONSECA, A.F. Viabilidade agronômico-ambiental da disposição de efluente de esgoto tratado em um sistema solo-pastagem. 2005. Tese (Doutorado) - Escola Superior de Agricultura “Luiz de Queiroz”, Universidade de São Paulo, Piracicaba.

FONSECA, A.F. ; MELFI, Adolpho José ; MONTEIRO, F. A. ; MONTES, Célia Regina ; ALMEIDA, Vagner Vidal de ; HERPIN, Uwe . Treated sewage effluent as a source of water and nitrogen for Tifton 85 bermudagrass. Agricultural Water Management, v. 87, p. 328-336, 2007.

FORSBERG, L.S.; LEDIN, S. Effects of sewage sludge on $\mathrm{pH}$ and plant availability of metals in oxidising sulphide mine tailings. Science of the Total Environment, v.358, p.21-35, 2006.

FRIEDEL, J.K.; LANGER, T.; SIEBE, C.; STAHR, K. Effects of long-term waste water irrigation on soil organic matter, soil microbial biomass and its activities in central Mexico. Biology and Fertility Soils, v.31, p.414-421, 2000.

FUENTES, A.; LLORENS, M.; SAEZ, J.;AGUILAR, M. I.; ORTUNO, J. F. Comparative study of six different sludges by sequential speciation of heavy metals. Bioresource Technology, v.99, n.3, p.517-25, 2007.

FUSCALDO, F.; BEDMAR, F.; MONTERUBBIANES, G. Persistence of atrazine, metribuzin and simazine herbicides in two soils. Pesquisa Agropecuária Brasileira, v.34, n.11, p.2037-2044, 1999.

FRIEDLER, E.; HADARI, M. Economic feasibility of on-site greywater reuse in multi-storey buildings. Desalination, v.190, p.221-234 , 2006.

GHIBERTO, P.J.; PILATTI, M.A.; IMHOFF, S.; ORELLANA, J.A. Hydraulic conductivity of Molisolls irrigated with sodic-bicarbonated waters in Santa Fe (Argentine). Agricultural Water Management. v.88, p.192-200, 2007.

GHISI, E.; MONTIBELLER, A.; SCHMIDT, R.W. Potential for potable water savings by using rainwater: An analysis over 62 cities in southern Brazil. Building and Environment, v.41, p.204-210, 2006. 
GHISI, E.; MENGOTTI DE OLIVEIRA, S. Potential for potable water savings by combining the use of rainwater and greywater in houses in southern Brazil. Building and Environment, v.42, p.1731-1742, 2007a.

GHISI, E.; FERREIRA, D.F. Potential for potable water savings by using rainwater and greywater in a multi-storey residential building in southern Brazil. Building and Environment, v.42, p.2512-2522, $2007 \mathrm{~b}$.

GLEICK, P.H.; YOLLES, P.; HATAMI, H. Water, war, and peace in the Middle East. Environment, v.36, n.3, p.6-15, 1994.

GLOAGUEN, T.V. Transferências de espécies químicas através de um solo cultivado com milho e girassol e fertirrigado com efluente de esgoto doméstico. 2006. Tese (Doutorado) - Instituto de Geociências, Universidade de São Paulo, São Paulo.

GODDARD, M. Urban greywater reuse at the D'LUX Development . Desalination. v.188, p.135-140, 2006.

GOLCHIN, A.; OADES, J.M.; SKJEMSTAD, J.O.; CLARKE, P. Study of free and occluded particulate organic matter in soils by solid state ${ }^{13} \mathrm{C}$ CP/MAS NMR spectroscopy and scanning electron microscopy. Australian Journal of Soil Research, v.32, p.285-309, 1994a.

GOLCHIN, A.; OADES, J.M.; SKJEMSTAD, J.O.; CLARKE, P. Soil structure and carbon cycling. Australian Journal of Soil Research, v.32, p.1043-1068, 1994 b.

GOLCHIN, A.; OADES, J.M.; SKJEMSTAD, J.O.; CLARKE, P. Structural and dynamic properties of soil organic matter as reflected by ${ }^{13} \mathrm{C}$ natural abundance, pyrolysis mass spectrometry and solid-state ${ }^{13} \mathrm{C}$ NMR spectroscopy in density fractions of an oxisol under forest and pasture. Australian Journal of Soil Research, v.33, p.59-76, 1995.

GOLCHIN, A.; CLARKE, P.; BALDOCK, J.A.; HIGASHI, T.; SKJEMSTAD, J.O.; OADES, J.M. The effects of vegetation and burning on the chemical composition of soil organic matter in a volcanic ash soil as shown by ${ }^{13} \mathrm{C}$ NMR spectroscopy. I. Whole soil and humic acid fraction. Geoderma, V.76, p.155-174, 1997.

GONÇALVES, R.A.B. Efeito da irrigação com efluente de esgoto tratado nas propriedades físico-hídricas de um latossolo. 2005. Tese (Doutorado) - Escola Superior de Agricultura de Luiz de Queiroz, Universidade de São Paulo, Piracicaba. 
GOTTLIEB, O.R. Introdução à espectrometria de ressonância magnética protônica. Rio de janiero, RJ: Universidade Federal rural de Rio de Janeiro, 1968. 206 p.

GRATTAN, S.R.; GRIEVE, C.M.; POSS, J.A.; ROBINSON, P.H.; SUAREZ, D.L.; BENES, S.E. Evaluation of salt-tolerant forages for sequential water reuse systems. I. Biomass production. Agricultural Water Management, v.70, p.109-120, 2004.

GRIEVE, C.M.; POSS, J.A.; GRATTAN, S.R.; SUAREZ, D.L.; BENES, S.E.; ROBINSON, P.H. Evaluation of salt-tolerant forages for sequential water reuse systems. II. Plantion relations. Agricultural Water Management, v.70, p.121-135, 2004.

GUGGENBERGEN, G.; BUSSEMER, S.; KARPOV, J.G.; BARANOVSKIJ E.L. Soils and soil organic matter along a transect from central taiga to forest tundra, siberia. In: Sustainable management of soil organic matter. Wallingforg, UK: CAB International, 2001. p.330-336. 0851994652.

HALLIWELL, D.J.; BARLOW, K.M.; NASH, D.M. A review of the effects of wastewater sodium on soil physical properties and their implicátions for irrigation systems. Australian Journal Of Soil Research, v.39, p.1259-1267, 2001.

HASLAM, S.F.I.; HOPKINS, D.W.; CHUDEK, J.A. Carbon dynamics in upland soils after serious fire. In: Sustainable management of soil organic matter. Wallingforg, UK: CAB International, 2001. p.337-342. 0851994652.

HELMKE, P.A. The chemical composition of soils. In: Handbook of soil science. Boca Raton, Fla: CRC Press, 2000. p.B25-B84. 0849331366.

HENSEL, P.R.; MITCHELL, S.M.L.; SOWERS T.E. Conflict management of riparian disputes, Political Geography, v.25, p.383e-411, 2006.

HILL, G.M.; GATES, R.N.; BURTON,G.W. Forage quality and grazing steer performance from Tifton 85 an Tifton 78 bermudagrass pastures. Journal of Animal Science, v.71, p.3219-3225, 1993.

HOLLAS, JM. Modern spectroscopy. Great Britain: Wiley, 1987. 388p. 0471911216.

HOMER-DIXON, T.H. Environmental Scarcities and Violent Conflict: Evidence from Cases. International Security, v.19, n.1, p.5-40, 1994. 
HOUGHTON, R.A. The Contemporary carbon cycle. In: Treatise on geochemistry. Elsevier, 2003. p.473-513. 0080437516

HÜTSCH, B.; AUGUSTIN, J.; MERBACH, W.: Plant rhizodeposition - an important source for carbon turnover in soils. Journal of Plant Nutrition and Soil Science, v.40, p.165397, 2002.

IBRAHIM, L. Caracterização física, química, mineralógica e morfológica de uma seqüência de solos em Lins/SP. 2002. Dissertação (Mestrado) - Escola de Agronomia de Luiz de Queiroz, Universidade de São Paulo, Piracicaba.

IBRAHIM, L. ; MELFI, A. J. . Qualidade de um sistema latossolo-argissolo como recptor de efluentes no município de Lins (SP). Revista Brasileira de Ciência do Solo, v.32, p.1369-1377, 2008.

INTERGOVERNMENTAL PANEL ON CLIMATE CHANGE. Climate Change 2007: Synthesis Report. Summary for Policymakers. 2007. 24 p. Disponível em <http://www.ipcc.ch/ipccreports/ar4-syr.htm>. Acesso em: 31 de Março 2007.

JANOSOVA, B.; MIKLANKOVA, J.; HLAVINEK, P.; WINTGENS, T. Drivers for wastewater reuse: regional analysis in the Czech Republic. Desalination, v.187, p.103-114, 2006.

JANSSEN, B.H.; VELD, H.B.; RODRIGUEZ, M.J. Some theoretical considerations on evaluating wastewater as a source of N, P and $\mathrm{K}$ for crops. Irrigation and Drainage, v.54, p.S35-S47, 2005.

JASTROW, J.D. Soil aggregate formation and the accrual of particulate and mineralassociated organic matter. Soil Biology and Biochemistry, v.32, p.2099-2103, 2000.

JAYARAM, R. Mass spectrometry: theory and applications. New York: Plenum Press, 1966. $225 \mathrm{p}$.

JÍMENEZ, J. J.; LAL, R. Mechanisms of C sequestration in soils of Latin America. Critical Reviews in Plant Sciences. v.25, p.337-365, 2006.

JONES; S.K.; REES, R.M.; SKIBA, U.M.; BALL, B.C. Greenhouse gas emissions from amanaged grassland. Global and Planetary Change, v.47, p.201-211, 2005.

KARVELAS, M.; KATSOYIANNIS, A.; SAMARA, C. Occurrence and fate of heavy metals in the wastewater treatment process. Chemosphere, v.53, p.1201-1210, 2003. 
KAISER, K. \& ZECH, W.. Sorption of dissolved organic nitrogen by acid subsoil horizons and individual mineral phases. European Journal of Soil Science, v.51, p.403-411, 2000 .

KIM, R.H.; LEE, S.; JEONG, J.; LEE, J.H.; KIM, Y.K. Reuse of greywater and rainwater using fiber filter media and metal membrane. Desalination, v.202, P.326-332, 2007.

KONONOVA, M.M. Soil organic matter: its nature, its role in soil formation, and in soil chemistry. 2. ed. Oxford, New York: Pergamon Press, 1966. 544 p.

KOSMAS, C. S.; CUFF, N.; BRYANT, R. B.,; FRANZMEIER, D. P. Characterization of iron oxide minerals by second derivative visible spectroscopy: Soil Science Society of America, v.48, p.401-405, 1984.

KUZYAKOV, Y.; FRIEDEL, J. K.; STAHR, K. Review of mechanisms and quantification of priming effects. Soil Biology and Biochemistry, v.32, p.1485-1498, 2000.

LADO, M.; BEN-HUR, M.; ASSOULINE, F. Effects of effluent irrigation on seal formation, infiltration, and soil loss during rainfall. Soil Science Society of America, v.69, p.1432-1439, 2005.

LEHMANN, J.; DA SILVA CRAVO, M.; ZECH, W. Organic matter stabilization in a Xanthic Ferralsol of the central Amazon as affected by single trees: chemical characterization of density, aggregate, and particle size fractions. Geoderma, v.99, p.147-168, 2001.

LINDEN, D.R.; CLAPP, C.E.; GILLEY, J.R. Effects of scheduling municipal waste-water effluent irrigation of reed canarygrass on nitrogen renovation and grass production. Journal of Environmental Quality, v.10, p.507-510, 1981.

LUBELLO, C.; GORI, R.; NICESEB, F.P.; FERRINI, F. Municipal-treated wastewater reuse for plant nurseries irrigation. Water Research, v.38, p.2939-2947, 2004.

LUCIANI, X.; MOUNIER, S.; REDON, R.; Bois, A. A simple correction method of inner filter effects affecting FEEM ans its application to the PARAFAC decomposition. Chemometrics and Intelligent Laboratory Systems, . v.96, p. 227-238, 2009.

MALENGREAU, N.; BEDIDI, A.; MULLER, J. P.; HERBILlON, A. J. Spectroscopic control of iron oxide dissolution in two ferralitic soils. European Journal of Soil Science, v.47 p.13-20, 1996. 
MANDEBVU, P.; WEST, J.W.; GATES, R.N.; HILL, G.M. In vitro digestion kinetics of natural detergent fiber extracted from Tifton 85 and Coastal bermudagrasses. Animal Feed Science and Tecnology, v.73, n.3/4, p.263-269, 1998a

MANDEBVU, P.; WEST, J.W.; GATES, R.N.; HILL, G.M. Effect of hay maturity, forage source, or neutral detergent fiber content on digestion of diets containing Tifton 85 bermudagrass and corn silage. Animal Feed Science and Tecnology, v.73, n.3/4, p.281-290, 1998b

MANDEBVU, P.; WEST, J.W.; HILL, G.M.; GATES, R.N.; HATFIELD, R.D.; MULLINIX, B.G.; PARKS, A.H.; CAUDLE, A.B. Comparison of Tifton 85 and Coastal bermudagrasses for yiels, nutrient traits, intake, and digestion by growing beef steers. Journal of Animal Science, v.77, n.6, p.1572-1586, 1999.

MARCELINO, K.R.A.; VILELA, L.; LEITE, G.G.; GUERRA, A.F.; DIOGO, J.M.S. Manejo da adubação nitrogenada de tensões hídricas sobre a produção de matéria seca e índice de área foliar de Tifton 85 cultivado no Cerrado. Revista Brasileira de Zootecnia, v.32, p.268-275, 2003.

MARTINEZ, C. E.; JACOBSON, A.; MC BRIDE, M. B. Thermally Induced Changes in Metal Solubility of Contaminated Soils Is Linked to Mineral Recrystallization and Organic Matter Transformations. Environmental Science and Technology, v.35, p.908-916, 2001.

MC BRIDE, M.B. Magnetic Methods. In: Part 1 Physical and Mineralogical Methods. Methods of soil analysis. Madison, Wisconsin, USA: Soil Science Society of America, 1986, capítulo 9. p.219-268. 0891180885.

MEHRA O. P.; JACKSON. M. L. Iron Oxide Removal from Soils and Clays by a DithioniteCitrate System Buffered with Sodium Bicarbonate. Clays and Clay Minerals, v.7, p.317-327, 1958.

MENÉNDEZ, I.; GALLARDO, J.F.; VICENTE, M.A. Functional and chemical calibrates of ceramic cup water samplers in forest soils. Communications in Soil Science and Plant Analysis, v.34, p.1153-1175, 2003.

MILORI, D. M. B. P.; MARTIN-NETO, L.; BAYER, C.; MIELNICZUK, J.; BAGNATO, V. $\mathrm{S}$. Humification degree of soil humic acids determined by fluorescence spectroscopy. Soil Science, v. 167, p. 739-749, 2002. 
MILORI, D. M. B. P.; GALETI, H. V. A.; MARTIN-NETO, L.; BAYER, C.; SALTON, J.; GONZALES-PEREZ, M. Humification degree of organic matter in whole soil determined by laser-induced fluorecence In: MARTIN-NETO, L.; MILORI, D.M.B.P.; SILVA, W.T.L. da. (Eds.). Humic Substances and Soil and Water Environment: International Meeting of IHSS, 12. São Carlos: Embrapa Instrumentação Agropecuária, p.609-611, 2004.

MILORI, D.M.B.P.; GALETI, H.V.A.; MARTIN-NETO, L.; DIECKOW, J.; GONZÁLEZPÉREZ, M.; BAYER, C.; SALTON, J. "Organic matter study of whole soil samples using laser-induced fluorescense spectroscopy". Soil Science Society of America Journal, v. 70, p. 57-63, 2006.

MISLEVY, P.; PATE, F.M. Establishment, management and utilization of Cynodon grasses in florida. In: Workshop sobre o potencial forrageiro do gênero Cynodon, Juiz de fora, 1996. Anais. Juiz de fora: EMBRAPA, CNPGL, 1996. p.127-138.

MISRA, B.M. Seawater desalination using nuclear heat/electricity - Prospects and challenges. Desalination, v.205, p.269-278, 2007.

MOREIRA, F. M. S.; SIQUEIRA, J. O. Microbiologia e bioquímica do solo. Lavras: Editora UFLA, 2006. 729p.

MUNSTERMAN, D.; KERSTHOLT, S. Sodium polytungstate, a new non-toxic alternative to bromoform in heavy liquid separation. Review of Palaeobotany and Palynology, v.91, p.417-422, 1996.

NELSON, D.W.; SOMMERS, L.E. Total carbon, organic carbon, and organic matter. In: SPARKS, D.L. (Ed.). Methods of soil analysis: chemical methods. pt. 3. Madison: Soil Science Society of America/American Society of Agronomy, 1996. p.961-1010.

NOGUEIRA S.F.; DO CARMO, J.B.; MONTES, C.R.; VICTORIA, R.V.; RAVAGNANI, E.C.; BARUFALDI, R.O. Indicadores eco-fisiológicos da qualidade de um solo irrigado com esgoto tratado. Revista Brasileira de Engenharia Agrícola e Ambiental, v.9, (Suplemento), p.138-142, 2005.

NOGUEIRA S.F. Efeitos da irrigação com esgoto tratado e fertilização nitrogenada na ciclagem de carbono e nitrogênio e no metabolismo microbiano de um solo cultivado com capim-Bermuda Tifton 85. 2008. Tese (Doutorado) - Escola Superior de Agricultura “Luiz de Queiroz", Universidade de São Paulo, Piracicaba. 
OADES, J.M. An introduction to organic matter in mineral soils. In: Soil Science Society of America Book Series 1: Minerals in Soil Environments, Madison, USA: Soil Science Society of America, 1989. p.89-159.

OADES, J.M.; WATERS, G. Aggregates hierarchy in soils. Australian Journal Of Soil Research, v.29, p.815-828, 1991.

OLIVEIRA, J.B. (1999) Solos do Estado de São Paulo: descrição das classes registradas no mapa pedológico. Campinas, Instituto Agronômico, 122p. (IAC, Boletim Científico, 45).

OLIVEIRA, M.F.; COLONNA, I.; PRATES, H.; MANTOVANI E. C.; GOMIDE R.L.; OLIVEIRA R.S.J. Sorção do herbicida imazaquin em Latossolo sob plantio direto e convencional. Pesquisa Agropecuária Brasileira, v.39, n.8, p.787-793, 2004.

PETALA, M.; TSIRIDISA, P.; SAMARAS, P.; ZOUBOULIS, A.; SAKELLAROPOULOS, G.P. Wastewater reclamation by advanced treatment of secondary effluents. Desalination. v.195, p.109-118, 2006.

PESCOD, M. B. Wastewater treatment and reuse in agriculture. Rome: FAO, 1992. 125p.

PICCOLO, A.; NARDI, S.; CCONCHERI, G. Micelle-like conformation of humic substances as revealed by size exclusion chromatography. Chemosphere, v.33, p.595-602, 1996.

PICOLO, A. The supramolecular structure of humic substances. Soil Science, v.166, n.11, p.810-832, 2001.

PICOLO, A.;CONTE, P.; TRIVELLONE, E.; VAN LAGEN, B.; BUURMAN, P. Reduced heterogeneity of a lignite humic acid by preparative HPSEC following interaction with an organic acid characterization of size separates by Pyr-GC-MS and ${ }^{1} \mathrm{H}-\mathrm{NMR}$ spectroscopy. Environmental Science and Technology, v.36, p.76-84, 2002.

PICOLO, A.; CONTE P.; SPACCINI, R.; CHIARELLA, M. Effect of some dicarboxylic acids on the association of dissolved humic substances. Biology and Fertility of Soils, v.37, p.255-259, 2003.

PRADO, A.G.S.; VIEIRA, E.M.; REZENDE, M.O.O. Monitoring of the harmful concentrations of 2,4-dichlorophenoxyacetic acid (2,4-D) in soils with and without organic matter. Journal of the Brazilian Chemistry Society, v.12, n.4, p.485-488, 2001. 
PRESTON, C.M.; NEWMAN, R.H.; ROTHER, P. Using ${ }^{13}$ C CP/MAS NMR to asses effects of cultivation on the organic matter of particle size fractions in a grassland soil. Soil Science, v.157, n.1, p.26-35, 1994.

PRESTON, C.M. Applications of NMR to soil organic matter analysis: history and prospects. Soil Science, v.161, n.3, p.144-166, 1996.

QADIR, M.; SHARMA, B.R.; BRUGGEMAN, A.; CHOUKR-ALLAH, R.; KARAJEH, F. Non-conventional water resources and opportunities for water augmentation to achieve food security in water scarce countries. Agricultural Water Wanagement, v.87, p.2-22, 2007.

QUIN, B.F; FORSYTHE, L.J. Surface irrigation of pasture with treated sewage effluent. II. Drainage losses of nitrate and other nutrients. New Zealand Journal of Agricultural Research, v.21, p.427-434, 1978.

REDDY, K.V.; GHAFFOU, N. Overview of the cost of desalinated water and costing methodologies. Desalination, v.205, p.340-353, 2007.

REICHARDT, K. ; TIMM, L.C. Solo, Planta e Atmosfera: conceitos, processos e aplicações. Barueri: Manole, 2004. 478 p. 8520417736.

ROBERT, M. Le sol: interface dans l'environnement, ressource pour le développement. Paris: Mason, 1996. 244p. 2225851778.

ROSCOE, R.; BUURTMAN, P.; VELThORSTA, E. J.; VASCONCELlOS, C. A. Soil organic matter dynamics in density and particle size fractions as revealed by the ${ }^{13} \mathrm{C} /{ }^{12} \mathrm{C}$ isotopic ratio in a Cerrado's oxisol. Geoderma, v.104, p.185-202, 2001.

SCHEINOST, A. C.; SCHUZLE, D. G.; SCHWERTMANN, U. Diffuse reflectance spectra of Al substituted Goethite: a ligand field approach. Clays and Clay Mineral. V. 47, p.156-164, 1999.

SCHNITZER, M. Water retention of humic substances peat and water. In: Aspects of Water Retention and Dewatering in Peat. New York: Elsevier, 1986. p.158-176.

SCHMIDT, M.W.I.; RUMPEL. C.; KÖGEL-KNABER, I. Evaluation of an ultrasonic dispersion procedure to isolate primary organomineral complexes from soils. European Journal of Soil Science, v.50, p.87-94, 1999. 
SCHULTEN, H.R. The three-dimensional structure of humic substances and soil organic matter studied by computational analytical chemistry. Fresenius' Journal of Analytical Chemistry, v.351, n.1, p.62-73, 1995.

SEGARRA, E.; DARWISH, M.R.; ETHRIDGE, D.E. Returns to municipalities from integrating crop production with wastewater disposal. Resources, Conservation and Recycling, v.17, p.97-107, 1996.

SENESI, N. Molecular and quantitative aspects of the chemistry of fulvic acid and its interactions with metal ions and organic chemicals. Analytica Chimica Acta, v.232, p.77-106, 1990.

SERVAIS, P.; GARCIA-ARMISEN, T.; GEORGE, I.; BILLEN, G. Fecal bacteria in the rivers of the Seine drainage network (France): Sources, fate and modelling. Science of the Total Environment, v.375, p.152-167, 2007.

SHARMA, A.; ASHWATH, N. Land disposal of municipal effluents: importance of choosing agroforestry systems . Desalination, v.187, p.361-374, 2006.

SIERRA, M.M.D., GIOVANELA, M., PARLANTI, E., AND SORIANO-SIERRA, E.J. Fluorescence fingerprint of fulvic and humic acids from varied origins as viewed by single-scan and excitation/emission matrix techniques. Chemosphere, v.58, p.715733, 2005.

SILVEIRA, M.L.; ALLEONI, L.R.F.; GUILHERME, L.R.G. Biosolids and heavy metals in soils. Scientia Agricola, v.60, n.4, p.793-806, 2003.

SILVERSTEIN, R.M.; BASSLER, G.C.; MORRILL, T.C. Identificação espectrométrica de compostos orgânicos. 5. ed. Rio de Janeiro: Guanabara koogan, 1994. 387 p.

SINGH, G.; BHATI, M. Growth of Dalbergia sissoo in desert regions of western India using municipal effluent and the subsequent changes in soil and plant chemistry. Bioresource Technology, v.96, p.1019-1028, 2005.

SINGH, R.P.; AGRAWAL, M. Effects of sewage sludge amendment on heavy metal accumulation and consequent responses of Beta vulgaris plants. Chemosphere, v.67, p.2229-2240, 2007.

SIX, J.; ELLIOTT, E.T.; PAUSTIAN, K.; DORAN J.W. Aggregation and soil organic matter accumultaion in cultivated and native grassland soils. Soil Science Society of America Journal, v.65, p.1367-1377, 1998. 
SIX, J.; SCHULTZ, P.A.; JASTROW, J.D.; MERCKX, R. Recycling of sodium polytungstate used in soil organic matter studies. Soil Biology and Biochemistry, v.31, p.11931196, 1999.

SKEMJAD, J.O.; CLARKE, P.; TAYLOR, J.A. The removal of magnetic materials from surface soils. A solid state 13C CP/MAS NMR study. Australian Journal Of Soil Research, v.35, p.1215-1229, 1994.

SOLLINS, P.; HOMANN, P.; CALDWELL, B.A. Stabilization and destabilization of soil organic matter: mechanisms and controls. Geoderma, v.74, p.65-105 , 1996.

STEVENSON, F.J. Humus chemistry. 2ed. New York: Wiley , 1994. 0471594741

SUMNER, M.E. Sodic soils: new perspectives. Australian Journal Of Soil Research, v.31, p.683-750, 1993.

THOMSEN, I.K.; SCHJØNNING, P.; JENSEN, B.; KRISTENSEN, K.; CHRISTENSEN, B.T. Turnover of organic matter in differently textured soils. Geoderma, v.89, p.199218, 1999.

TISDALL, J.M.; OADES, J.M. Organic matter and water-stable aggregates in soils. Journal of Soil Science, v.33, p.141-163,1982.

TOZE, S. Reuse of effluent water-benefits and risks. Agricultural Water Management, v.80, p.147-159, 2006.

TRUJILLO, W.; FISHER, M. J.; LAL, R. Root dynamics of native savanna and introduced pastures in the Eastern Plains of Colombia. Soil and Tillage Research, Amsterdam, v.87, p.28-38, 2006.

U.S. ENVIRONMENTAL PROTECTION AGENCY. Guidelines for Water Reuse. Washington: USEPA, 2004. 478 p. Disponível em <www.epa.gov/nrmrl/pubs/625r04108/625r04108.pdf>. Acesso em: 31 de Março 2007.

VALIELA, I.; TOMASKY, G.; HAUXWELL, J.; COLE, M.L.; CEBRIAN, J.; KROEGER, K.D. Operationalizing sustainability: management and risk assessment of landderived nitrogen loads to estuaries. Ecological Applications, v.10, n.4, p.1006-1023, 2000a. 
VALIELA, I.; GEIST, M.; MCCLELLAND, J.; TOMASKY, G. Nitrogen loading from watersheds to estuaries: verification of the waquoit bay nitrogen loading model . Biogeochemistry, v.49, p.277-293, $2000 \mathrm{~b}$.

VAN GENUCHTEN, M.T. A closed form equation for predicting the hydraulic conductivity of unsaturated soils. Soil Science Society of American Journal, v. 44, p.892-898, 1980.

VEERESH, H.; TRIPATHY, S.; CHAUDHURI, D.; GHOSH, B.C.; HART, B.R.; POWELL, M.A. Changes in physical and chemical properties of three soil types in India as a result of amendment with fly ash and sewage sludge. Environmental Geology, v.43, p.513-520, 2003a.

VEERESH, H.; TRIPATHY, S.; CHAUDHURI, D.; HART, B.R.; POWELL, M.A. Competitive adsorption behavior of selected heavy metals in three soil types of India amended with fly ash and sewage sludge . Environmental Geology, v.44, p.363-370, $2003 b$.

VILLAREALA, E.L.; DIXON, A. Analysis of a rainwater collection system for domestic water supply in Ringdansen, Norrkoping, Sweden. Building and Environment, v.40, p.1174-1184, 2005.

VON LÜTZOW, M.; KÖGEL-KNABNER, I.; LUDWIG, B.; MATZNER, E.; FLESSA, H.; EKSCHMITT, K.; GUGGENBERGER, G.; MARSCHNER, B.; KALBITZ, K. Stabilization mechanisms of organic matter in four temperate soils: Development and application of a conceptual model. Journal of Plant Nutrition and Soil Science, v.171, p.111-124, 2008.

WAGAI, R.; MMAYER, L.M. Sorptive stabilization of organic matter in soils by hydrous iron oxides. Geochimica et Cosmochimica Acta, v.71, p.25-35, 2007.

WAGNER, G.H. Use of porous ceramic cups to sample soil water within the profile. Soil Science, v.94, p.379-386, 1962.

WAKSMAN, S.A. Humus. 2. ed. Baltimore, USA: The Williams and Wilkins Company, 1938. $526 \mathrm{p}$.

WALTER, I.; MARTÍNEZ, F.; CALA, B. Heavy metal speciation and phytotoxic effects of three representative sewage sludges for agricultural uses. Environmental Pollution, v.139, p.507-514, 2006. 
WATER, A.G.; OADES, J.M. Organic matter in water-stable aggregates. In: Advances in Soil Organic Matter Research. The impact on Agriculture and the environment. Cambridge, UK: Wilson, 1991. p.163-175. 0851863876.

WEHRY, E.L. Molecular fluorescence, phosphorescence, and chemiluminescence spectrometry, Analytical Chemistry, v.58, p.13R-33R, 1986.

WERNER, J.C.; PAULINO, V.T.; CANTARELlA, H.; ANDRADE, N.O.; QUAGGIO, J.A. Forrageiras. In: Recomendações de adubação e calagem para o Estado de São Paulo. 2. ed. Campinas: Instituto Agronômico, 1996. p.263-273. (Boletim Técnico, 100).

WERTH, M. AND KUZYAKOV, Y. ${ }^{13} \mathrm{C}$ fractionation at the root-microorganisms-soil interface: A review and outlook for partitioning studies. Soil Biology and Biochemistry, v.42, p.1372-1384, 2010.

WEST, J.W.; HILL, G.M.; GATES, R.N.; MULLINIX, B.G. Effects of dietary forage and amount of storage addition on intake, milk, yield, and digestion for lacting dairy cows. Journal of Dairy Science, v.80, p.1656-1665, 1997.

WEST, J.W.; MANDEBVU, P.; HILL, G.M.; GATES, R.N. Intake, milk, yield and digestion by dairy cows fed diets with incresing fiber content from bermudagrass hay or silage. Journal of Dairy Science, v.81, n.6, p.1599-1607, 1998.

WHITTIG, L.D.; ALLARDICE, W.R. X-ray diffraction techniques. In: Part 1 Physical and Mineralogical Methods. Methods of soil analysis. Madison, Wisconsin, USA: Soil Science Society of America, 1986, capítulo 12. p.331-362. 0891180885.

WILLIAMS, D.H.; FLEMMING, M.A. Spectroscopic methods in organic chemistry. McGraw-Hill, 1966. 222 p.

WILSON, M.A. NMR techniques and applications in geochemistry and soil chemistry. Oxford, New York: Pergamon Press, 1987. 387 p.

WORLD HEALTH ORGANIZATION. Guidelines for drinking-water quality incorporating

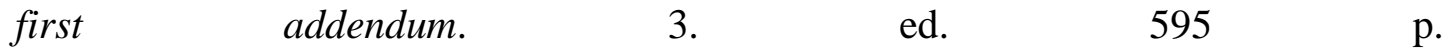
<http://www.who.int/water_sanitation_health/dwq/gdwq3rev/en/>

ZECH, W.; SENESI, N.; GUGGENBERGER, G.; KAISER, K.; LEHMANN, J.; MIANO, T.M.; MILTNER, A.; SCHROTH, G. Factor controlling humification and mineralization of soil organic in the tropics. Geoderma, v.79, p.117-161, 1997. 
ZSOLNAY, A.; BAIGAR, E.; JIMENEZ, M.; STEINWEG B.; SACCOMANDI, F. Differentiating with fluorescence spectroscopy the source of dissolved organic matter in soils subjected to drying. Chemosphere, v.38, n.1, p.45-50, 1999. 


\section{Anexo}

Tabela A 1 - Amostras de solução do solo para os tratamentos E66, SI e W100.

\begin{tabular}{|c|c|c|c|c|c|c|c|c|c|c|c|c|c|c|c|}
\hline Tratamento & profundidade & repetição & COD & $\begin{array}{l}\text { SD } \\
\text { COD }\end{array}$ & $\mathrm{Na}^{+}$ & $\mathrm{NH} 4^{+}$ & $\mathrm{K}^{+}$ & $\mathrm{Mg}{ }^{+}$ & $\mathrm{Ca}^{2+}$ & $\mathrm{F}^{-}$ & $\mathrm{Cl}^{-}$ & $\mathrm{NO}_{2}^{-}$ & $\mathrm{NO}_{3}{ }^{-}$ & $\mathrm{PO}_{4}^{2-}$ & $\mathrm{SO}_{4}{ }^{2-}$ \\
\hline \multicolumn{16}{|c|}{ Junho de 2007} \\
\hline SI & $20-40$ & & 15,84 & 0,60 & 221,94 & ND & 1,63 & 0,88 & 4,24 & ND & ND & ND & ND & ND & ND \\
\hline SI & $60-80$ & & 14,87 & 0,71 & 50,39 & 1,37 & 0,60 & 0,32 & ND & ND & ND & ND & ND & ND & ND \\
\hline SI & $80-100$ & & 21,75 & 0,50 & 52,43 & 1,45 & 4,22 & 0,90 & 3,53 & ND & ND & ND & ND & ND & ND \\
\hline E66 & $20-40$ & & 24,39 & 3,64 & ND & ND & ND & ND & ND & ND & ND & ND & ND & ND & ND \\
\hline E66 & $60-80$ & & 9,84 & 4,62 & ND & ND & ND & ND & $\mathrm{ND}$ & ND & ND & ND & ND & ND & ND \\
\hline E66 & $60-80$ & & 3,27 & 0,01 & ND & $\mathrm{ND}$ & ND & ND & ND & ND & ND & ND & ND & ND & ND \\
\hline W100 & $40-60$ & & 22,36 & 6,99 & 138,83 & $<0,03$ & 2,92 & 1,40 & 11,43 & ND & ND & ND & ND & ND & ND \\
\hline W100 & $40-60$ & & 8,39 & 0,03 & ND & $\mathrm{ND}$ & ND & ND & ND & ND & ND & ND & ND & ND & ND \\
\hline W100 & $60-80$ & & 25,95 & 12,30 & ND & $\mathrm{ND}$ & ND & ND & ND & ND & ND & ND & ND & ND & ND \\
\hline W100 & $60-80$ & & 11,68 & 0,16 & ND & ND & ND & ND & $\mathrm{ND}$ & ND & ND & ND & ND & ND & $\mathrm{ND}$ \\
\hline \multicolumn{16}{|c|}{ Dezembro de 2007} \\
\hline SI & $60-80$ & & 86,64 & 1,42 & ND & ND & ND & ND & ND & ND & ND & ND & ND & ND & ND \\
\hline E66 & $20-40$ & & 44,97 & 0,73 & ND & ND & ND & ND & ND & ND & ND & ND & ND & ND & ND \\
\hline E66 & $20-40$ & & 33,85 & 0,21 & ND & ND & ND & ND & ND & ND & ND & ND & ND & ND & ND \\
\hline E66 & $20-40$ & & 23,71 & 0,28 & ND & ND & ND & ND & ND & ND & ND & ND & ND & ND & ND \\
\hline E66 & $40-60$ & & 55,27 & 0,44 & ND & ND & ND & ND & ND & ND & ND & ND & ND & ND & ND \\
\hline E66 & $40-60$ & & 61,83 & 0,70 & ND & ND & ND & ND & ND & ND & ND & ND & ND & ND & ND \\
\hline E66 & $80-100$ & & 24,37 & 0,15 & ND & ND & ND & ND & ND & ND & ND & ND & ND & ND & ND \\
\hline
\end{tabular}




\begin{tabular}{|c|c|c|c|c|c|c|c|c|c|c|c|c|c|c|c|}
\hline E66 & $80-100$ & & 103,30 & 1,67 & ND & ND & ND & ND & ND & ND & ND & ND & ND & ND & ND \\
\hline E66 & $80-100$ & & ND & ND & 64,01 & $<0,03$ & 6,27 & 1,88 & 3,85 & 0,54 & 50,58 & 0,04 & 16,55 & 2,42 & 32,63 \\
\hline E66 & $80-100$ & & 18,24 & 0,29 & ND & ND & ND & ND & ND & ND & ND & ND & ND & ND & ND \\
\hline E66 & $80-100$ & & 19,88 & 0,40 & ND & ND & ND & ND & ND & ND & ND & ND & ND & ND & ND \\
\hline E66 & $80-100$ & & 20,14 & 0,36 & ND & ND & ND & ND & ND & ND & ND & ND & ND & ND & ND \\
\hline W100 & $20-40$ & & 47,85 & 0,75 & ND & ND & ND & ND & ND & 0,61 & 125,46 & 0,60 & 254,83 & $<0,07$ & 42,45 \\
\hline W100 & $20-40$ & & 64,88 & 1,13 & ND & ND & ND & ND & ND & 0,54 & 118,72 & 0,61 & 240,42 & $<0,07$ & 40,32 \\
\hline W100 & $40-60$ & & 69,18 & 5,22 & ND & ND & ND & ND & ND & 0,55 & 58,36 & 0,05 & 53,55 & 0,09 & 38,61 \\
\hline \multicolumn{16}{|c|}{ Maio de 2008} \\
\hline E66 & $20-40$ & & ND & ND & 129,53 & ND & 1,29 & 0,52 & 2,80 & 0,60 & 73,19 & 0,09 & 0,99 & $<0,07$ & 74,57 \\
\hline E66 & $40-60$ & & 56,29 & 0,42 & ND & ND & ND & ND & ND & ND & ND & ND & ND & ND & ND \\
\hline E66 & $60-80$ & & 641,20 & 0,46 & ND & ND & ND & ND & ND & ND & ND & ND & ND & ND & ND \\
\hline W100 & $20-40$ & & 351,40 & 2,31 & ND & ND & ND & ND & ND & 0,50 & 13,75 & $<0,03$ & 1,24 & 0,15 & 47,69 \\
\hline W100 & $40-60$ & $\mathrm{R} 3$ & ND & ND & ND & ND & ND & ND & ND & 0,59 & 29,53 & 0,07 & 1,57 & 0,17 & 47,02 \\
\hline W100 & $40-60$ & & 222,70 & 1,88 & ND & ND & ND & ND & ND & 0,65 & 21,22 & 0,09 & 2,53 & 0,35 & 44,46 \\
\hline W100 & $60-80$ & & ND & ND & $-0,01$ & $-0,22$ & $-0,11$ & $-0,24$ & $-0,33$ & ND & ND & ND & ND & ND & ND \\
\hline W100 & 80-100 & & 122,80 & 0,29 & ND & ND & ND & ND & ND & 0,15 & 43,13 & 0,08 & 1,46 & 0,02 & 35,47 \\
\hline \multicolumn{16}{|c|}{ Junho de 2008} \\
\hline E66 & $20-40$ & R3 & ND & ND & 83,06 & ND & 2,34 & 0,72 & 4,09 & 0,58 & 83,12 & 0,09 & 0,43 & $<0,07$ & 86,78 \\
\hline E66 & $20-40$ & $\mathrm{R} 2$ & ND & ND & 86,09 & ND & 0,54 & 0,64 & 4,10 & 0,49 & 51,91 & 0,09 & 1,75 & 0,11 & 68,86 \\
\hline E66 & $20-40$ & $\mathrm{R} 1$ & ND & ND & 126,23 & ND & 0,65 & 0,74 & 2,47 & ND & ND & ND & ND & ND & ND \\
\hline E66 & $40-60$ & $\mathrm{R} 1$ & ND & ND & 67,81 & ND & 1,42 & 2,47 & 4,11 & ND & ND & ND & ND & ND & ND \\
\hline E66 & $60-80$ & $\mathrm{R} 1$ & ND & ND & 55,07 & ND & 1,47 & 0,71 & 2,20 & ND & ND & ND & ND & ND & ND \\
\hline E66 & $80-100$ & R3 & ND & ND & 38,62 & 0,67 & 4,23 & 1,22 & 6,17 & ND & ND & ND & ND & ND & ND \\
\hline E66 & $80-100$ & $\mathrm{R} 4$ & ND & ND & 99,08 & ND & 2,28 & 2,36 & 2,71 & ND & ND & ND & ND & ND & ND \\
\hline W100 & $20-40$ & $\mathrm{R} 2$ & ND & ND & 65,71 & ND & 1,15 & 1,16 & 5,19 & 0,66 & 16,44 & $<0,03$ & 0,91 & 0,56 & 39,13 \\
\hline W100 & $20-40$ & $\mathrm{R} 4$ & ND & ND & 887,26 & ND & 2,54 & 1,45 & 3,53 & 0,58 & 28,09 & 0,06 & 0,45 & 0,01 & 37,33 \\
\hline W100 & $40-60$ & $\mathrm{R} 4$ & 32,10 & 0,35 & 117,30 & ND & 2,88 & 1,81 & 9,99 & ND & ND & ND & ND & ND & ND \\
\hline W100 & $40-60$ & R3 & 19,70 & 0,11 & ND & ND & ND & ND & ND & ND & ND & ND & ND & ND & ND \\
\hline W100 & $40-60$ & $\mathrm{R} 3$ & ND & ND & 86,05 & ND & 1,69 & 0,69 & 2,33 & 0,53 & 27,05 & 0,07 & 1,21 & 0,19 & 41,80 \\
\hline W100 & $40-60$ & $\mathrm{R} 3$ & ND & ND & ND & ND & ND & ND & ND & 0,59 & 29,84 & 0,07 & 1,14 & 0,20 & 48,12 \\
\hline W100 & $40-60$ & $\mathrm{R} 4$ & ND & ND & 121,66 & 1,76 & 3,55 & 1,58 & 6,35 & ND & ND & ND & ND & ND & ND \\
\hline \multicolumn{16}{|c|}{ Junho de 2009} \\
\hline E66 & $20-40$ & R4 & 39,59 & 0,67 & 389,34 & ND & 2,56 & 3,29 & 9,01 & 1,50 & 172,02 & $<, 03$ & 1,92 & $<0,07$ & 20,85 \\
\hline E66 & $20-40$ & R1-R3 & 39,86 & 0,47 & 229,83 & ND & 1,38 & 1,02 & 2,73 & 0,81 & 155,90 & $<, 03$ & 0,77 & $<0,07$ & 72,11 \\
\hline E66 & $40-60$ & $\mathrm{R} 1-\mathrm{R} 3$ & 34,71 & 0,18 & 284,33 & ND & 2,55 & 2,43 & 6,31 & ND & ND & $\mathrm{ND}$ & ND & ND & ND \\
\hline W100 & $20-40$ & $\mathrm{R} 3$ & 43,42 & 0,29 & 110,13 & 2,04 & 1,43 & 0,89 & 2,39 & 0,66 & 6,04 & 0,06 & 0,89 & 0,17 & 13,81 \\
\hline W100 & $20-40$ & $\mathrm{R} 2$ & 46,93 & 0,52 & 85,67 & 1,74 & 2,11 & 1,37 & 6,41 & 0,63 & 13,82 & $<, 03$ & 0,47 & 0,12 & 15,64 \\
\hline
\end{tabular}




\begin{tabular}{|c|c|c|c|c|c|c|c|c|c|c|c|c|c|c|c|}
\hline W100 & $20-40$ & $\mathrm{R} 1$ & 48,17 & 0,68 & 111,58 & 1,88 & 0,19 & 0,92 & ND & 0,59 & 17,69 & 0,07 & 0,59 & $<0,07$ & $\begin{array}{c}20,23 \\
8,33\end{array}$ \\
\hline W100 & $20-40$ & R4 & 22,47 & 0,35 & 277,43 & ND & 1,61 & 2,51 & 7,72 & 0,84 & 99,47 & $<, 03$ & 0,57 & 0,10 & 8,33 \\
\hline W100 & $40-60$ & $\mathrm{R} 1-\mathrm{R} 2$ & 31,64 & 0,22 & 82,22 & 1,57 & 0,40 & 0,49 & $\mathrm{ND}$ & 0,69 & 11,69 & 0,07 & 0,92 & 0,22 & 13,18 \\
\hline W100 & $40-60$ & R4 & 31,85 & 0,09 & 134,18 & 2,11 & 0,40 & 0,96 & 15,04 & 0,62 & 37,55 & 0,10 & 1,15 & $<0,07$ & 24,48 \\
\hline W100 & $60-80$ & R1-R4 & 47,32 & 0,89 & 112,16 & 2,02 & 0,85 & 1,08 & 1,59 & 0,63 & 21,74 & 0,08 & 1,34 & $<0,07$ & 25,12 \\
\hline W100 & $80-100$ & R3 & 55,04 & 0,04 & 140,78 & 2,71 & 5,11 & 1,50 & 1,30 & ND & ND & ND & ND & ND & ND \\
\hline SI & $60-80$ & & 86,64 & 1,42 & ND & ND & ND & ND & ND & ND & ND & ND & ND & ND & ND \\
\hline E66 & $20-40$ & & 44,97 & 0,73 & ND & ND & ND & ND & ND & ND & ND & ND & ND & ND & ND \\
\hline E66 & $20-40$ & & 33,85 & 0,21 & ND & ND & ND & ND & ND & ND & ND & ND & ND & ND & ND \\
\hline E66 & $20-40$ & & 23,71 & 0,28 & ND & ND & ND & ND & ND & ND & ND & ND & ND & ND & ND \\
\hline E66 & $40-60$ & & 55,27 & 0,44 & ND & ND & ND & ND & ND & ND & ND & ND & ND & ND & ND \\
\hline E66 & $40-60$ & & 61,83 & 0,70 & ND & ND & ND & ND & ND & ND & ND & ND & ND & ND & ND \\
\hline E66 & $80-100$ & & 24,37 & 0,15 & ND & ND & ND & ND & ND & ND & ND & ND & ND & ND & ND \\
\hline E66 & $80-100$ & & 103,30 & 1,67 & ND & ND & ND & ND & ND & ND & ND & ND & ND & ND & ND \\
\hline E66 & $80-100$ & & ND & ND & 64,01 & $<0,03$ & 6,27 & 1,88 & 3,85 & 0,54 & 50,58 & 0,04 & 16,55 & 2,42 & 32,63 \\
\hline E66 & $80-100$ & & 18,24 & 0,29 & ND & ND & ND & ND & ND & ND & ND & ND & ND & ND & ND \\
\hline E66 & $80-100$ & & 19,88 & 0,40 & ND & ND & ND & ND & ND & ND & ND & ND & ND & ND & ND \\
\hline E66 & $80-100$ & & 20,14 & 0,36 & ND & ND & ND & ND & ND & ND & ND & $\mathrm{ND}$ & ND & ND & ND \\
\hline W100 & $20-40$ & & 47,85 & 0,75 & ND & ND & ND & ND & ND & 0,61 & 125,46 & 0,60 & 254,83 & $<0,07$ & 42,45 \\
\hline W100 & $20-40$ & & 64,88 & 1,13 & ND & ND & ND & ND & ND & 0,54 & 118,72 & 0,61 & 240,42 & $<0,07$ & 40,32 \\
\hline W100 & $20-40$ & & ND & ND & ND & ND & ND & ND & ND & ND & ND & ND & ND & ND & ND \\
\hline W100 & $40-60$ & & 69,18 & 5,22 & ND & ND & ND & ND & ND & 0,55 & 58,36 & 0,05 & 53,55 & 0,09 & 38,61 \\
\hline
\end{tabular}
nitrato de amônio, $416 \mathrm{~kg} \mathrm{ha}^{-1}$ ano $^{-1}$ de $\mathrm{K}_{2} \mathrm{O}$ e $140 \mathrm{~kg} \mathrm{ha}^{-1}$ ano $^{-1} \mathrm{P}_{2} \mathrm{O}_{5}$; W100: irrigação com água potável e adição de $520 \mathrm{~kg} \mathrm{ha}^{-1}$ ano ${ }^{-1}$ de nitrogênio via nitrato de amônio, 416 $\mathrm{kg} \mathrm{ha}^{-1} \mathrm{ano}^{-1}$ de $\mathrm{K}_{2} \mathrm{O}$ e $140 \mathrm{~kg} \mathrm{ha}^{-1} \mathrm{ano}^{-1} \mathrm{P}_{2} \mathrm{O}_{5}$. 
Tabela A 2 - Dados de carbono total (COT) e da fluorescência dos extratos das amostras de solo de junho 2007.

\begin{tabular}{clccccc}
\multirow{2}{*}{ Tratamento } & \multicolumn{1}{c}{ Profondidade } & \multicolumn{2}{c}{ COT } & c1/COT & cluorescência dos extratos \\
& & & & c2/COT & c3/COT & Ia/Ic \\
\hline \multirow{6}{*}{ SI } & $0-5$ & 0,808 & 1037,11 & 3693,94 & 1068,97 & 3,46 \\
& $5-10$ & 0,685 & 0,00 & 7330,75 & 2168,38 & 3,38 \\
& $10-20$ & 0,628 & 1798,55 & 14454,41 & 4538,90 & 3,18 \\
& $20-40$ & 0,580 & 1850,35 & 7942,06 & 2915,89 & 2,72 \\
& $40-60$ & 0,500 & 2251,94 & 13300,10 & 4363,58 & 3,05 \\
& $60-80$ & 0,366 & 4684,78 & 3725,97 & 1710,17 & 2,18 \\
& $80-100$ & 0,270 & 1968,53 & 6431,27 & 1643,69 & 3,91 \\
& $0-5$ & 0,779 & 2886,04 & 14242,04 & 8564,35 & 1,66 \\
& $5-10$ & 0,523 & 1343,16 & 11009,67 & 5218,90 & 2,11 \\
& $10-20$ & 0,513 & & & & \\
& $20-40$ & 0,480 & 1741,13 & 11409,82 & 3426,37 & 3,33 \\
& $40-60$ & 0,455 & 4620,72 & 7536,86 & 3478,57 & 2,17 \\
& $60-80$ & 0,343 & 2378,10 & 7572,34 & 2006,74 & 3,77 \\
& $80-100$ & 0,267 & 1389,93 & 3441,85 & 830,79 & 4,14
\end{tabular}

SI: sem irrigação e sem fertilização; E66 - irrigação com EETE e adubação de $343 \mathrm{~kg} \mathrm{ha}^{-1}$ ano ${ }^{-1}$ de nitrato de amônio, $416 \mathrm{~kg} \mathrm{ha}^{-1}$ ano ${ }^{-1}$ de $\mathrm{K}_{2} \mathrm{O}$ e $140 \mathrm{~kg}$ ha- 1 ano $^{-1} \mathrm{P}_{2} \mathrm{O}_{5}$. 
Tabela A 3 - Dados de carbono total (COT) e da fluorescência dos extratos das frações densimétrica das amostras de solo de junho 2007.

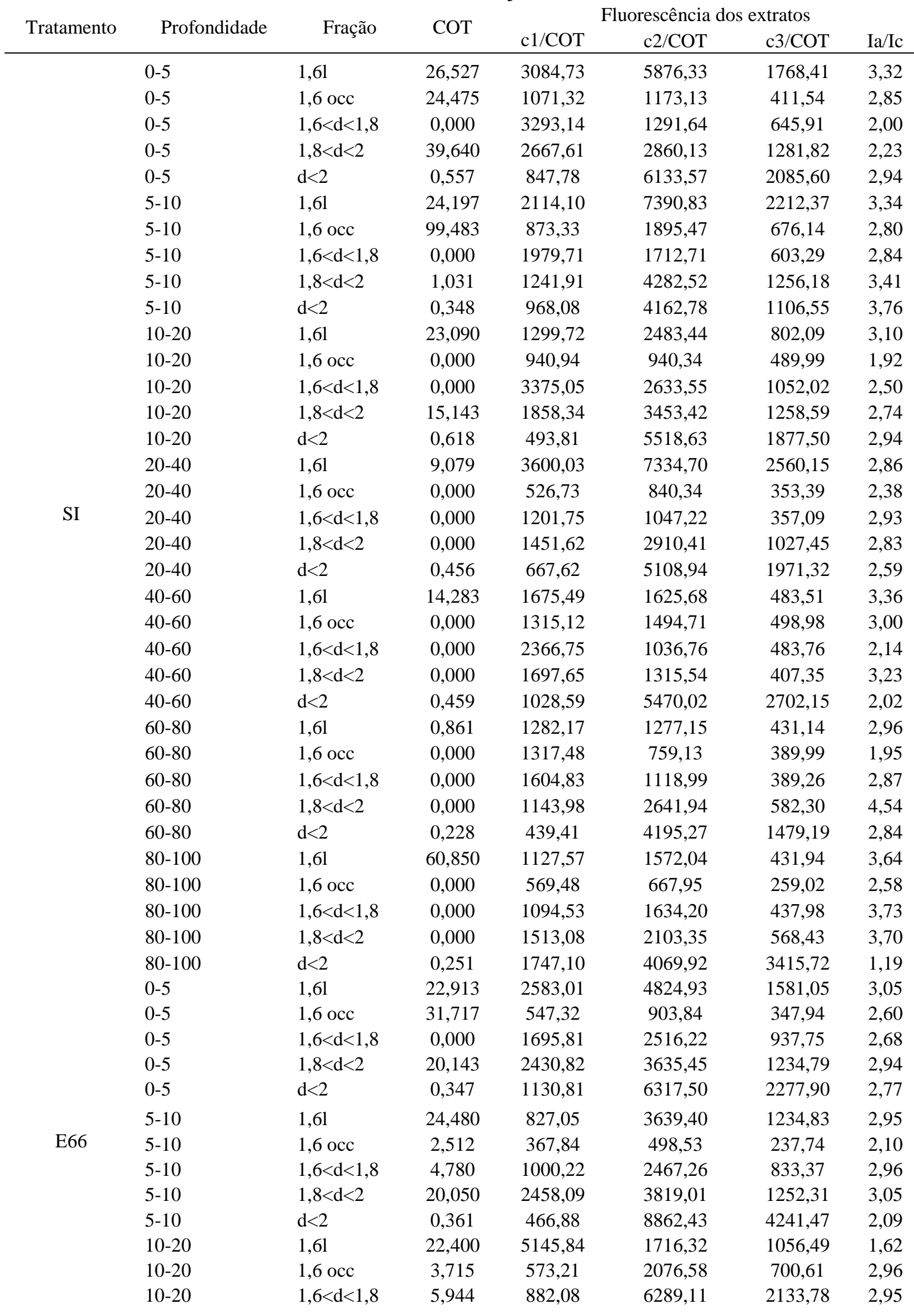




\begin{tabular}{llccccc}
$10-20$ & $1,8<\mathrm{d}<2$ & 4,188 & 2047,75 & 10219,41 & 3244,43 & 3,15 \\
$10-20$ & $\mathrm{~d}<2$ & 0,386 & 0,00 & 5117,68 & 1849,56 & 2,77 \\
$20-40$ & 1,61 & 30,055 & 2899,37 & 3298,11 & 1050,67 & 3,14 \\
$20-40$ & 1,6 occ & 0,000 & 2050,50 & 1476,08 & 418,46 & 3,53 \\
$20-40$ & $1,6<\mathrm{d}<1,8$ & 14,926 & 1801,56 & 3221,80 & 1298,04 & 2,48 \\
$20-40$ & $1,8<\mathrm{d}<2$ & 2,265 & 1568,52 & 5302,07 & 1326,04 & 4,00 \\
$20-40$ & $\mathrm{~d}<2$ & 0,753 & 59,39 & 7233,67 & 2918,17 & 2,48 \\
$40-60$ & 1,61 & 20,376 & 1509,58 & 1563,96 & 515,82 & 3,03 \\
$40-60$ & 1,6 occ & 0,000 & 432,47 & 791,36 & 311,86 & 2,54 \\
$40-60$ & $1,6<\mathrm{d}<1,8$ & 0,000 & 261,39 & 3766,73 & 1017,01 & 3,70 \\
$40-60$ & $1,8<\mathrm{d}<2$ & 0,000 & 2570,10 & 4487,43 & 1443,76 & 3,11 \\
$40-60$ & $\mathrm{~d}<2$ & 0,489 & 1534,12 & 6723,63 & 1755,41 & 3,83 \\
$60-80$ & 1,61 & 35,065 & 2465,23 & 2054,78 & 682,84 & 2,91 \\
$60-80$ & 1,6 occ & 0,000 & 1998,73 & 1014,39 & 362,74 & 2,80 \\
$60-80$ & $1,6<\mathrm{d}<1,8$ & 0,000 & 721,76 & 2892,30 & 831,71 & 3,48 \\
$60-80$ & $1,8<\mathrm{d}<2$ & 0,000 & 1665,59 & 2469,56 & 632,82 & 3,90 \\
$60-80$ & $\mathrm{~d}<2$ & 0,484 & 1435,59 & 5252,38 & 1908,72 & 2,75 \\
$80-100$ & 1,61 & 0,000 & 2419,43 & 857,61 & 353,17 & 2,43 \\
$80-100$ & 1,6 occ & 0,000 & 580,22 & 1118,65 & 409,84 & 2,73 \\
$80-100$ & $1,6<\mathrm{d}<1,8$ & 0,000 & 2454,66 & 5140,72 & 1306,82 & 3,93 \\
$80-100$ & $1,8<\mathrm{d}<2$ & 0,218 & 854,01 & 393,38 & 1735,26 & 0,23 \\
$80-100$ & $\mathrm{~d}<2$ & 0,334 & 1946,11 & 3604,61 & 3533,26 & 1,02 \\
\hline
\end{tabular}

SI: sem irrigação e sem fertilização; E66 - irrigação com EETE e adubação de $343 \mathrm{~kg} \mathrm{ha}^{-1}$ ano $^{-1}$ de nitrato de amônio, $416 \mathrm{~kg} \mathrm{ha}^{-1}$ ano ${ }^{-1}$ de $\mathrm{K}_{2} \mathrm{O}$ e $140 \mathrm{~kg}$ ha- 1 ano $^{-1} \mathrm{P}_{2} \mathrm{O}_{5}$. 